University of Rhode Island

DigitalCommons@URI

Open Access Dissertations

2017

\title{
Early Childhood Educators' Perspectives on Autism and Evidence- Based Practices
}

Amy S. Grattan

University of Rhode Island, grattanfour@verizon.net

Follow this and additional works at: https://digitalcommons.uri.edu/oa_diss

\section{Recommended Citation}

Grattan, Amy S., "Early Childhood Educators' Perspectives on Autism and Evidence-Based Practices" (2017). Open Access Dissertations. Paper 645.

https://digitalcommons.uri.edu/oa_diss/645

This Dissertation is brought to you for free and open access by DigitalCommons@URI. It has been accepted for inclusion in Open Access Dissertations by an authorized administrator of DigitalCommons@URI. For more information, please contact digitalcommons-group@uri.edu. 
EARLY CHILDHOOD EDUCATORS' PERSPECTIVES ON AUTISM AND EVIDENCED-BASED PRACTICES

BY

AMY S. GRATTAN

A DISSERTATION SUBMITTED IN PARTIAL FULFILLMENT OF THE REQUIREMENTS FOR THE DEGREE OF

DOCTOR OF PHILOSOPHY

IN

EDUCATION

UNIVERSITY OF RHODE ISLAND

AND

RHODE ISLAND COLLEGE

2017 
DOCTOR OF PHILOSOPHY DISSERTATION

$\mathrm{OF}$

AMY S. GRATTAN

\author{
APPROVED \\ Dissertation Committee: \\ Major Professor: $\quad$ Paul LaCava \\ Susan Dell \\ Adam Moore \\ Minsuk Shim \\ Gerri August \& Julie Horwitz \\ Interim Co-Deans, Feinstein School of Education, RIC \\ Nasser H. Zawia \\ Dean, The Graduate School, URI
}

\author{
UNIVERISTY OF RHODE ISLAND \\ AND \\ RHODE ISLAND COLLEGE \\ 2017
}




\begin{abstract}
The role of early childhood educators (ECE) is changing as a result of increasing numbers of young children with autism participating in natural preschool classrooms. To understand what ECE know about autism and the evidence-based practices (EBP) that support children with autism to make progress in learning and development, 125 preschool teachers working in community, State Funded and Head Start preschool classrooms were surveyed using a researcher created tool the Perspectives of Early Childhood Educators on Autism Scale (PECE-ASD). Results showed that ECE had basic knowledge of autism related to observable behaviors of autism but limited general knowledge of autism. Participants reported having knowledge of EBP they perceived as aligned to developmentally appropriate practice and a limited understanding of behavior-based interventions. Implications and recommendations for research and practice are discussed.
\end{abstract}




\section{ACKNOWLEDGMENTS}

This dissertation could not have been completed without the support and encouragement that I have received from so many people. With heartfelt gratitude I would like to thank the following people.

To Joe and Anthony, the best IT guys! Thank you for keeping me (and my mac) updated and running. I appreciate your patience for every "I think there's a problem" and your kindness as things were updated, borrowed and replaced. I couldn't have done this with out your IT support.

To Kristen and Tracey, thank you for being my EC advisors. Your commitment to supporting all young children to have high quality learning experiences inspires me everyday.

To Dr. Tony Antosh, thank you for always believing in me and always making time to talk about "LIFE". Your dedication to ensuring that people of all abilities have quality of life has inspired my life's work. I am honored to say that I started my educational journey with you and have been able to complete this journey with the support of you and my Sherlock family.

Thank you to my committee members for walking this journey with me. Dr. Adam Moore, your positive outlook and words inspired me every step of the way. Dr. Minsuk Shim, your patience and kindness when helping with statistics were an immeasurable support to me. Dr. Shannon Dowd-Eagle, thank you for being my committee chair and for providing me constant reassurance that I would successfully finish this dissertation. Dr. Susan Dell, you have been my teacher, my guide, my 
mentor and friend for so many years. You always make me laugh and know how to help me see what is important - thank you!

Dr. Paul LaCava, thank you for taking the time to be my major professor. Your encouragement to begin a doctoral program, guidance throughout the process and ongoing support across these years has been limitless. I appreciate your availability and always answering the phone/text no matter the day or time. Thank you for your time, patience and constant reassurance!

To my family, thank you for the unconditional love and support you have provided me throughout the years. Mom and Dad, you have always encouraged me to reach for the stars. Thank you for listening to every thought, idea and argument in all areas of life! Mandi and Kimbers, thank you for sharing your educational space with me. I have loved learning from you and with you. Mike, words cannot express my gratitude for your support and encouragement. Thank you for making me a better thinker, writer and educator.

Lastly, to the many early childhood educators, children with autism and their families, thank you for helping me to grow and learn in ways that I never dreamed. I am forever grateful that you have allowed me to be part of your lives. Thank you! 


\section{TABLE OF CONTENTS}

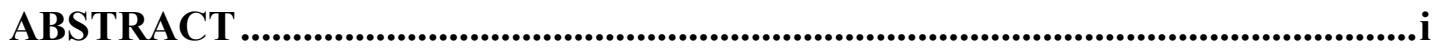

ACKNOWLEDGEMENTS................................................................................ii

LIST OF TABLES......................................................................................

TABLE OF FIGURES .................................................................................................ix

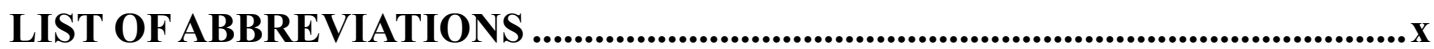

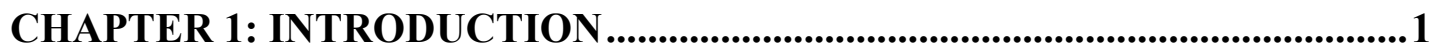

Early Childhood Educators Teaching Children with Autism ................................. 1

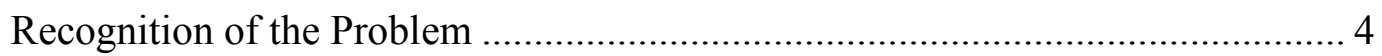

Statement of Purpose ...................................................................................... 7

Definitions of Important Terms and Concepts ................................................. 8

CHAPTER 2: REVIEW OF THE LITERATURE .................................................. 11

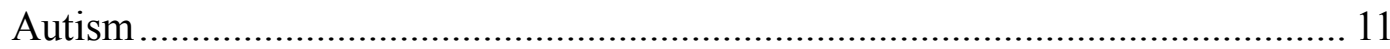

Individuals with Disabilities Education Act..................................................... 12

Developmentally Appropriate Practice (DAP) ...................................................... 13

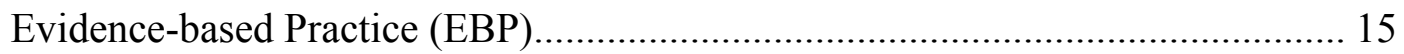

Context of Early Childhood Education and Early Childhood Special Education.. 20

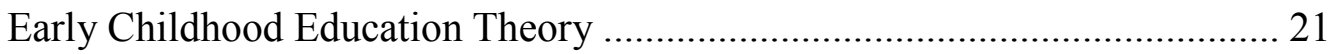

Early Childhood Special Education Theory ...................................................... 25

Early Childhood Educators' Knowledge of Autism................................................ 28

Early Childhood Educators' knowledge and Use of Evidence-based Practices for

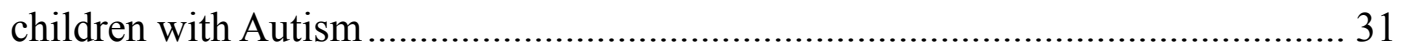


Early Childhood Educators: A Mixed Delivery System

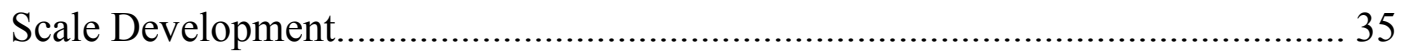

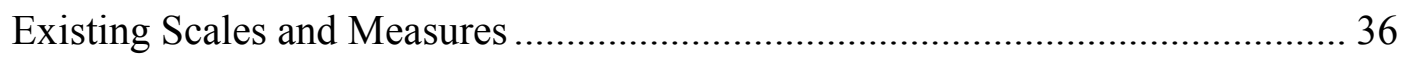

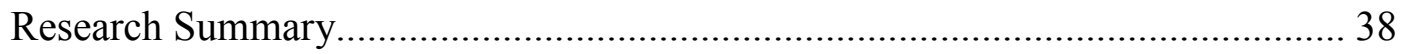

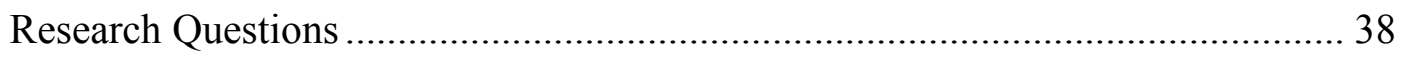

CHAPTER 3: METHODOLOGY.................................................................................. 40

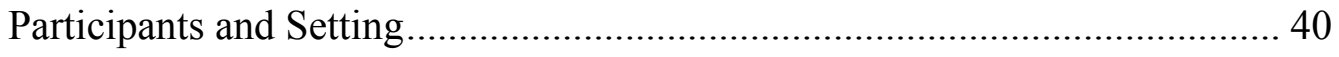

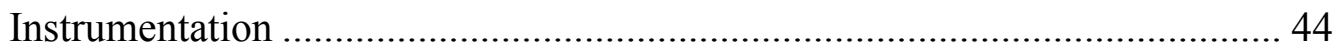

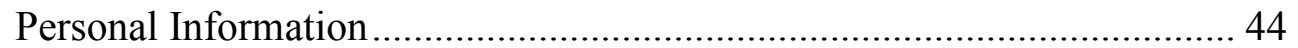

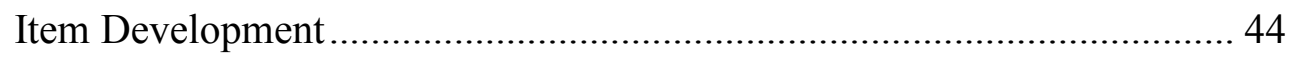

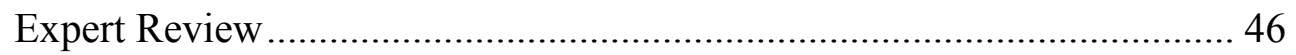

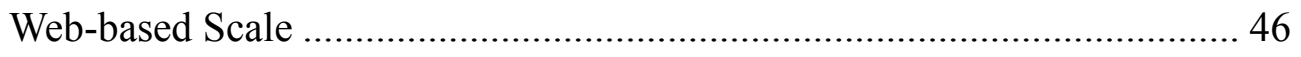

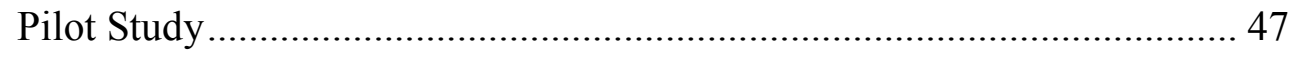

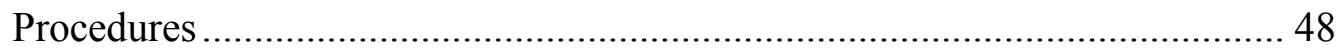

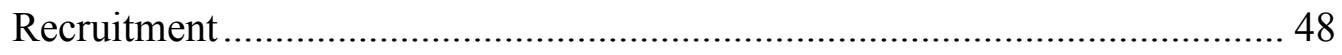

Overview of Data Analysis .................................................................... 48

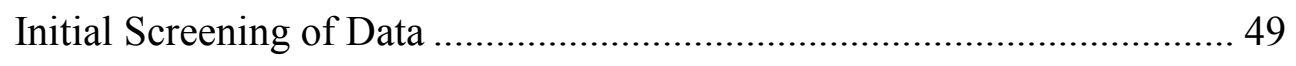

Answering the Research Questions.............................................................. 55

CHAPTER 4: RESULTS ............................................................................................... 58

Results of PFA and Item Analysis .............................................................. 58

Participant Experiences with Autism ................................................................ 64

Results of Research Questions ......................................................................... 66

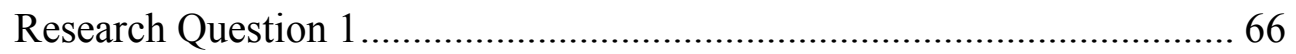




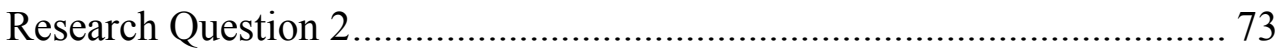

Research Question 3.................................................................... 76

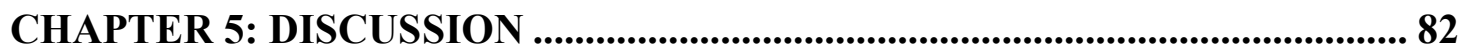

Psychometric properties of the PECE-ASD ........................................... 82

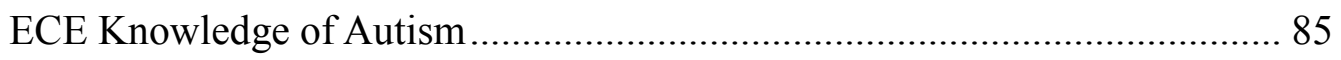

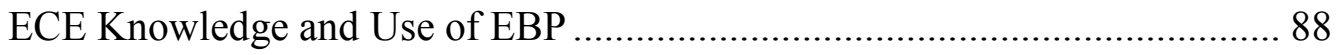

Predictors of EBP use for Children with Autism ....................................... 90

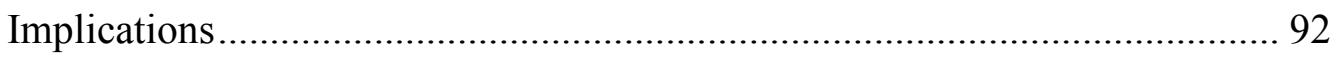

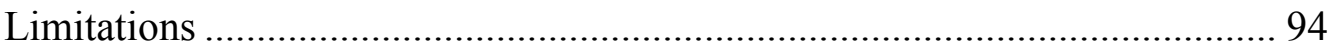

Future Research........................................................................... 95

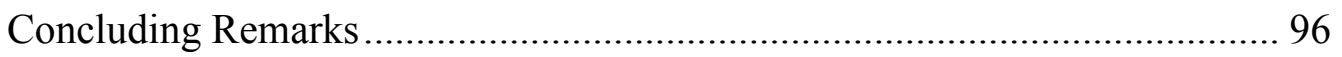

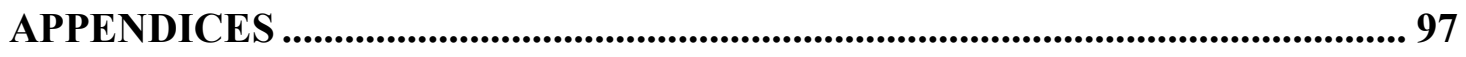

Appendix A - NAEYC Position Statement.............................................. 97

Appendix B - PECE-ASD Scale .......................................................... 98

Appendix C - PECE-ASD Reviewer Form........................................ 106

Appendix D - IRB Approved Consent Document ................................. 108

Appendix E - Initial Email to Administrators and Organizations ............... 110

Appendix F - Follow Up Email ....................................................... 111

Appendix G - Summary of Variables Aligned to Research Questions ........ 112

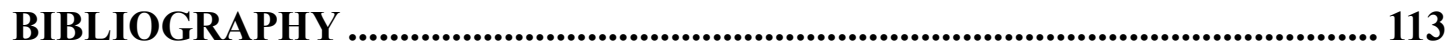




\section{LIST OF TABLES}

TABLE

PAGE

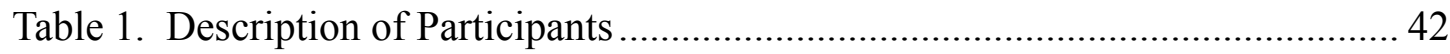

Table 2. Summary Table for PFA with Direct Oblimin rotation of PECE-ASD ....... 60

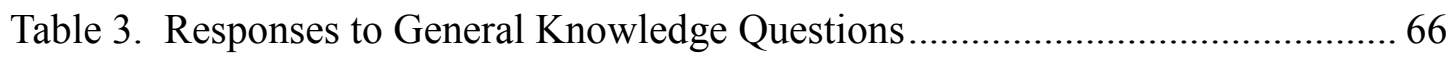

Table 4. Responses to Items for Social/Communication Characteristics................... 68

Table 5. Responses to Items for Behavioral Characteristics ..................................69 69

Table 6. Group Correlations Related to Knowledge/Use of Specialized Practices..... 73

Table 7. Correlations Related to Knowledge/Use of Practices Aligned with DAP ... 75

Table 8. Multiple Regression Model Summary For Specialized Practices ................ 76

Table 9. Multiple Regression ANOVA for Specialized Practices ............................. 77

Table 10. Linear Model of Predictors of Specialized Practices ............................... 77

Table 11. Multiple Regression Model Summary for Use of Practices to DAP .......... 79

Table 12. Linear Model of Predictors of Practices Aligned to DAP .......................... 80

Table 13. Linear Model of Predictors of Practices Aligned to DAP................................. 80

Table 14. Final PECE-ASD Items by Subscale .............................................. 84 


\section{TABLE OF FIGURES}

Figure 1. Scree Plot for PFA with Direct Oblimin Rotation of PECE-ASD .............. 59

Figure 2. Histograms of Transformation of Aligned with DAP Variable................... 62

Figure 3. Histograms of Transformation of Specialized Practices Variable .............. 63

Figure 4. Educational Experiences Related to Autism........................................... 64

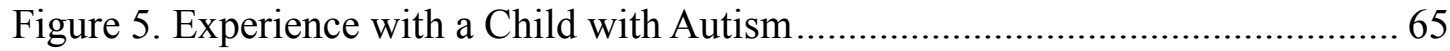

Figure 6. Knowledge of Evidence-based Practices ................................................. 71

Figure 7. Use of Evidence-based Practices .......................................................... 73 


\section{LIST OF ABBREVIATIONS}

\begin{tabular}{|c|c|}
\hline ABA - Applied Behavior Analysis & IEP - Individualized Education \\
\hline ASD - Autism Spectrum Disorders & Program \\
\hline CDC - Centers for Disease Control & LRE - Least Restrictive Environment \\
\hline CEC - Council for Exceptional & NAEYC - National Association for the \\
\hline Children & Education of Young Children \\
\hline DAP - Developmentally Appropriate & NRC - National Research Council \\
\hline Practice & NPDC-ASD - National Professional \\
\hline DOE - Department of Education & Development Center on Autism \\
\hline DOH- Department of Health & Spectrum Disorder \\
\hline DHHS - Department of Health and & OSERS - Office of Special Education \\
\hline Human Services & and Rehabilitative Services \\
\hline EBP - Evidence-based Practice & OSEP - Office of Special Education \\
\hline EC - Early Childhood & Programs \\
\hline ECE - Early Childhood Educators & PECE-ASD - Perspectives of Early \\
\hline ECSE - Early Childhood Special & Childhood Educators on Autism \\
\hline Education & RI - Rhode Island \\
\hline EI - Early Intervention & RIDE - Rhode Island Department of \\
\hline IDEA - Individuals with Disabilities & Education \\
\hline Education Act & RCT - Randomized Control Trials \\
\hline IECSE - Itinerant Early Childhood & QED - Quasi-experimental designs \\
\hline Special Educators & ZPD - Zone of Proximal Development \\
\hline
\end{tabular}




\section{CHAPTER 1}

INTRODUCTION

\section{Early Childhood Educators Teaching Children with Autism}

There is a growing expectation of early childhood educators (ECE) to provide preschool education to children with disabilities in natural environments (U.S.

Department of Health and Human Services [U.S. DHHS] \& U.S. Department of Education [U.S. DOE], 2015). ECE are the primary teachers responsible for providing highquality early learning environments for young children with a variety of diverse needs (National Association for the Education of Young Children [NAEYC], 2009), including young children with a diagnosis of autism (Vakil, Welton, O'Connor, \& Kline, 2009).

Autism Spectrum Disorders (ASD), referred to as autism or ASD in this study, is a complex neurodevelopmental condition manifesting in social, communication and restrictive, repetitive behaviors that range in severity and intensity (American Psychiatric Association [APA], 2013). Children with autism demonstrate behavioral characteristics that vary in the intensity of the manifestation of these behaviors (APA, 2013). Children with autism have unique presentations, which influence their development and learning; thus requiring highly individualized educational programs (Mesibov \& Shea, 2008). A recent national policy statement by the U.S DHHS and U.S. DOE (2015) promotes that young children with disabilities, including ASD, be educated in general education classrooms. The DHHS/DOE Early Childhood Policy Statement, has sparked an initiative that is rapidly moving forward and resulting in the need for professional development designed to support ECE to have knowledge and skills that help children with 
autism in their classrooms. The Centers for Disease Control [CDC] (2016) reports that 1 in 68 school-aged children have a diagnosis of autism, with only $43 \%$ of these children receiving a diagnostic evaluation prior to age 3 years. The CDC also reports that while the children can receive a reliable diagnosis of autism at 2 years of age, most children are receiving the diagnosis after the age of 4 (CDC, 2016).

Throughout the years, two distinct philosophical approaches have guided educators to implement instructional practices with children with autism, a behavioral approach and a developmental approach (Jennett, Harris, \& Mesibov, 2003; Quill, 1997). Then, in 2001, the National Research Council's (NRC) report, Educating Children with Autism, recommended that young children with autism receive an educational program with a minimum of 25 hours per week with a focus on the use of effective interventions. As a result of behavioral underpinnings of instruction and reccommendation that young children with autism receive intensive educational programming, many children receive their education in specialized settings (Karagiannis, Stainback, \& Stainback, 1996). A specialized setting can be described as a self-contained classroom where children with autism are educated with children of the same age who also have a diagnosis of autism. In a self-contained classroom, the primary classroom teacher is typically a special education teacher with training in autism and the evidence-based practices (EBP) known to help children with autism learn (Chen, 2017). While licensing varies from state to state, early childhood special education (ECSE) teachers receive pre-service education in both ECSE and early childhood (EC) education and can often hold teaching certifications in both fields (Council for Exceptional Children [CEC], 2000). 
Although the concept of the least restrictive environment (LRE), defined as educating children with disabilities in an environment with their same age peers who do not have disabilities, has been a law since 1975 (Office of Special Education and Rehabilitative Services [OSERS], 2010) the use of self-contained classrooms has been prevalent when educating children with autism. However, more recently there has been a shift away from educating children with autism in self-contained classrooms to educating children with autism in early childhood classrooms with same age children who do not have disabilities (U.S. DHHS \& U.S. DOE, 2015). While meeting the needs of individual children is a longstanding principle of developmentally appropriate practice (DAP) in early childhood education (Bredkamp \& Copple, 1997; NAEYC, 2009), the inclusion of children with autism in an EC classroom requires a change in the roles and responsibilities of ECE (Vakil et al., 2009). Traditionally, ECE have had little to no formal education or professional development related to working with children with autism and have relied on the knowledge and expertise of ECSE to work directly with children who have autism (Finch, Watson, MacGregor, \& Precise, 2013). In addition to understanding DAP, ECE now need to know what it means for a child to have autism and the types of EBP used to instruct a child with autism in order for the child to make progress in the EC environment (Akalın, Demir, Sucuoğlu, Bakkaloğlu, \& İşcen, 2014; Baker, 2012). ECE should also have knowledge of the continuum of autism features and how to collaborate with special education teachers, as well as families of children with autism (Banks et al., 2005). Due to the increasing numbers of children with autism in EC classrooms, ECE require a new set of knowledge and skills, as they are the primary educator in the classroom. ECE will continue to need to 
collaborate with ECSE teachers: however, in this new role, they become the primary instructor who is responsible for embedding opportunities to use EBP with children who have autism throughout their day (Dinnebeil \& McInerney, 2011; Dinnebeil, McInerney, \& Hale, 2006). In addition, the nature of their collaboration with special education personnel changes from a cordial relationship to one in which they engage in active participation, problem solving and decision-making with an Itinerant Special Education (IECSE) teacher (Dinnebeil \& McInerney, 2011). Collectively, systems of pre-service teacher education, professional development, and technical assistance providers are responsible for adjusting to a swelling demand to develop new programs that support ECE to acquire the necessary skills to accommodate the changing needs in their classroom (Early et al., 2007). Current information related to what ECE know about autism and EBP is needed to create professional development opportunities that are responsive to their current levels of knowledge associated with autism and EBP.

\section{Recognition of the Problem}

With increasing numbers of young children being diagnosed with autism (CDC, 2016; U.S. DOE, 2016b, 2016c) and receiving their special education services in general education environments (Rhode Island KIDS COUNT, 2015, 2016; U.S. DOE, 2016a), ECE are in a critical position of ensuring children with autism continue to make progress developing their skills. A broad base of literature reflects that the inclusion of young children with autism and other developmental disabilities in regular education preschools supports them in achieving better academic, social and lifelong skills (Holahan \& Costenbader, 2000; Green, Terry, \& Gallagher, 2014; Nahmias, Kase \& Mandell, 2014; Rafferty, Piscitelli, \& Boettcher, 2003; Strain, 2015; Strain \& Bovey, 2011). To achieve 
positive outcomes for children with autism, ECE must be prepared with knowledge of the autism diagnosis and EBP. Understanding autism and EBP gives ECE the information required to make instructional decisions and implement the practices known to help young children with autism learn new skills.

On the national landscape, there is limited evidence suggesting ECE have the knowledge of autism and the EBP necessary to provide inclusive programming that supports children with autism spectrum disorders and other developmental disabilities in preschool classrooms (Austin, Kipnis, Sakai, Whitebook, \& Ryan, 2013; Buysse, Wesley, Keyes, \& Bailey, 1996; Chang, Early, \& Winton, 2005; Dunst \& Bruder, 2013).

A national workforce survey found an estimated 1 million ECE are working in childcare settings (Snow, 2013). This same survey found that only $39 \%$ of these childcare teachers held at least a bachelor's degree in ECE; thus, demonstrating that a majority of community ECE have had little to no pre-service coursework in EC education topics related to supporting children's growth and development (Snow, 2013). ECE also work in State-Funded Pre-K (SFPK) classrooms, which require teachers to hold a bachelor's level degree and Head Start programs in which $73 \%$ of preschool teachers hold a bachelor's level degree (Barnett et al., 2017; Head Start, 2016). Those holding bachelor degrees in EC have had coursework primarily focused on typical learning and development. Additional research has found that ECE have minimal in-service professional development related to the inclusion of children with disabilities in a general EC classroom (Buysse \& Hollingsworth, 2009; Mogharreban \& Bruns, 2009; U.S.DOE, OSERS \& OSEP, 2014). With little to no pre-service experience and/or in-service training, researchers have found limited evidence demonstrating that teachers in EC settings have the background 
knowledge of autism, knowledge of EBP, and use of EBP necessary to provide programming in inclusive classrooms (Austin et al., 2013; Buysse et al., 1996; Chang, Early, \& Winton, 2005; Dunst \& Bruder, 2013).

In-service professional development has been identified as one way to support current teachers and interventionists to learn knowledge of autism and support the use of EBP in their classrooms (Dunst \& Trivette, 2012; Kretlow \& Bartholomew, 2010; Leblanc, Richardson, \& Burns, 2009; National Research Council, 2001). Research investigating the use of EBP by special educators demonstrated that their level of knowledge and attitudes regarding the EBP impacted their decision-making and use of the practices (Nakamura, Higa-McMillan, Okamura, \& Shimabukuro, 2011; Paynter et al., 2017; Paytner \& Keen, 2015). Nakamura et al. (2011) found that when clinical practitioners lacked knowledge in EBP, they had negative attitudes towards the use of EBP and engaged in limited use of EBP. Likewise, Paynter et al. (2017) found that increased knowledge of EBP supported both a positive attitude towards EBP and greater use of EBP when working with young children with autism. To ensure that professional development (PD) supports individuals to increase their knowledge and use of EBP, PD opportunities need to be informed by the level of knowledge of and experience of participants (Lee, 2005; Raab, Trivet, \& Dunst, 2013); thus, highlighting the need to focus research efforts on investigating ECE knowledge of autism (Bowman, 2011, Johnson, Porter, \& McPherson, 2012), knowledge of EBP and their use of EBP related to including children with autism (Simpson, Mundschenk, \& Heflin, 2011) across a variety of preschool environments. 


\section{Statement of Purpose}

The 2015 DHHS/DOE policy articulates an expectation that young children with disabilities will receive their special education services and supports in EC classrooms. To implement this policy, some state EC administrators are promoting the use of the itinerant early childhood special education (IECSE) service delivery model outlined by Dinnebeil and McInerney (2011). The IECSE service delivery model supports inclusion by providing special education services to children with disabilities in a natural preschool classroom (Dinnebeil \& McInerney, 2011). Using the IECSE model changes the role of the ECE, as the ECE become the primary practitioner implementing EBP with children who have disabilities (Dinnebeil \& McInerney, 2011; Dinnebeil et al., 2006; Vakil, Welton, O'Connor, \& Kline, 2008). In the EC field, Buysse and Wesley (2006) defined evidencebased practice as "a decision-making process that integrates the best available research evidence with family and professional wisdom and values" (p. xiv). Therefore, it is essential that ECE have knowledge of autism and EBP to support children with autism and other disabilities in their classroom (Purper, VanderPyl, \& Juarez, 2015; U.S.DHHS \& U.S. DOE, 2015).

ECE across the country are only required to participate in one or two introductory to special education courses during their pre-service training (Barnett, 2003b, 2011). Community ECE may have no experience with coursework or professional development related to supporting children with disabilities (Bowman, 2011), including autism, in the general education classroom. Professional development opportunities are traditionally provided by the ECE organization or a state-funded EC professional development centers 
and are related to general EC topics such as curriculum, context, classroom organization, behavior management and social skills (Barnett et al., 2017).

The purpose of this investigation is to examine the relationship between ECE knowledge of autism, knowledge of EBP and use of EBP when teaching children with autism across settings. A quantitative survey design method allows the researcher to gather data regarding these variables more efficiently and effectively than if using an alternative research method (Creswell, 2014; Fraenkel, Wallen, \& Hyun, 2012). Information collected from a survey that includes the perspectives of ECE in Head Start, SFPK, and communitybased preschool programs is needed to inform professional development activities. The findings from the survey will allow ECE professional development providers to design meaningful opportunities that align with the current levels of knowledge of teachers responsible for implementing a differentiated curriculum.

\section{Definitions of Important Terms and Concepts}

Early Childhood Educators (ECE): An ECE is an individual who has daily interaction with young children in a preschool classroom. An ECE may work in a community, Head Start or SFPK classroom and could hold a variety of educational credentials including a high school diploma, a bachelor's degree or a master's degree.

Developmentally appropriate practice (DAP)- DAP is a teaching approach with a foundation based on research of children's development and learning and the practices known to be effective in early education (Copple \& Bredekamp, 2009a).

Early Childhood (EC) Classroom: The early childhood classroom refers to a class that serves all young children, regardless of ability or presence of a disability, and employs 
developmentally appropriate practices expected to support children's learning and development (NAEYC, 2009).

Autism: Autism Spectrum Disorders (ASD), referred to as ASD or autism in this study, is a complex neurodevelopmental condition manifesting in social, communication and restrictive, repetitive behaviors that range in severity and intensity (APA, 2013).

Evidence-based Practice (EBP): The definition of EBP used in this study is consistent with the definition utilized by the National Professional Development Center on ASD (NPDC-ASD). To be considered an evidenced-based practice, the practice is supported in the literature to show efficacy with the following criteria:

(a) at least two experimental or quasi-experimental group design studies carried out by independent researchers, b) at least five single case design studies from at least three independent investigators, or

(c) a combination of at least one experimental and one quasiexperimental study and three single case design studies from independent investigators (Wong, Odom, Hume, Cox, Fettig, Kucharczyk, ... Schultz, 2015, p. 1956)

Inclusion: Inclusion as a term is a complex concept with multiple viewpoints. Some consider inclusion to be just about the placement or location of where children receive their educational program (Odom, Buysse, \& Soukakou, 2011). Others have evolved from this definition to include the quality of the educational experiences defined in 
the 2009 DEC/NAEYC position statement addressing high-quality inclusion. Access, participation, and supports are included in the definition of high-quality inclusion, meaning that children are not only in the same educational environment as their peers but they also have the supports necessary to meaningfully participate in daily curricular activities (DEC/NAEYC, 2009; Odom, Buysse, \& Soukakou, 2011). Inclusion, in this study, refers to children with autism participating, alongside their peers without autism, in an EC classroom and receiving instruction helping them to learn, develop and maintain new skills. 


\title{
CHAPTER 2
}

\section{REVIEW OF THE LITERATURE}

\begin{abstract}
Autism
A physician named Leo Kanner first used the term autism in 1943 to describe the behaviors he observed in 11 of his male patients (Kanner, 1943). Autism was first recognized in the American Psychiatric Association's Diagnostic and Statistical Manual of Mental Disorders (DSM) 3rd edition in 1980 (Baker, 2013). Since then, the term has undergone several revisions to better define and more accurately describe a group of behaviors presented by individuals with the complex neurological condition known as autism. DSM-V (2013) changed the criteria for autism from having 3 specific sets of behavioral criteria (Social, communication and restricted/repetitive behavior) to having 2 sets of behavior criteria in which social and communication behaviors were combined to become social communication; with the second set remaining restricted/repetitive behaviors (Buron \& Wolfberg, 2008; 2014). Although the DSM$\mathrm{V}$ uses the term autism spectrum disorder (ASD), the term autism continues to be used to describe the disorder (Baker, 2013). The clinical diagnosis of autism is made by a team of medical professionals using a comprehensive evaluation approach matching a child's behavioral presentations to the set of criteria outlined in the DSMV. The behaviors of autism can interfere and interrupt children's learning across five domains of learning which include social, communication and cognitive development, as well as sensory processing and typical behavior responses (Buron \& Wolfberg, 2008). Symptoms of autism can be observed as early as one year of age but are often not acted upon due to the variations present in typical child development.
\end{abstract}


As a result, children can be diagnosed at the age of 2 years, but are most often diagnosed at or around the age of 4 years (CDC, 2016). In addition, boys are 5 times more likely to be diagnosed with autism than girls (CDC, 2016). The age of diagnosis is important as it falls within the EC timeframe when many children begin participating in their first structured educational setting known as preschool. For this reason, ECE must have some knowledge about autism in order to identify if a child is experiencing atypical development and to work with families to access needed supports.

\section{Individuals with Disabilities Education Improvement Act (IDEIA)}

The Individuals with Disabilities Education Improvement Act [IDEIA] (2004), a reauthorization of what was once known as the Education for All Handicapped Children Act, ensures that all children with disabilities are afforded a free appropriate public education (FAPE) and an educational experience in the least restrictive environment (LRE). For young children with disabilities, the LRE is also called the natural environment (Odom et al., 2011). LRE means individuals with disabilities receive the specialized instruction, accommodations and modifications they need to learn in a regular education environment with their peers to the greatest extent possible. Specific to children with disabilities at the age of 3 years, this mandate creates a challenge for public schools to deliver LRE because public school experiences most often begin at age 5 years when children enter Kindergarten. As previously described, public schools are being encouraged to access the natural environments of young children to provide special education services to children with disabilities. IDEIA acknowledges autism as a specific disability category through which children who have autism are eligible for special education services. While 
all the main principles of IDEIA impact young children with disabilities, two principles are critical to the education of young children with autism. These principles are: 1) teachers be provided the professional development required to support children with specialized needs and 2) educational programs should be scientifically or evidenced based (IDEIA, 2004).

\section{Developmentally Appropriate Practice (DAP)}

Developmentally appropriate practice (DAP) is a framework that organizes the EC theories of Dewey, Vygotsky, Piaget, and others and is used to guide teachers' decisionmaking based on what is known about children's learning, development and the practices shown to help children achieve positive learning outcomes (Copple \& Bredekamp, 2009). Adopted in 1996 and revised in 2009, the National Association for the Education of Young Children (NAEYC) released a position statement defining DAP using core considerations of knowledge, principles for practice and guidelines. First, the document describes 3 core considerations related to the knowledge ECE should think about when working with young children. They explain that effective ECE consider what is known about children's learning and development, individual children skills and children's social and cultural contexts when developing high-quality learning experiences (NAEYC, 2009). The core knowledge considerations mean that teachers understand characteristics of individual children's learning so they can make intentional decisions about how to support their learning and development in the context of an EC classroom (Copple \& Bredekamp, 2009). This core consideration should be applied to children of all abilities, including autism, in the EC classroom.

The position statement continues to guide ECE by describing 12 principles of child development and learning, found in Appendix A, that teachers should use to guide their 
teaching practices. Together these 12 principles weave together the EC theories and research to identify the critical ideas that should be used to support intentional decisionmaking in EC classrooms. Among many important points, the principles include recognizing the cultural context of children's learning, the importance of relationships, the importance of play and how learning develops when children are challenged in supportive and nurturing environments (NAEYC, 2009). All principles are relevant to working with children who have autism; however, the principle that reminds teachers that children learn at different rates and can vary across areas of learning is of particular importance because children with autism often experience an uneven pattern of learning and development (Buron \& Wolfberg, 2014).

Lastly the NAEYC position statement (2009) provides 5 key areas of EC practice, including (1) creating a caring community of learners, (2) teaching to enhance development and learning, (3) planning curriculum to achieve important goals, (4) assessing children's development and learning, and (5) establishing reciprocal relationships with families, which all effective teachers use to improve learning outcomes for young children (Copple \& Bredekamp, 2009). In order to enhance learning and development, ECE use core knowledge and the principles of practice to make decisions in the 5 key areas of practice. For example, teachers apply the principle of creating a caring community of learners to the EC classroom curriculum by intentionally designing learning opportunities that promote social-emotional development. The teachers use consistent routines and schedules to promote a safe and predictable environment. When teaching to enhance development and learning, teachers use visuals as environmental print to support the acquisition of literacy skills. In the preschool environment, quality EC experiences are 
developed using a balance of child led and teacher led activities, providing children the opportunity for autonomy and ownership over their learning (Copple \& Bredekamp, 2009).

\section{Evidence-based Practice (EBP)}

Scientifically based research and instruction were introduced to the education field by the 2001 No Child Left Behind legislation and then applied in the field of special education in the 2004 IDEIA legislation (Cook et al., 2014). These two historic laws emphasized that teacher training and practice should be based on research; however, standards defining what constitutes EBP differs and has led to different interpretations of EBP. To illustrate the various conceptual views on EBP, Prizant (2011) describes two ways to define EBP: 1) EBP-A, a broad view of practices that take into consideration accepted definitions of professional organizations and 2) EBP-N, a narrowly defined set of practices using only evidence from research on practices used with individuals who have autism. The field of early childhood education broadly defines EBP as illustrated in Buysse and Welsey's (2006) definition including research evidence along with family and professional values and wisdom. In the special education field, IDEIA (2004) describes that teachers utilize scientifically based instruction with young children with disabilities in the context of general education classrooms. For children with autism, the set of EBP is narrowly defined using research-based practices (Wong et al., 2015) and will be discussed further in this literature review. Alignment of these two definitions relies on defining what is meant by scientifically based and evidence-based. These terms are not mutually exclusive but come together with the notion that there is empirical evidence, or research that suggests a practice that supports young children to make progress towards learning skills across a variety of domains, including both functional and academic skills. Most importantly, for 
EBP to be highly beneficial for children with autism, they must be matched to a child's needs and implemented with fidelity (Buron \& Wolfberg, 2008).

There have been several literature reviews conducted to define and identify EBP that show positive outcomes for individuals with autism; however, there are two comprehensive studies, relevant to ECE, that were carried out by national organizations. Both reviews were first completed in 2009 and have been updated to reflect current knowledge. Each study investigates the literature from two different time periods (Wong et al., 2015). The first study, National Standards Project (NSP), was conducted and published by the National Autism Center and included published studies from 1957 through September of 2007 (National Autism Center [NAC], 2009). Studies were evaluated using a scientific merit rating scale (SMRS) assessing the strength of the studies including the quality, quantity, and consistency of the practices utilized in a variety of research designs (Buron \& Wolfberg, 2014). Criteria for an established treatment included several published peer-reviewed studies, and NSP identified 11 interventions found to meet their criteria for "established treatment" shown to have positive outcomes for individuals with autism (Wilczynski, 2017; National Autism Center, 2009). An established treatment extends beyond an individual practice and includes blended practices that make up a treatment package (Wilcynski, 2017). For example, the established treatment called "behavioral package" includes a combination of the individual behavioral strategies known as discrete trial, reinforcement, and incidental teaching (NAC, 2009). Phase II of the NSP study conducted the literature review adding on the time frame of 2007 through February of 2012 (NAC, 2015). The results 
of this review found 2 additional categories were added, for children thru adolescence, making the total of EBP for individuals with autism, 14 interventions (NAC, 2015).

The National Professional Development Center on ASD (NPDC-ASD) was the second organization to conduct a review of the literature to identify EBP for individuals with autism. The first study in 2009, found 24 practices met their criteria for EBP from 19972007 (Buron \& Wolfberg, 2014; Odom et al., 2010). The second comprehensive review of the literature covered the 15-year time frame from 1997 - 2012. Both investigations evaluated the literature base to describe a set of individual practices shown to have positive results when used to support the learning and development of individuals with autism. A rigorous criterion was applied for the inclusion of studies in their review. Criteria included focused interventions related to behavioral, developmental and educational practices, a comparison condition, outcome data and a study design of randomized controlled trials (RCT), quasi-experimental designs (QED) or regression discontinuity designs (Wong et al., 2015). Wong et al. (2015) evaluated each to determine if the intervention resulted in outcomes in 12 areas including social, communication, behavior, joint attention, play, cognition, school readiness, academic, motor, adaptive skills, vocational and mental health development. Their study identified a total of 27 practices that improve skill development in individuals with autism in the age ranges from toddler ( 2 years) to young adult (22 years). Of these 27 practices, 24 demonstrated outcomes for four-year-old children in 1 or more of the 10 out of the 12 outcome areas. Three outcome categories were relevant to adult outcomes, such as vocational skills, and were not applicable to this age group.

The variablity in the intensity of how autism characteristics present in young children leads to the need for highly individualized programs tailored to meet the needs of young 
children in the early childhood classroom (Buron \& Wolfberg, 2014). The NPDC-ASD review promotes individual practices as EBP allow for practitioners to choose the practices or combination of practices that best meet the unique needs of children with autism.

This dissertation uses the results of the 2015 NPDC study on EBP identified for preschool-aged children with autism and those that showed evidence of improved outcomes across six or more developmental areas of learning. In order to achieve improved learning outcomes, EBP are implemented with fidelity to implementation procedures. The practices identified for this study include:

- Time Delay - the practice of giving wait time between instruction and providing assistance for a child to complete a task. With 12 single case design studies, children demonstrating positive outcomes across the 10 areas of skill development.

- Reinforcement: a systematic process in which children are provided positive consequences following the desired behavior. A total of 43 single case studies were found to meet the evidence based criteria and can be used to support development in 9 learning areas.

- Prompting: procedures include providing a child with visual, verbal or gestural help to complete a skill. Prompting is provided before or at the same time a child attempts a skill. Thirty-two single case studies and one group study met the evidence-based criteria and showed outcomes across 8 areas of learning.

- Video Modeling: a visual movie demonstrating a desired behavior or skill to a child. Video Modeling meets the criteria for an evidenced-based practice with 1 group design and 31 single case studies. 
- Discrete Trial: a type of adult-directed systematic instruction using repetitive teaching, prompting, and reinforcement that breaks learning down into smaller steps. Thirteen single case studies met the criteria for evidence-based practices and showed progress across 6 of the learning areas.

- Visual supports: visuals used in the classroom to provide children with information about appropriate behavior, expectations, social information and daily routines. Examples include stop signs, daily schedule, maps and visuals that show a routine such as hand washing. Eighteen single case studies met criteria showing outcomes in 7 areas of learning.

- Social Narratives: support children to understand a social situation by providing social information and expectations of how to behave during a particular interaction, using a visual story. Seventeen single case studies showed outcomes for 7 learning areas. (Wong et al., 2015)

\section{Context of Early Childhood Education and Early Childhood Special Education}

To fully appreciate the new demands placed on ECE, this research study acknowledges divergent theories, espoused by the fields of EC education and ECSE, as they are merged to create a new context for the theoretical basis of early childhood education. Contextualizing the research means recognizing that ECE, situated in the theories of EC education, are being challenged to consider and accept theories as they construct new knowledge of learning that guides their knowledge and use of ECSE practices to support children with autism in their classroom.

EC education has a long history of connecting theory to children's learning and development. Predominant fields guiding EC education include both constructivist and 
social constructivist theories (Bredekamp \& Copple, 1997; Copple \& Bredekamp, 2009; Odom \& Wolery, 2003). In the field of special education, theories align with more behavioral areas of theory (Strain \& McConnell, 1992; Trent, Artiles, \& Englert, 1998). Some claim the ECSE field neglects the use of theory in research and practice in order to focus on pragmatic issues of interventions, diagnosis and service delivery (Mallory \& New, 1994; Trent et al., 1998). As a result, ECE are faced with competing theoretical models and asked to reconcile these theories to enhance their practice of educating all children in their EC classrooms.

Relevant to this dissertation of the ECE knowledge of autism, knowledge of EBP and use of EBP, is the understanding that theory serves as a guide for teaching practices. Understanding theory helps practitioners to choose instructional strategies, evaluate the effectiveness of the strategies, and know why they should use specific strategies to support children's learning (DeValenzuela, Connery, \& Musanti, 2000; Kennedy, 2012; Knight, 1982). As the field continues to move toward supporting the education of children with autism within natural early childhood settings, professionals need to be prepared with knowledge of learning and development in both ECE and ECSE fields to guide practice of inclusion (Odom \& Wolery, 2003). The convergence of both ECE and ECSE theories builds a knowledge base for practitioners to be familiar with DAP and EBP for young children with autism. In order to illustrate how these theories support EC inclusion, this dissertation considers how major EC education and ECSE theories frame the practice of ECE. 


\section{Early Childhood Education Theory}

One of the most prominent theories in EC education is constructivism, which espouses that children use past knowledge in current learning experiences to build new knowledge and create meaning (Mooney, 2013). Constructivist theory evolved from cognitive constructive theory to social constructivist theory, which identified the role social interaction plays in the formation of knowledge. Leading constructivist theorists influencing ECE practice include Jean Piaget, Lev Vygotsky and John Dewey (Bredekamp \& Copple, 1997; Mooney, 2013; Odom \& Wolery, 2003). Jean Piaget described the Stages of Cognitive Development and believed that children's development is constructed in series of stages aligned with their physical age. Piaget posited all children pass through these stages as they develop thinking skills (Kozulin, 1994; Mooney, 2013). He acknowledged children might move through the stages of development at varying rates; however, the sequence through which they pass is the same. The EC education field is influenced by the first two stages of development: the sensorimotor stage (birth to age 2) and the preoperational stage (ages 2-7 years).

During the sensory-motor stage, children learn through their senses and the manipulation of materials. As children grow they move into the preoperational stage where they begin to form ideas based on perceptions (Mooney, 2013). ECE use this theory as they create multisensory play experiences through which children express their thoughts and begin to lead their own play. For children with autism, the stages of development are rarely uniform and typically do not align with how Piaget imagined. Children with autism often experience atypical development compared to same-aged peers. For example, some of the early signs of autism are described as a child not 
looking at an adult in response to their name, pointing to an object or person to have joint attention and/or not developing simple imitation skills such as waving (Buron \& Wolfberg, 2008; Wetherby \& Prutting, 1984). A young child with autism may experience extreme sensory-motor challenges, which limits their ability to access and use their senses as a way to generate new knowledge. In fact, the child may adhere to unusual patterns of play such as repeatedly lining up toys as a way to control their environment and reduce the amount of sensory input they are experiencing (Wetherby \& Prutting, 1984). These examples demonstrate how a child who has autism may develop in ways that contradict Piaget's theory of the stages of development. For ECE, understanding this difference and the early signs of autism can influence how they use EBP to support a child with autism in their classroom.

Unlike Piaget who was a cognitive constructivist, Lev Vygotsky was a social constructivist. He believed both social and personal interactions during play support children's learning and construction of new knowledge, rather than just building knowledge as one gets older (Kozulin, 1994; Mooney, 2013; Vygotsky, 1978). Vygotsky purported that play experiences, such as make-believe play, allow children the opportunity to build skills beyond their current skill level by acting out and rehearsing adult roles (Krishnan, 2010; Moll, 2014). Play as the primary mode of children's learning has become one of the most important principles guiding ECE instructional practice as evidenced by the use of play centers where children have the opportunity to make believe and build skills using their imaginations. Difficulties with pretend play, such as assuming other roles or using objects in new and novel ways, are 
hallmark deficits denoted as a characteristic of autism in young children (APA, 2013; Jarrold, 2016).

One of Vygotsky's most important contributions to ECE practice is his zone of proximal development (ZPD) theory. ZPD is defined as "the distance between the most difficult task a child can do alone and the most difficult task a child can do with help" (Mooney, 2013, p.101). Both teachers and peers in the classroom support learning by providing assistance (via modeling and scaffolding) to children to learn a skill that challenges them or is next in the developmental sequence (Mallory \& New, 1994). The ZPD theory contributes to the rationale for including children with autism into an EC classroom where they can learn with their peers. For example, a child with autism who struggles to learn social and emotional skills, benefits from being in a classroom with typically developing children who have more developed skills, by having models to learn the skills they do not have.

Finally, John Dewey was a social philosopher whose theories influence EC education through conceptualization of community building, developmentally appropriate practice and play as the process of learning (Gartrell, 2012). Dewey believed teachers should be organized, understand children's individual needs and be intentional in their curriculum by planning (Mooney, 2013); this has been well established in the EC community by the introduction of the use of standards to guide children's learning (Gronland, 2006; NAEYC, 2002). Dewey also believed learning experiences should be self-directed and purposeful and the ultimate goal of these experiences is to teach the child "how to learn" (Gartrell, 2012). Applied to the EC classroom, teachers design inquiry centers providing children the opportunity to be 
self-directed in their play and learning (NAEYC, 2009). Due to the social nature of inquiry center learning, children with autism are challenged to acquire new skills in this context and often demonstrate unconventional ways of playing with toys such as lining them up over and over again (Buron \& Wolfberg, 2008).

Constructivist theory has been the backbone of EC education by supporting educators to understand and value open-ended play-based learning opportunities allowing children to direct and discover their own learning (Mooney, 2013). Constructivist ideas are evidenced in today's EC guidance from the NAEYC (2009) Position Statement on DAP where there is an emphasis on play-based learning. Applied to ECSE, constructivism is considered a child-centered or individualized mode of learning which supports the notion that children of all abilities can construct their own knowledge (Mallory \& New, 1994). Together children play in ways that allow them to build social relationship skills and create friendships which is difficult for children with autism who, by way of their diagnosis, have challenges with imaginative play and social interactions (Wolfberg \& DeWitt, 2009). Vygotsky's theory of ZPD has been used to aid the argument that inclusion supports children with autism to learn because they benefit from the opportunity to learn social contexts with children who have more advanced skills (Mallory \& New, 1994; Trent et al., 1998). Dewey's notion that school is a place to build community also aligns with the goals of inclusion in that all individuals have the opportunity to build their own capacity and participate within a democratic society (Danforth \& Rhodes, 1997). However, constructivism falls short when addressing the needs of children who require a more structured and repetitive approach to learning. Many young children with autism 
benefit from a structured teaching approach espoused in behavioral theories (Mesibov \& Shea, 2008). In addition, a child who experiences significant social disability may not have same innate social understanding skills that would help them to learn from their peers. One example is a child who is significantly impacted by autism. This child may require a more direct instruction approach to acquire imitation and social thinking skills that would help them to be successful in a play based model (Garcia Winner, 2008).

\section{Early Childhood Special Education Theory}

Behavioral theories, including theories from John Watson, B. F. Skinner, and social learning theorist Albert Bandura, have been a foundation from which many ECSE programs focusing on autism have been designed (Barnhill, Polloway, \& Sumutka, 2010) and from which ECE have distanced themselves (Odom \& Wolery, 2003). Behavioral theories suggest "the importance of the environment" and that humans are programmed to behave in response to the environment (Knight, 1982; Krishnan, 2010). Watson and Rayner (1920) demonstrated that children could be conditioned to have specific responses, which would then be generalized to other stimuli resembling the initial stimuli. Skinner coined the term "operant conditioning" that described how learning results from children responding to their environment (Husen, 2001; Krishnan, 2010). He believed that children learn through behavioral modification; therefore the role of the teacher is to set up a learning environment and reward children for engaging in appropriate actions (Knight, 1982). A notable psychologist inspired by Skinner, Ivar Lovaas focused his life's work on the research and development of a practice called applied behavioral analytic intervention (Smith 
\& Eikeseth, 2011). Lovaas' approach is based on behavioral principles and is used for children with autism, ages 2-8 years, and has been a focus of many special education programs designed for young children (Cohen, Amerine-Dickens, \& Smith, 2006). Discrete trial teaching (or training) is an EBP used to teach skills with a systematic approach aligned with a progression of skills (Cohen, Amerine-Dickens, \& Smith, 2006; Gongola \& Sweeney, 2012).

Albert Bandura, agreeing with the notion of conditioning behavior with reinforcement, contributed to behavioral theory by adding that individuals learn by observing what is happening in their environment (McLeod, 2016). Unlike Watson, Skinner, and Lovaas, his social learning theory describes that children observe people in their environment and imitate their actions and in doing so build knowledge of the world around them (Bandura, 1971). While behaviorists Watson and Skinner described learning as cause and effect, Bandura's work embedded a cognitive element to behavioral theory suggesting the cognitive process mediates an individual's response to the environment (McLeod, 2016). In other words, Bandura believed that people think about and consider how behavior influences consequences before engaging in the behavior. Teachers applying Bandura's theories use a direct modeling approach in which a child receives reinforcement for correctly imitating the teacher.

While behavioral theories have a place in ECSE, the over-reliance on adult reinforcement and a "False premise that equates, training and manipulation with education" takes away from children's learning through inquiry and exploration (Knight, 1982, p.120). For example, the Lovaas approach for very young children includes a highly structured, intensive approach where learning opportunities are 
situated in one to one adult/child interactions (Cohen, Amerine-Dickens, \& Smith, 2006). The role of a teacher is to mediate or directly teach, using preplanned systematic instruction to target discrete skills to children with autism (Odom \& Wolery, 2003). The intensity and structure of the Lovaas method are in direct conflict with the constructivist play-based approach that views dramatic play and children's inquiry with other children as the primary mode of learning. As a result, ECE are challenged to understand how the discrete methods of instruction can be used to facilitate learning in a play based EC environment. A similar problem exists for ECE with the social learning theory, as they critically question the foundation of this theory, in particular, how children continue to learn and generalize their skills into a new environment without a model present (McLeod, 2016).

Odom and Wolery (2003) describe a Unified Theory of Practice in Early Intervention/Early Childhood Special Education (EI/ECSE) allowing the tenets of what is known about DAP for EC education to combine with the individualized goal oriented practices in ECSE. The theoretical base for EC education and ECSE come together to create a Unified Theory of Practice used to guide the teachers in the instruction of children, including those with autism. Teachers embracing this theory facilitate open-ended constructivist play opportunities as well as provide mediated opportunities for children with autism to learn discrete skills. For example, a teacher provides short 1:1 teaching sessions across the routines and activities and embeds opportunities for the child to practice within the daily schedule.

As more young children with autism enter into early childhood classrooms, all teachers can utilize a Unified Theory of Practice (Odom \& Wolery, 2003) to both facilitate 
and mediate instruction so that children with autism have successful experiences improving learning outcomes. With this frame as the backdrop for what teachers need to know and be able to do to support children with autism in the EC classroom, this dissertation examines the ECE knowledge of autism as the independent variables and their knowledge and use of EBP as the dependent variable. With respect to the fact that ECE work in a mixed delivery system, the group differences between teachers working in Head Start, SFPK, and community-based settings are also studied as an independent variable.

\section{Early Childhood Educators' Knowledge of Autism}

Knowledge of autism and inclusion are essential for the implementation of inclusive practices that support children with autism and related disabilities to participate in daily preschool activities (Bruns \& Mogharreban, 2007). As the educators providing the majority of services to children with autism, they should have knowledge of the range of the autism spectrum and some of the recommended instructional practices (NRC, 2001; Simpson et al., 2011). There is a paucity of research describing what ECE know about autism in the United States. A number of studies related to knowledge of autism focused on pre-service ECE or were conducted internationally (Arif, Niazy, Hassan, \& Ahmed, 2013; Lindsay, Proulx, Thomson, \& Scott, 2013; Liu et al., 2016).

Barned et al. (2011) conducted a small survey $(\mathrm{n}=15)$ with pre-service teachers enrolled in ECE preparation programs who expressed a desire to work with young children. Although part of a larger survey related to inclusion, they found that the pre-service teachers had misconceptions related to the diagnosis of autism including knowledge related to common observable behaviors, that children with autism are very similar in the presentation of characteristics to one another, and that autism exists only in EC. 
Additionally, they found that the pre-service teachers did agree that the core characteristics aligned to the diagnostic criteria (Barned et al., 2011).

In addition to understanding pre-service ECE knowledge, the research conducted related to ECE and autism knowledge often has a healthcare related focus. Such a study conducted by Strunk (2009) related to the knowledge of school nurses. She found that school nurses have general knowledge of autism in regards to the diagnostic criteria as well as the medication associated with autism; however, the nurses lacked knowledge of communication skills, behavioral therapies and safety issues (Strunk, 2009). Johnson, Porter, and McPherson (2012) surveyed undergraduate pre-service teachers studying in programs preparing them to work with children, birth to 5, in the Southeastern United States. With 148 responses, they found that $75 \%$ of the pre-service educators lacked experience with children with autism and lacked knowledge of autism. Johnson et al.'s (2012) study focused on how this information would support health educators and could support the pre-service preparation programs provide more information related to autism to the pre-service teachers.

International studies have also concluded that ECE lack knowledge of autism. A study conducted in Singapore surveyed 504 preschool teachers and found they had minimal knowledge of autism, including the primary diagnostic characteristics (Lian et al., 2008). In Ontario, Canada, a qualitative study using interviews, was conducted with 15 teachers regarding the inclusion of children with autism in their classrooms. The teachers reported a lack of understanding of autism, specifically related to the behavioral characteristics and strategies to support children when challenging behaviors emerged in the classroom (Lindsay, Proulx, Thomson, \& Scott, 2013). Another study with 471 preschool teachers in 
Guangzhou and Foshan, China, found that $83 \%$ of teachers incorrectly answered more than half of the knowledge items on a questionnaire related to autism (Liu et al., 2016). Liu et al. (2016) also found that knowledge of autism was associated with geographic location, with Guangzhou teachers having more knowledge of autism than those in Foshan and more knowledge of autism was associated with higher education. In Pakistan, 170 primary school teachers completed a questionnaire related to autism from which Arif, Niazy, Hassan, and Ahmed (2013) concluded that 55\% of teachers had knowledge of autism from media only sources and that only $10 \%$ had received professional development related to autism resulting in a lack of knowledge in preschool teachers across the private and public sectors.

These concerns support the need for professional development to increase ECE knowledge of concepts related to inclusion and ASD in the EC classroom (Buysse \& Hollingsworth, 2009; Cassidy, 2011; Paynter et al., 2016)

\section{Early Childhood Educators' Knowledge and Use of Evidence-Based Practices for Children with Autism}

While evidence regarding EBP is strong, there is little research documenting ECE use of EBP in the classroom setting to support students with autism (NPDC on ASD, 2014; Odom, 2000, 2008). Other studies, related to ECE, report a lack of content pedagogical knowledge related to the inclusion of children with autism (Barned, Knapp, \& NeuharthPritchett, 2011; Bruns \& Mogharreban, 2007; Odom, 2000). Bruns and Mogharreban (2007) surveyed Pre-K teachers and Head Start preschool teachers about their beliefs of and use of practices for servicing children with disabilities in their classroom. Their findings show positive beliefs towards inclusion; however, they expressed a lack of 
knowledge and training in the use of specialized techniques (Bruns \& Mogharreban, 2007). Unable to be generalized due to the small sample size and narrow geographic location, this study remains one of the few to shed light on the practices of regular EC classrooms as it relates to the inclusion of children with disabilities.

Although available research that describes ECE knowledge and use of EBP is limited, the ECSE field has been focused on understanding how special education teachers and pre-service teachers are learning and applying knowledge of EBP with children with autism. Stahmer, Colling, and Palinkas (2005) conducted a qualitative reseach study using focus groups with 22 early intervention staff to learn about their knowledge and use of EBP within natural settings for children, ages birth-5 years, with autism. The results indicated that many of the participants had "only superficial knowledge of specific intervention techniques and the adequacy of their implementation of these techniques (is) unclear" (Stahmer, Collings, \& Palinkas, 2005, p. 14). Participants reported selecting practices for children with autism based on personal comfort, the setting in which they perceived the practice best fit (e.g., challenged to implement one to one strategies within a group setting) and characteristics of the child. In addition, participants reported modifying practices based on adapting the protocol or combining practices (Stahmer et al., 2005). Not only did these providers, who supported ECE to implement practices with children with autism, have limited knowledge of the practices they also did not implement protocols with fidelity. This significant finding sheds light on the fact that all early childhood providers, both ECSE and ECE, require knowledge and information about how to implement EBP so children with autism can maximize the benefit of the practices. 
A second study focusing on 99 Austrailian metropolitan early intervention providers in community placements was conducted by Paynter and Keen in 2015 using an EBP questionaire. The questionnaire listed 40 practices from the literature that varied in the amount of research supporting the practice as evidence-based $(n=24]$, emerging practice $[n=6]$ and unsupported practices $[n=10]$ ) (Paytner \& Keen, 2015). The results demonstrated that practitioners knowledge of an EBP significantly predicted their stated use of the EBP as well as the structure, culture, and attitude of the organization in which they worked (Paytner \& Keen, 2015). Paytner and Keen (2015) also found the participants reported having more knowledge of and using more practices from the EBP list than from the emerging practices or unsupported practices list. In an effort to confirm their finding, Paytner and Keen (2017) revised their scale to address 44 practices and repeated their study with 72 participants working in early intervention agencies. Consistent with their first study, the pair found a significant predictive value between participants knowledge of EBP and their use of an EBP, as well as a positive organizational culture towards EBP (p.8). Based on their findings, Paytner and Keen (2017) report a continued need to study the link between knowledge and use of EBP for professionals working with children who have autism.

Related to EBP, some studies have found that teachers working with students who have emotional challenges have limited knowledge and use of EBP (Gable, Tonelson, Sheth, \& Park, 2012; Stormont, Reinke, \& Herman, 2011). Gable et al. (2012) surveyed 3,060 special education and general education teachers across the Pre-K to grade 12 public school systems. Included in this sample were 78 preschool teachers, 44 were from regular education classrooms and 34 from special education classrooms. The focus of this study 
was the practitioners' use of 20 EBP associated with supporting students to build positive behavioral strategies. Findings included that both special education and regular education teachers at all levels are unprepared to support children with emotional dis-regulation in the classroom (Gable et al., 2012). While this study was not focused on children with autism, many children with autism experience challenging behaviors, as well as difficulty with emotional regulation (Buron \& Wolfberg, 2014), and this study therefore contributes to the overall need for information related to what teachers know about using EBP to support children with social-emotional learning differences in the classroom.

A similar study was conducted in 2011 by Stormont, Reinke, and Herman, in which 239 regular early childhood teachers, from preschool and elementary schools across five school districts, were surveyed on their knowledge and use of 10 EBP used to support children with mental health problems. The major finding from this study was that the majority of teachers were unaware of 9 out of the 10 EBP used to support children with social-emotional needs (Stormont et al., 2011). Becuase children with autism experience social-emotional challenges and often are diagnosed with comorbid mental health diagnosis, this study further contributes to the notion that ECE need to have knowledge of EBP in order to support children with social-emotional learning needs.

The knowledge and use of EBP by ECE to help children with autism is limited. In light of a scarcity of research demonstrating this, studies that enlightened the field on what regular education teachers understand about EBP for children with social-emotional challenges can be used to underscore the need for professional development related to EBP. Although the EC field has defined the meaning of evidence-based practices, this research (Gableson et al., 2012; Paytner \& Keen, 2017; Storemont et al., 2011) demonstrates a 
shortcoming related to teachers use and knowledge of EBP to enhance the learning of children with autism and other social-emotional needs.

\section{Early Childhood Educators: A Mixed Delivery System}

The operational definition for ECE used for this research is an individual working in a regular education pre-school classroom who has a primary role interacting with children in the classroom including teachers and teacher assistants. Requirements for teachers vary across settings with only half of the early childhood programs in the U.S. requiring teachers to hold a bachelor's degree to teach preschool (Austin et al., 2013; Barnett, 2003a). Barnett (2003a) found that community programs and Head Start programs have the lowest education requirements for employment versus state-funded classrooms, which require teachers to have a bachelor's degree or higher. In 2013, Head Start required programs to ensure $50 \%$ of ECE teachers in their centers hold at least a bachelor's degree in EC education (Improving Head Start for School Readiness Act of 2007).

\section{Scale Development}

Scales can be used to collect information from specific populations to reflect perceptions of knowledge and use of instructional practices (Fraenkel et al., 2012). To create a scale, the researcher begins with a literature review of the construct to understand the theories defining it, allowing the researcher to narrow and define the purpose of the scale (DeVellis, 2003). With a specific goal, the researcher constructs the scale beginning with item generation and item review. Items are created using information found in the literature and reviewing previous scales to write items that directly ask participants to reflect on the specific theory or theories being measured to accomplish this. Once items are developed, and a platform chosen for dissemination, the items are put into a final format 
and tested in a pilot study. In order to determine if the items correctly measure the intended construct the researcher must establish content validity. Content validity is established by having experts in the field review the items to determine if the items are consistent with theory and context of the topic (DeVellis, 2003).

Construct validity is a second element the researcher considers when developing a scale. Construct validity is how well the scale " 'behaves' the way the construct it purports to measure should behave" (Devellis, 2003, p.53). To determine construct validity, researchers can use factor analysis to determine if the items in the scale hold together to measure the identified construct (DeVellis, 2003; Hutcheson \& Sofroniou, 1999).

Coverage, sampling, and nonresponse errors are of concern when using a survey design (Dillman, Smyth, \& Chrstian, 2009); therefore with consideration to increasing participation, the researcher should develop a well-crafted questionnaire (Dillman et al., 2009). Additional considerations, such as a sample survey, survey procedures and the inclusion of positive social exchanges (Dillman et al., 2009), can be embedded into the scale development process and implementation as a way to increase the motivation of participants to respond to the survey.

\section{Existing Scales and Measures}

With an increasing number of individuals having autism, there have been many studies that have sought to capture what people know and understand about the disorder (Harrison, Slane, Hoang, \& Cambell, 2017). Harrison et al. (2017) conducted an international review of the literature that specifically looked at the tools used to measure what is known about autism. Their review consisted of 67 studies in 21 countries and yielded a total of 44 different measures used to collect information about people's 
knowledge of autism. Most notable, the studies revealed that the measures were used with populations including medical professionals (40\%), school based professionals (34\%), siblings and same aged-peers (95\%) and only $6 \%$ focused on caregiver or parent perspectives. Absent in this study was recognition of the population of educators who work within the context of the early care and education environment, revealing that there are no studies specific to that population of educators.

One of the most widely used autism scales is the Autism Knowledge Survey (AKS) developed by Stone (1987). The AKS was designed as a 32-item Likert scale measuring the knowledge of 239 clinical professionals related to the diagnostic criteria of autism. Categories identified were descriptive, social-emotional and cognitive features; however, the survey was not developed using statistical analysis (Campbell, Reichle, \& Bourgondien, 1996). The findings from this study revealed differences in the level of autism knowledge between pediatricians, psychologists and speech and language pathologists (Stone, 1987). Stone and Rosenbaum (1988) used the AKS with 116 parents and special educators and revealed discrepancies in levels of their knowledge, as well as misperceptions about autism. Although the psychometric properties of this scale were not reported for the use in the 1988 study, Campbell, Reichle and Bourgondien (1996) conducted a confirmatory analysis on the AKS. They found that the survey represented a one-factor model with a reliability score of an alpha coefficient of .66 (Campbell et al., 1996). The AKS has been used or modified for use with medical professionals, pre-service teachers and education administrators (Harrison et al., 2017).

In 2011, Campbell and Barger developed the Knowledge of Autism (KOA) measurement tool using a 10-item True/False questionnaire to understand the autism 
knowledge of middle school students. Reliability for the KOA was low with Chronbach's $\mathrm{a}=.47$ (Campbell \& Barger, 2011). The KOA has also been used or modified for use with siblings in Australia, college students and education professionals (Harrison et al., 2017).

The Autism Inclusion Questionnaire (AIQ) measure was developed by Segall and Campbell (2012) using True/False/Don't Know items to measure school-based personnel's knowledge of autism, opinions of inclusion, classroom behaviors and practices used to support students with autism (Segall \& Campbell, 2012). Formal subscales for this instrument were not reported (Harrison et al., 2017).

\section{Research Summary}

The reviewed research illustrates the need for ECE to have knowledge of autism and EBP in order to fulfill their instructional responsibilities as ECE who are prepared to teach children of all abilities, including those with autism. Given the context of EC education and a paucity of research related to what ECE know about autism and EBP, there is a need to gather information to guide professionals to teach ECE about autism and the EBP used to teach children with autism. The existing autism knowledge measures have not been designed to target ECE and do not support the information needed for this research inquiry.

\section{Research Questions}

The Perspectives of Early Childhood Educators on ASD Scale (PECE- ASD) was created and used to examine the relationship among ECE knowledge of autism, and their knowledge and use of EBP guided by the following research questions.

RQ1: What are the levels of knowledge of autism, knowledge of EBP and use of EBP related to inclusion of children with ASD reported by ECE? 
RQ2: To what extent is there a relationship between ECE knowledge of autism and their knowledge and use of EBP to support young children with ASD?

RQ 3: To what extent are the use of EBP of ECE influenced by their experiences, group, and knowledge of autism? 


\section{CHAPTER 3}

\section{METHODOLOGY}

\section{Participants and Setting}

Rhode Island (RI) is the smallest state in the United States, covering a land area of 1,045 square miles and with a North/South and East/West distance of 48 and 37 miles respectively. In 2016, there were just over 1 million $(1,056,426)$ people living in RI, with $5.2 \%(54,934)$ being children under the age of 5 years old (United States Census Bureau, 2017). With 39 municipalities, young children have the opportunities to participate in preschool programs within a mixed delivery system that includes Head Start programs, SFPK, community-based programs, religious programs, private education programs and public school. Differences between these classrooms are related to the teacher's level of required education, funding sources, wages and program management (Whitebook, McLean, \& Austin, 2016). This dissertation focuses on three types of preschool classrooms: SFPK, Head Start and community based. RI programs are staffed with a reported 1,420 ECE preschool teachers (U.S. Department of Labor Statistics [U.S.DOLS], 2016), providing 12,677 spaces for children ages 3-5 to attend an EC education program (Kids Count, 2017). While RI numbers illustrate the capacity of early care and education programs to provide opportunities for children, nationally Kids Count reports that $73 \%$ of preschool children participate in EC preschool programs. With that said, despite federal laws pertaining to children with disabilities having access to those same early childhood classrooms (IDEIA, 2004), children with disabilities continue to have difficulty accessing early care and education programs (Kids Count, 2017). The same is also true in Rhode Island as only $30 \%$ of children with disabilities are receiving services in general EC setting 
(RIDE, 2016). Of those children receiving services, RI reports that 177 of the 2,942 children (6\%), ages 3-5 are diagnosed with autism (RIDE, 2016). The small size of the state allowed this researcher to access the early childhood educator population through the state early childhood professional development organization and direct contact with the administrators of early care and education programs, which support preschool-aged children.

When designing this study an a priori power analysis was performed to determine the number of responses needed to conduct inferential statistical tests to detect statistically significant differences when answering the research questions (DeVellis, 2003; Faul, Erdfelder, Lang, \& Buchner, 2007; McDonald, 2014). Four essential parameters are used when conducting a priori power analysis for inferential statistics; thus allowing the researcher to reduce Type II errors which can cause the researcher to miss the effects expressed by the population (Field, 2013). The parameters include 1) identification of the effect size, which describes the minimum deviation from the null hypothesis the researcher wishes to detect, 2) the alpha or probability of rejecting the null hypothesis, 3 ) the Beta (or power) describing the likelihood of accepting the null hypothesis and 4) the number of predictor factor variables expected (McDonald, 2014). Using the G-Power 3.1 power analysis computer application for a two-tailed linear multiple regression statistical procedure, the four parameters were set with a medium effect size $=.15$ (Faul et al., 2007), alpha level $=.05$, Beta $=.90$ and five predictor factor variables. The needed sample size for this study was 116 responses.

Convenience sampling recruited 128 ECE (see Table 1) who participated in the survey, representing EC educators (71.9\%), teacher assistants $(21.1 \%)$ and others $(.7 \%)$ 
who work in SFPK classrooms (17.2\%), Head Start preschool classrooms (42.2\%) and community preschool classrooms (40.6\%). The participants represented approximately $9 \%$ of the 1,420 ECE working in Rhode Island (U.S.DOLS, 2016) including SFPK (1.5\%), Head Start preschool classrooms (3.8\%); while teachers from community-based settings $(3.6 \%)$ were underrepresented. In the state of RI Head Start teachers make up $12 \%$ of the teacher population and SFPK make up 7\%. In this dissertation sample both groups were over represented. On the other hand, community preschool teachers make up $81 \%$ of the EC population in RI and in this sample they were underrepresented with a total of $40.6 \%$ of the sample.

Exclusion criteria for the survey population included ECE currently working as ECSE and ECE working with children between the ages of birth to three years old.

\begin{tabular}{lcc}
\hline Table 1 & & \\
Description of Participants & $\%$ & $\mathrm{~N}$ \\
\hline Demographic Information & & 128 \\
Professional Role & 71.9 & 92 \\
$\quad$ ECE & 21.1 & 27 \\
Teacher Assistant & 7.0 & 9 \\
Other: Administrator or EC Coordinator & 98.4 & 126 \\
Female & & 127 \\
Race/Ethnicity & 3.6 & 4 \\
Black & 10.7 & 13 \\
Hispanic & 81.8 & 105 \\
White & .9 & 1 \\
Other: Native American & 3 & 4 \\
Declined to respond & & 128 \\
Classroom Type & 40.6 & 52 \\
Community & 17.2 & 22 \\
SFPK & 42.2 & 54 \\
Head Start & & 128 \\
Location of Employment & 54.3 & 70 \\
$\quad$ Urban &
\end{tabular}

Table 1

Description of Participants 


\begin{tabular}{lcc}
\hline Suburban & 38.6 & 49 \\
Rural & 7.1 & 9 \\
Age (in years) & & 128 \\
$21-30$ & 23.9 & 30 \\
$31-40$ & 23.9 & 27 \\
$41-50$ & 42.5 & 58 \\
$60+$ & 4.9 & 7 \\
Declined & 4.9 & 6 \\
Highest Degree Earned & & 128 \\
High school & 10.0 & 13 \\
Associates Degree & 18.3 & 23 \\
Bachelors Degree & 53.5 & 68 \\
Masters Degree & 18.4 & 24 \\
\hline
\end{tabular}

Consistent with the national data reported in Bradley, Herzenberg and Price's Losing Ground in Early Childhood Education (2005) and a RI Department of Labor and training report (2014), the vast majority of preschool educators who participated in the study were women (98.4\%), with an average age of 41-50 years and who reported varied educational experiences including having obtained a high school diploma with or without some college experience $(10 \%)$, an associate's degree $(18.3 \%)$, a bachelor's degree with or without a teaching certification (53.5\%) or a Masters degree (18.4\%). Eighty-two percent of the survey participants identified themselves as White, followed by $10 \%$ Hispanic, $3 \%$ Black, $1 \%$ Native American, and 3\% preferred to decline to offer information on their racial identity. Geographically, the majority of participants (54.3\%) reported working in an urban community, while the remaining participants reported working a suburban community $(38.6 \%)$ or in a rural community $(7.1 \%)$.

\section{Instrumentation}

A researcher-developed scale, Perspectives of Early Childhood Educators on ASD (PECE-ASD), was used collect to information on the knowledge of autism and 
knowledge/use of EBP related to the inclusion of children with ASD. The final scale consisted of 4 sections with a total of 44 items. See Appendix B for the PECE-ASD.

\section{Personal Information}

The initial section of the survey included 13 items that collected personal and demographic information. The first five items were designed to collect personal information about age, gender, race, years working in early childhood and location of work. The next question asked participants to identify their level of education.

Participants responding that they had some college experience were then asked if they had information about autism presented to them throughout their collegiate experience.

Following the education questions, all participants were asked if they had participated in professional development experiences on autism. Those answering yes, were directed to another question asking them to identify the type of professional development they have taken part in. Lastly, there was an item unique to personal experience with an individual with autism.

\section{Item Development}

Phase one of the scale construction consisted of generating a pool of close-ended items that focused on the research of 3 categories: knowledge of autism, knowledge of EBP, and use of EBP. Questions in the knowledge of autism section were generated using the diagnostic criteria of autism and aimed to collect information related to the characteristics of autism including challenges with social communication and restrictive, repetitive behaviors (APA, 2013; Buron \& Wolfberg, 2008). These items were matched to Likert scale ratings using a 1-5 rating scale, where participants were asked if they 
agree/disagree with provided statements. The scale ratings were as follows: 1 strongly disagree, 2 disagree, 3 neutral, 4 agree, and 5 strongly agree.

The final two variables, knowledge of EBP and use of EBP, were addressed by creating questions using the literature review, Evidence-Based Practices for Children, Youth, and Young Adults with Autism Spectrum Disorder, completed by Wong et al. (2014). Criteria for inclusion in the survey was that the EBP met the following criteria: the practice was used with 4-year-old children with autism and evidence of the practice showed positive outcomes for 6 or more of the 12 outcomes. As previously described, seven practices were included in this survey and met this criterion. These EBP include visual supports, reinforcement, social narratives, prompting, discrete trial, time delay and video modeling. Inclusion, the practice of having children with autism in a classroom with same age peers who do not have a disability, was added as an $8^{\text {th }}$ category in the survey. The items for the knowledge of EBP were matched to Likert scale items with 1-5 rating, where 1 - I don't know anything about this practice, 2- I have heard of this practice but don't know anything about it, 3-I have very little knowledge about this practice, 4- I have some knowledge about this practice and 5- I know a lot about this practice. The items for the use of EBP were matched to Likert scale items with a 1-5 rating. The ratings are as follows: 1 Never used it, don't intend to use it, 2- Never used it, intend to use it sometimes, 3- Never used it, intend to use it frequently, 4- Have used it, intend to use it sometimes and 5- Have used it, intend to use it frequently.

\section{Expert Review}

Phase 2, Item analyses, was conducted by a group of 10 professionals representing ECE, ECSE teachers, and national content experts. Reviewers were asked to look at the 
clarity and the content validity of the questions to ensure that the items represented the knowledge that ECE could have related to the characteristics of autism and the EBP use to support children with autism. Reviewers used a structured format, found in Appendix C, that required them to answer specific questions capturing their feedback on the accuracy of content, clarity of statement and sensitivity to the diversity of potential survey participants. A comprehensive review document, including all reviewer responses, was created to assist the researcher in identifying common ideas related to necessary changes to improve the item quality, clarity, and sensitivity.

\section{Web-based Scale}

After expert review and feedback, phase three included inputting the information into the web-based tool Survey Gizmo. The small size of the state and estimated sample size needed, allowed the researcher to collect information using a survey design. In RI $81 \%$ of the population is reported to use the internet (Miniwatts Marking Group, 2016) and therefore, accessing a web-based format allowed the ECE to control their participation in the research and the ability to deploy the survey in a place of convenience such as in their place of employment, at home or in a community setting with Internet access (Dillman, Smyth, \& Christian, 2009). Final formatting included the study description, purpose, and benefits for respondents, as well as an informed consent for participation in the study (Dillman, Smyth, \& Chrstian, 2009). Appendix D is a copy of the Rhode Island College Institutional Review Board's (IRB) approved description of the study and consent forms.

\section{Pilot Study}

Phase four was a pilot study conducted to evaluate the PECE- $A S D$ questionnaire's implementation procedures, the time commitment for completion and final feedback on the 
questions (Dillman, Smyth, \& Chrstian, 2009, p.28). The data collected from the pilot was used to determine if the survey questions provided reliable information for the identified variables and if there were underlying factors that would explain variance in the scores. Implementation of the pilot study took place in Massachusetts and North Carolina and yielded 60 responses. As an incentive for completing the pilot survey, participants in the study had the opportunity to add their name to a drawing for one of two $\$ 50$ Amazon gift cards. Factor analysis of the survey data showed that individual items did not load as expected. The analysis revealed that the items in the knowledge of autism category loaded to many different, separate factors; however, the knowledge of practices and use of practices each loaded to independent factors. This data showed that a revision of the items was necessary to collect information on ECE's knowledge of autism. In each section, the questions were revised to align with anticipated factors that explained the variables of knowledge of autism, knowledge of practices and use of practices. In addition to item revision, the web-based format was restructured from table format, including all the items, to individual questions. This change allowed easier access to the questions/answers, which reduced the overall average amount of time to complete the scale from fifteen minutes to eight minutes.

\section{Procedures}

\section{Recruitment}

Once completed, the PECE-ASD was used to collect demographic information and measure the knowledge of autism and knowledge and use of EBP of early childhood educators related to the inclusion of children with ASD in Rhode Island. Following Rhode Island College IRB approval, the researcher sent an email to directors and administrators of 
EC programs and personnel in key EC organizations in RI. See Appendix E for the initial email. The email requested the administrators forward the PECE-ASD research announcement to ECE working in preschool classrooms. ECE were able to open the research announcement and directly access the web page with the description of the research project and the Rhode Island College IRB consent form. Once the participant consented to participate in the study, they were able to access the survey. Follow up emails to directors and administrators were sent weekly, for 4 weeks, asking them to forward the research announcement to ECE. The reminder email can be found in Appendix F. To increase motivation for participation and completion of the survey (Dillman, Smyth, \& Chrstian, 2009), participants were given the option to add their name to a lottery to win one of two $\$ 50.00$ Amazon gift cards. Participants, wanting to be in the drawing, were redirected to a separate web page to disconnect their participation in the lottery from their survey responses.

\section{Overview of Data Analysis}

Data from this inquiry was used to determine the relationship between ECE knowledge with ASD and their knowledge and use of EBP. Also, data was used to reveal if there were any differences between the three ECE groups. The data analysis will serve two purposes: one, the validation of the PECE-ASD and two, to answer the research questions.

\section{Initial Screening of the Data}

Data collected from the online Survey Gizmo tool was downloaded and entered into IBM SPSS 21 statistical software for data analysis. Items that were absent of all data were removed from the data set. Negatively worded items were reverse scored to represent consistency between both sets, positively and negatively worded, of items as they measure 
the variables related to autism and EBP. In anticipation of running multivariate analysis, dummy coding was used to create variables denoting each ECE group associated with the organization's community preschools, Head Start and SFPK.

Validation of the PECE-ASD was achieved by determining construct validity, using principal factor analysis (PFA), and reliability, using item analysis. During the initial development of the PECE-ASD, EC and ASD content experts reviewed items to ensure the items appropriately reflected the content related to the inclusion of preschool children with ASD (DeVellis, 2003). Content reviewers used a structured format to review items focusing on the accuracy of information and appropriate word choice to ensure comprehension by the participants.

PFA procedure was used to understand the structure of the variables (DeVellis, 2003; Field, 2013) and develop the scales combining multiple items (Field, 2013; Williams, Onsman, \& Brown, 2010). PFA represents a group of statistical procedures, within each requiring the researcher to make decisions and choices influencing the quality of the variables (Beavers et al., 2013; Fabrigar, Wegener, MacCallum, \& Strahan, 1999). PFA was used to determine an appropriate number of variables within a scale (Fabrigar et al., 1999; Field, 2013) by placing items into groups of highly correlated items that can explain the "maximum amount of common variance" (Field, 2013, p. 667). The following strategies were used in an iterative process to make decisions regarding the PFA.

\section{Checking the Data}

The first decision point was to determine if the sample size yielded the necessary data to conduct a PFA. With variability noted in the research as to an appropriate sample size (Costello \& Osborne, 2005; Hogarty, Hines, Kromrey, Ferron, \& Mumford, 2005), the 
researcher used two tests to determine if the response data were suitable for factor analysis: the Kaiser-Meyer-Olkin (KMO) Measure of Sampling Adequacy and Bartlett's Test of Sphericity (Beavers et al., 2013; Field, 2013). The KMO index runs from 0 to 1 . Values close to 0 indicate a "diffusion in the pattern of correlations" (Field, 2013, p. 684) and are unacceptable for factor analysis. Values closer to 1 identify patterns of correlations that are closer together revealing more reliable factors (Field, 2013). Researchers are also directed by the guidelines set by Hutcheson and Sofroniou (1999). Bartlett's Test of Sphericity suggests that the data used for factor analysis have a significant test result of $p<.05$.

In addition, the initial data review included checking the assumptions of data using histograms, boxplots and the Shapiro-Wilk Test of homogeneity to determine if the data were normally distributed (Field, 2013).

\section{Method of Extraction}

Principal axis factoring procedures were chosen as the method of extraction based on the advantage that principal axis factoring could be used with data that are not normally distributed (Fabrigar et al., 1999).

\section{Method of Rotation}

Factor rotation was used to improve the interpretation of factors. Rotation results in variables loading maximally to the factor most closely related (Beavers et al., 2013). Multiple iterations using both direct Varimax and Direct Oblimin rotation methods were used to strengthen the reliability of the results. Varimax rotation simplified the interpretation of factors by having a smaller number of highly loaded variables in each factor (Field, 2013). The Direct Oblimin technique uses a constant value called delta, set to 
equal 0 , which allows the underlying factors the opportunity to correlate (Field, 2013) and is said produce accurate results (Costello \& Osborne, 2005).

\section{Criteria for Factor Extraction}

Factor extraction was approached using multiple rotation methods, allowing the researcher to simplify the data using several criteria (Beavers et al., 2013; Field, 2013; Williams et al., 2010). Techniques included the Scree test, Kaiser's Criteria, reviewing the cumulative percentage of variance explained and parallel analysis. The result of using Cattell's Scree Plot test was that factors and their corresponding eigenvalues were illustrated in a graphical plot (Beavers et al., 2013; Field, 2013). When reviewing the scree plot, a line was drawn through the plotted eigenvalues illustrating the number of factors with high eigenvalues and factors with low eigenvalues; thus allowing the researcher to visually see the point in which line changes. Called the inflection line, or point of dramatic change, the researcher retained the factors that fell to the left of the inflection or the factors with the highest associated eigenvalues (Field, 2013; Williams et al., 2010).

Kaiser's criterion guided the researcher to retain factors with eigenvalues greater than 1 , based on the "idea that eigenvalues represent the amount of variance explained by the factor" (Field, 2013, p.677). An eigenvalue of 1 means the factor represents a large amount of the variance in the factor. Communalities, which represent the values of common variance in a factor, are also considered when determining a factor.

Communalities of a 1 , represent common variance and communalities of 0 represent no common variance; thus helping to determine how a variable contributed to the overall variance of a factor (Field, 2013). Costello \& Osborne (2005) found that common magnitudes for item correlation in the "social sciences are low to moderate communalities 
of .40 to .70 " (p. 4). If the item has a communality of less than .40 , the researchers should consider if the item should be included or dropped.

Percent variance explained was based on reviewing the total amount variance the factor explains (Beavers et al., 2013). Beavers et al. (2013) describe that the literature suggests that $75-90 \%$ of variance should be accounted for when including all the factors.

\section{Interpretation Selection of Items and Labeling}

As previously noted, determining factors was an iterative process relying on the review and evaluation of each step which resulted in factors that made both statistical and theoretical sense to answer the research questions (Beavers et al., 2013). When using the multiple rotation techniques, the researcher used the pattern matrix to identify the factor/item loadings and the factor/correlation matrix for the correlations between the items (Costello \& Osborne, 2005). The selection of items was based on how significantly items correlated to one another within each factor. Items with a loading of .30 or below are not significantly correlated (Beavers et al., 2013; Field, 2013) and the researcher should exclude the item. In addition, when an item loads to multiple factors with .32 or higher, called cross loading, the researcher is advised to evaluate if the item should be eliminated from the analysis (Costello \& Osborne, 2005; Field, 2013). A final criterion for items purported by Field (2013) is for the researcher should be cautious of two or more items that load with a high correlation, at .80 or higher, which results in multicollinearity. In this case,

Field (2013) recommends eliminating one of the items to allow for the unique contribution of the item to the factor to be expressed. The number of items and their correlation values determines the strength of identified factors. A strong or stable factor is said to have at least five items with .5 or higher and a weak factor has less than 3 items (Costello \& Osborne, 
2005); however, the final numbers of items are relative to the correlations, the loadings and the sample size (Field, 2013).

\section{Reliability Analysis}

A reliability analysis was conducted using Cronbach's alpha for each of the subscales to determine if the variables consistently measured the constructs (Field, 2013). An acceptable level of reliability for a scale is achieved with a Cronbach's alpha level of .7 or above (Field, 2013).

\section{Dependent Variable Assumptions}

Once the new variables were created, the dependent variables were checked for assumptions to reduce Type I and Type II errors. Normality was viewed using histograms, Kolmogorov-Smirnov (K-S) and Shapiro-Wilk tests of normality. The K-S and ShapiroWilk tests of normality identify a normal distribution of data with a score of a 0 (Field, 2013). Review of scatterplots and Levene's test was used to assess homogeneity of variance/homoscedasticity. Levene's test, assessing homogeneity, is considered significant when a score has a $\mathrm{p}=<.05$; thus demonstrating there is a significant difference in the variances of the groups. If the p-value is greater than .05 , "homogeneity of variance can be assumed" (Field, 2013, p.195).

Based on the pilot data and theoretical underpinnings of knowledge of autism, knowledge of EBP and use of practices, the expected number of factors for this model was 5. This included the knowledge of autism items loading into three factors aligned with social, communication and behavioral diagnostic criteria; as well as 2 additional factors, one representing knowledge of EBP and the other representing use of EBP. The actual factor loadings did not describe this expected outcome; instead, a four-factor model was 
found and used to answer the research questions. The four identified factors created new variables and were subsequently named knowledge of behaviors of autism, general knowledge of autism, knowledge and use of specialized practices and knowledge and use of practices aligned to DAP. Appendix G provides an explanation of were used to answer the research questions. The factor analysis results are further discussed in the results and discussion sections.

\section{Answering the Research Questions}

To answer RQ1 (what are the levels of knowledge of autism, knowledge of EBP and the use of EBP of children with autism of children with autism reported by ECE), descriptive statistics including frequencies and standard deviations were used to identify how ECE report their knowledge of autism and EBP as well as their use of EBP to support the inclusion of children with ASD. Descriptive statistics were also used to report demographic information, including years of experience, program type, and level of education. Descriptive data allowed the researcher to identify any differences in the education level and mean values among the three preschool program types.

To answer RQ2 (To what extent is there a relationship between ECE knowledge of autism and their knowledge and use of EBP to support young children with ASD?) a bivariate correlation using a two-tailed Pearson's correlation coefficient test was conducted to determine the extent of a relationship between the independent variables of group association, general knowledge of autism, knowledge of behaviors of autism and the dependent variable use/knowledge of specialized practices.

A bivariate correlation using a two-tailed Pearson's correlation coefficient test was conducted with a bootstrapping option to assess the extent of the relationship between the 
independent variables of the group, general knowledge of autism, knowledge of behaviors of autism and use/knowledge of practices aligned to DAP. The bootstrapping option overcomes the distribution problem by estimating the properties of the sample by calculating the mean from the sample creating 1000 parameter estimates (Field, 2013, p.199). SPSS performs a bootstrapping when selected for data that does not meet the assumption of normal distribution

Pearson's correlation coefficient standardizes the covariance resulting in a value that lies between -1 and +1 (Field, 2013). Field (2013) explains that a positive correlation (value $=+1)$ means that as one variable increases, the other does as well and with a negative correlation (value $=-1$ ) as one variable increases, the other will decrease. He goes on to state that when the correlation value is equal to 0 , one variable changes while the other stays the same (Field, 2013, p. 267). Statistically significant relationships will have significance values less than .05 .

RQ3 (To what extent are use of EBP of ECE teachers influenced by their experiences, group association and knowledge of autism?) was answered using a multiple-regression statistical analysis procedure. Again to answer this research question, a null hypothesis,

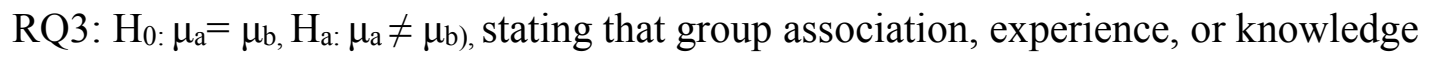
of autism does not influence their use of EBP was used. Multiple linear regression allows the researcher to analyze data with multiple independent explanatory variables (Hutcheson \& Sofroniou, 1999). Using hierarchical, also called block-wise, multipleregression allows the researchers to select the variables and enter them into SPSS in the order of importance for predicting the outcome (Field, 2013, p. 322). Knowledge of autism has been found to be an important factor related to use of EBP for early intervention 
(Paytner \& Keen, 2015) more so than group associations or experience with children with autism. As such selection explanatory variables in the multiple regression were input using the following order; knowledge of behaviors (KB), general knowledge (GK), group association, education and experience (E) with the dependent or outcome variable as either knowledge and use of specialized practices or knowledge and use of practices aligned to DAP. Based on a second GPower analysis to determine if the sample size would support multiple regression statistical testing, a total sample size of 123 was needed to conduct multiple regressions with 6 predictor variables. This allowed the researcher to also use education level and experience with children with autism as explanatory variables in the analysis. As a result of an inconsistent finding of the violation of the assumption of normality between two outcome variables, two separate multiple regression tests were conducted, one using specialized practices and one using practices aligned to DAP. The outcome variable of specialized practices did not violate the assumption of normality while the practices aligned to DAP variable did violate the assumption of normality. With this finding, the researcher could proceed using two separate multiple regression tests, one with bootstrapping to account for the violation of normality rule. Both outcome variables were tested using the null and alternative hypothesis: $\mathrm{H}_{0:} \mu_{\mathrm{a}}=\mu_{\mathrm{b}}, \mathrm{H}_{\mathrm{a}}: \mu_{\mathrm{a}} \neq \mu_{\mathrm{b}}$. The two regression models used to answer RQ3 are as follows:

$$
\begin{aligned}
& \text { Specialized Practices }=\mathrm{b}_{0}+\left(\mathrm{b}_{1} \mathrm{~KB}_{1}+\mathrm{b}_{2} \mathrm{GK}_{2}\right)+\left(\mathrm{b}_{3} \mathrm{Community}_{3}+\mathrm{b}_{4} \mathrm{HS}_{3}+\mathrm{b}_{4} \mathrm{PreK}_{4}\right)+ \\
& \left(\mathrm{b}_{5}\right. \text { education } \\
& 5
\end{aligned}
$$




\section{CHAPTER 4}

RESULTS

\section{Results of Principal Factor Analysis (PFA) and Item Analysis}

A Principal Factor Analysis was conducted on 28 of the 30 PECE-ASD items using multiple rotation options, including Varimax and Direct Oblimin. The researcher used both Varimax and Direct Oblimin rotation techniques to determine the factor loading of items, which resulted in a more reliable set of factors. The item related to inclusion as a practice was excluded because inclusion is a concept that includes several practices that are individualized to support children with disabilities. The practices included in the factor analysis are all discrete practices, each with a set of evidence-based procedures that support the fidelity of the use of the practice. The Kaiser-Meyer-Olkin measure confirmed the sampling adequacy for the analysis,

$\mathrm{KMO}=.733$. Individual item KMO scores ranged between .189 and .690. Field (2013) suggests that the acceptable item KMO score be greater than.50; however, with a small sample size, he suggests averaging the KMO scores (p. 698) which produced an average $\mathrm{KMO}=.686(19.23 / 28)$ which exceeds the acceptable level. The factor analysis produced 10 factors, five factors with eigenvalues greater than. 10 , explaining $41.78 \%$ of the variance. The Scree Plot, shown in Figure 1., illustrates the 5 factors with eigenvalues greater 1.0. 
Figure 1.

Scree Plot for PFA with Direct Oblimin Rotation of PECE-ASD

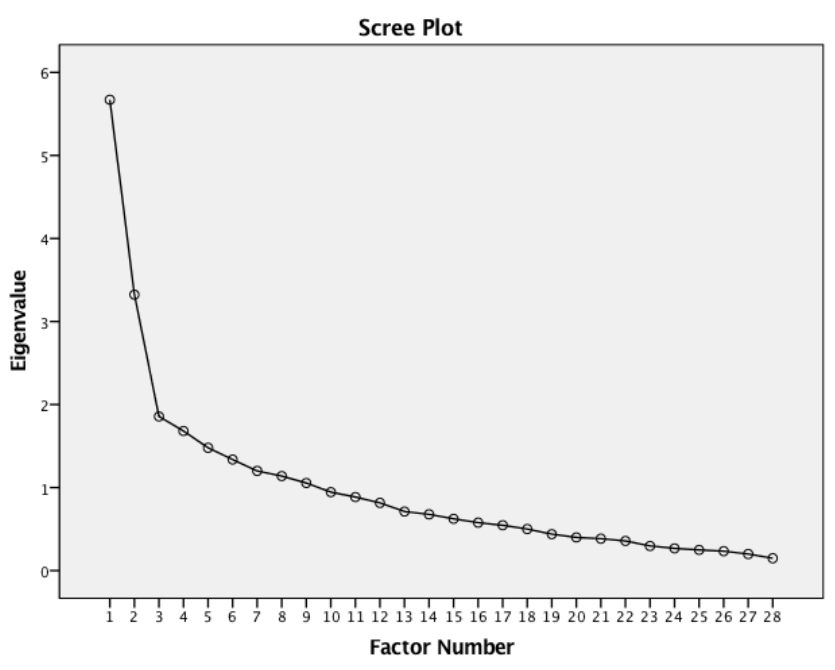

In review of the item loadings, four factors emerged with items loading to each with scores ranging between .369 and .771 . Each factor had a distinct pattern of five items loading, each with one high loading $(>.7)$ and then mediocre loadings $(>.3$ and $<.5)$. The fifth factor had one item loaded with a score of .884. In order to determine if the loadings could be improved, a second PFA was conducted with the option of selecting a five-factor model. The second PFA also produced a KMO of .733; however, the average KMO scores of the items was $\mathrm{KMO}=.396$. While a five-factor model was selected, only 4 factors emerged with eigenvalues $>1$ and an explained $39 \%$ of total variance.

The results from the first PFA were used as the accepted factors for the PECEASD. Scales based on multiple items tend to represent the constructs more reliably and validly than each item. Several analyses were conducted to determine the best factor model for the scale. Table 3 illustrates a summary of the results of the PFA. Total variance explained with the retained four-factor model was $37.98 \%$.

Table 2

Summary Table for PFA with Direct Oblimin Rotation of PECE-ASD 


\begin{tabular}{|c|c|c|c|c|}
\hline Scale & $\begin{array}{l}\text { Align with } \\
\text { DAP }\end{array}$ & Behaviors & Specialize & General \\
\hline Knowledge of Reinforcement & .802 & .021 & .003 & .066 \\
\hline Knowledge of Visual Supports & .771 & .018 & .047 & .094 \\
\hline $\begin{array}{l}\text { Knowledge of Social } \\
\text { Narratives }\end{array}$ & .492 & .046 & .305 & .099 \\
\hline Use of Visual Supports & .468 & .091 & .037 & .010 \\
\hline Knowledge of Prompting & .450 & .128 & .184 & .183 \\
\hline Use of Reinforcement & .436 & .205 & .023 & .225 \\
\hline Use of Prompting & .316 & -.033 & .386 & .108 \\
\hline $\begin{array}{l}\text { Children with autism know } \\
\text { how to act in social situations. }\end{array}$ & -.125 & .749 & .203 & .022 \\
\hline $\begin{array}{l}\text { Children with autism have } \\
\text { unusual ways of playing with } \\
\text { toys. }\end{array}$ & .060 & .617 & 190 & .108 \\
\hline $\begin{array}{l}\text { Autism impacts a child's ability } \\
\text { to socially communicate. }\end{array}$ & .056 & .506 & .021 & .250 \\
\hline $\begin{array}{l}\text { Children with autism have a } \\
\text { need for routines and } \\
\text { sameness. }\end{array}$ & .059 & .478 & .147 & .011 \\
\hline $\begin{array}{l}\text { Children with autism have very } \\
\text { strong interests }\end{array}$ & .207 & .430 & .019 & .040 \\
\hline Knowledge of Video Modeling & .062 & .133 & .813 & .010 \\
\hline Use of Video Modeling & -.072 & -.054 & .606 & .098 \\
\hline Knowledge of Discrete Trial & .215 & -.019 & .589 & .129 \\
\hline Use of Discrete Trial & .004 & -.023 & .519 & .119 \\
\hline Knowledge of Time Delay & 137 & .000 & .405 & 114 \\
\hline Use of Time Delay & .265 & -.006 & .289 & .111 \\
\hline $\begin{array}{l}\text { A child with autism may repeat } \\
\text { a phrase over and over again. }\end{array}$ & -.093 & .084 & .046 & .699 \\
\hline $\begin{array}{l}\text { Children with autism are more } \\
\text { likely to play alone than with } \\
\text { other children. }\end{array}$ & .062 & .188 & .161 & .515 \\
\hline $\begin{array}{l}\text { Boys are more likely to be } \\
\text { diagnosed with autism than } \\
\text { girls. }\end{array}$ & .102 & -.014 & .061 & .481 \\
\hline $\begin{array}{l}\text { Autism is a developmental, } \\
\text { neurological disorder. }\end{array}$ & .004 & -.184 & .103 & .369 \\
\hline Eigenvalues & 5.27 & 2.84 & .39 & .13 \\
\hline$\%$ Variance & 18.81 & 10.13 & .98 & .07 \\
\hline$a$ & .802 & .718 & .821 & .577 \\
\hline
\end{tabular}


Within the four factors, 22 items in total loaded to the four factors. Of note, is the item named "use of time Delay" with a loading of .298. Typically a low loading $<.3$ would be removed from the factor; however, when the reliability analysis was conducted with and without the item, the results was that the inclusion of the item strengthened the reliability from Cronbach $a=.794$ to $a=.821$. Additionally the item "use of prompting" loaded to the two factors Align with DAP (.316) and Specialized Practices (.386). Although a lower loading, the item was retained in the Align with DAP for two reasons, 1) keeping the item with the Align to DAP factor makes conceptual sense and 2) the reliability of the Align to DAP factor was increased with "use of prompting included." In the final four factors, the items that group together for factor 1 suggest they represent practices that aligned to DAP, factor 2 represents behaviors of autism, factor 3 represents specialized practices and factor 4 represents general knowledge of autism. Reliabilities for the subscales aligned to DAP, behaviors and specialized practices were all acceptable with Cronbach $a=.802, a=.718$ and $a=.821$ respectively. The last factor, general knowledge of autism had a lower reliability of Cronbach $a=.577$.

The four-factor model resulted in two dependent variables for this study: practices aligned with DAP and specialized practices. The dependent variables were checked for distribution normality, which identified that both dependent variables were negatively skewed suggesting that there is a "build up of high scores" (Field, 2013, p. 185), which align with DAP and specialized practices. In SPSS the skew and kurtosis values are based on a 0 value for normal distribution. For the variable aligned with DAP, the skew value was -1.11 and the kurtosis value was 1.26 which is lower/higher than the 0 value for normally distributed data. In addition, the Kolmogorov-Smirnov ${ }^{\mathrm{a}}(\mathrm{K}-\mathrm{S})$ test of normality was 
significant $(\mathrm{p}=.000)$, as was the Shapiro-Wilk test $(\mathrm{p}=.000)$; both demonstrating data that was not normally distributed. For specialized practices, the skew value was -.619 and the kurtosis value was -.212 , both being removed from the ideal score of 0 . The K-S and Shapiro-Wilk tests of normality were also both significant, $(p=.000)$ and $(p=.001)$ respectfully, demonstrating data that is not normally distributed.

Transforming data was used to attempt to correct for distributional problems (Field, 2013, p. 201) of the alignment with DAP variable. A transformation was conducted using $\log$ transformation with a reverse score, or reflection, technique that corrects for a negative skew, unequal variances and a lack of linearity (Field, 2013, p. 203). Before and after results of the transformation are illustrated in Figure 2.

Figure 2.

Histograms of Before/After Transformation of Data for Aligned with DAP
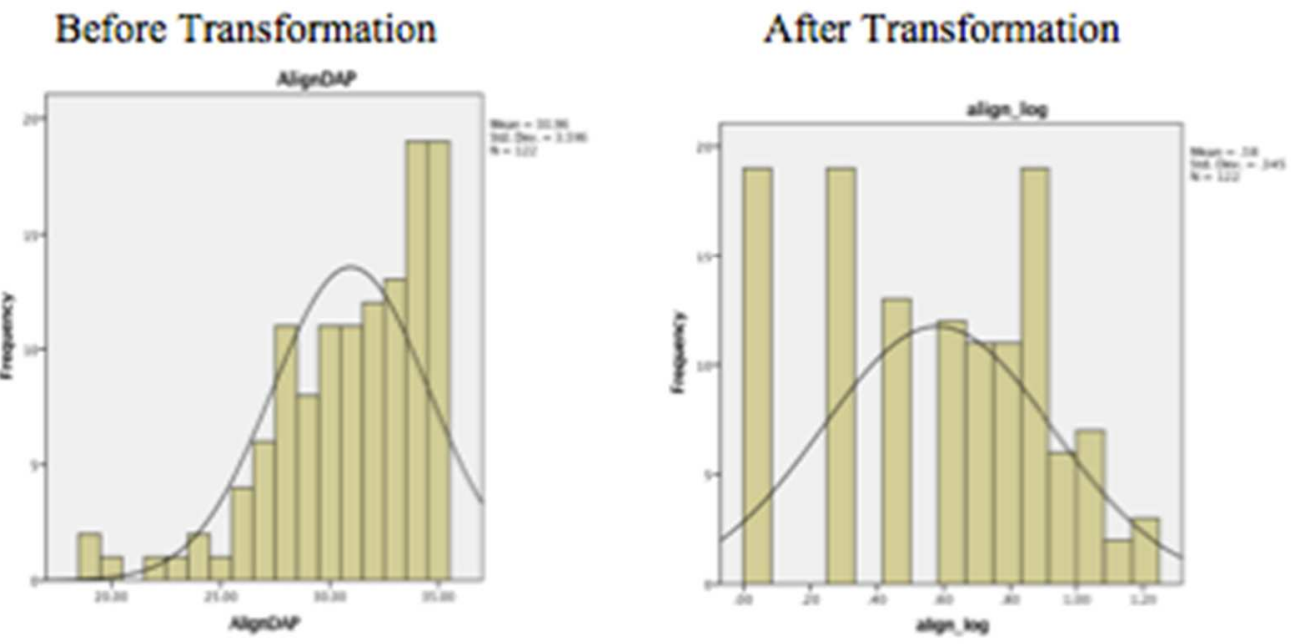

The transformation of the aligned with DAP variable did not yield a more normal distribution of data; however, the value of negative skewness was reduced. The transformed skew value was -.304 and kurtosis value was -.896. The K-S and Shapiro-Wilk tests of normality stayed consistent for significant non-normal distributions with each 
having a $p=.000$. Thus the variable, aligned with DAP, will only be used with nonparametric testing. On the other hand, the transformation did result in more normally distributed data for the variable of specialized practices. For this variable removal of 4 items, with values of 0 , were also used to achieve more normally distributed data as shown in Figure 3.

Figure 3.

Histograms of Before/After Transformation of Data for Specialized Practices Variable

Before Transformation

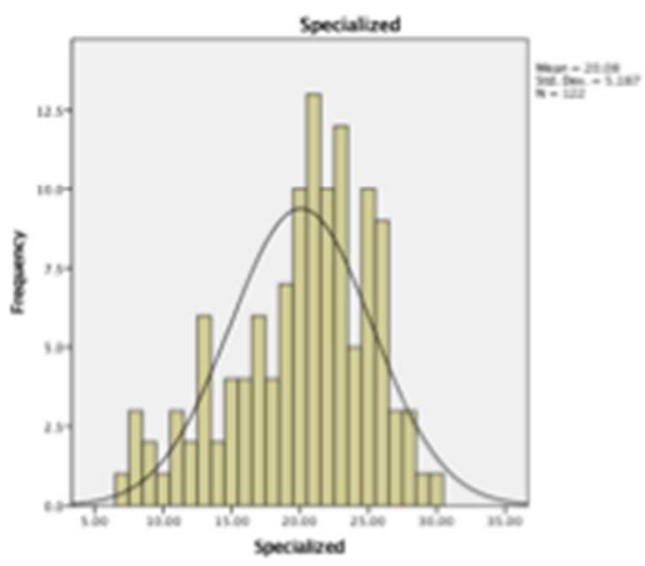

After Transformation

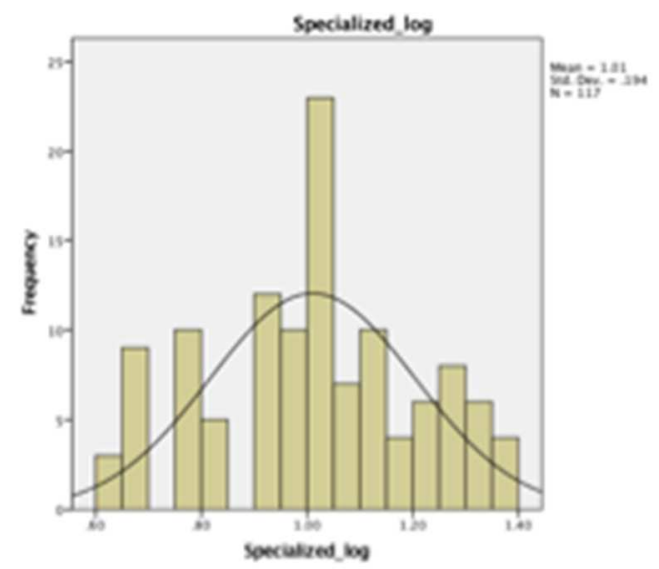

The removal and transformation resulted in a skew value of -.081 and a kurtosis value of .695 , which is removed from the preferred values of 0 . The $\mathrm{K}-\mathrm{S}$ value was $\mathrm{p}=.185$ and the Shapiro-Wilk was $p=.036$. When assessing the homogeneity of variances among the groups with the dependent variable specialized practice scores, the variances for specialized practices were unequal for community, Head Start, and SFPK teachers, F $(1,111)=2.242$, $\mathrm{p}=.111$. Levene's test also showed unequal variances among the groups concerning the dependent variable: practices aligned with DAP, $F(1,111)=3.072, p=.050$.

\section{Participant Experiences with Autism}

The participants were asked two types of demographic questions related to experience with autism: one related to their educational experiences and one related to their 
experience with children who have autism. Figure 4 provides an overview of the respondents who reported having an experience related to learning about autism. Of particular note, 128 participants answered the questions related to coursework and professional development but less than half of the participants reported having participated in coursework (44\%) or professional development (44.8\%) related to learning about autism. Once answered, those responding yes were then asked to provide more information about the types of coursework and professional development they experienced.

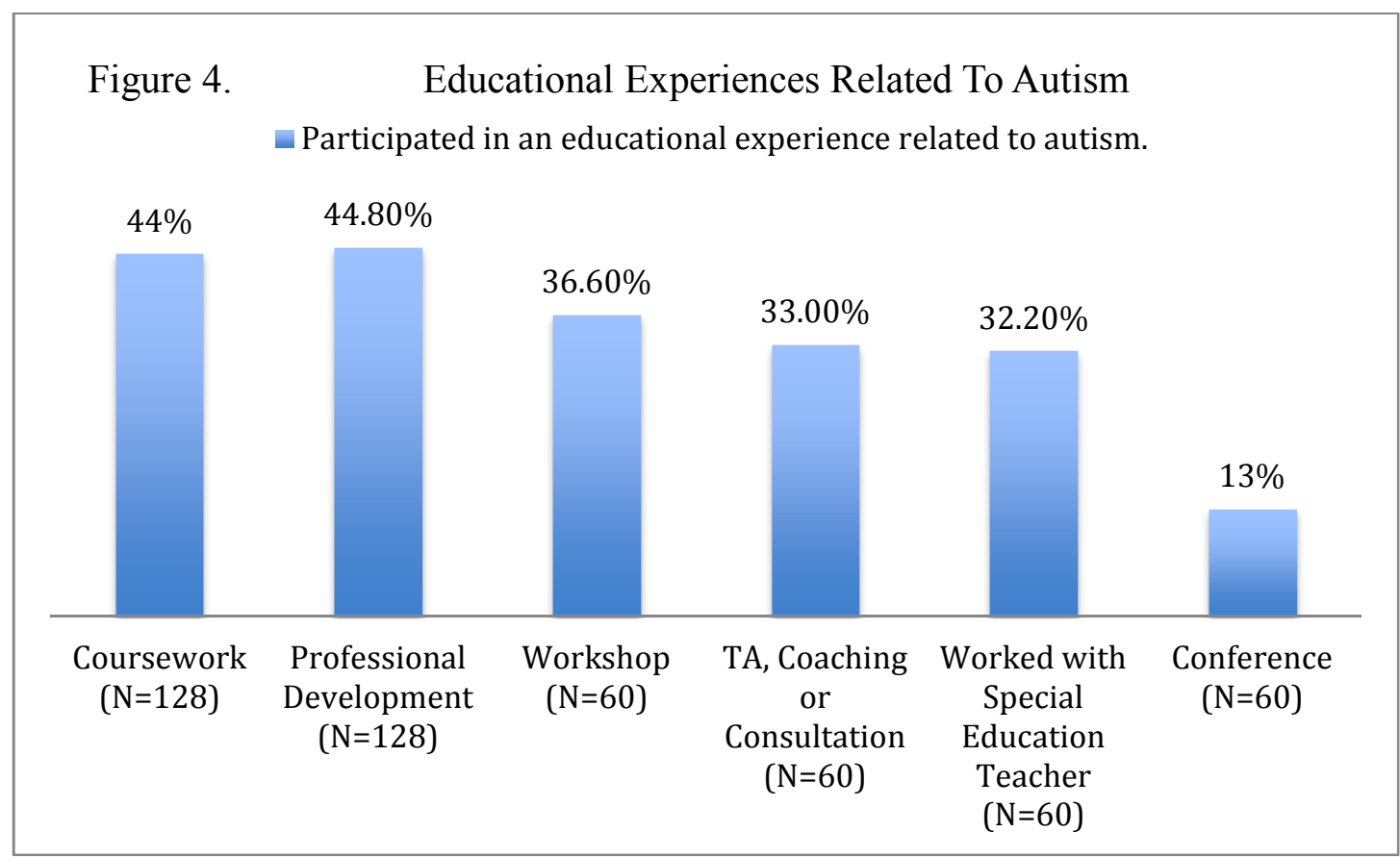

While not depicted in Figure 4, participants who did have coursework related to autism (44\%) reported the amount of time devoted to this topic was as follows: $23.3 \%$ briefly presented in one class, $23.3 \%$ one whole class period, $35 \%$ multiple class sessions, $11.7 \%$ an entire course, and $6.7 \%$ several courses resulting in a certificate or certification in autism studies.

Regarding their participation in professional development, only $44.89 \%$ of the participants answered "yes" to these items. Results showed the majority of participants 
reported working with another professional (65\%), including a technical assistance provider, coach, consultant or special education teacher, to learn about autism, followed by attendance in a workshop devoted to autism (36.6\%). The majority of participants $(80 \%)$ also reported not having educational experiences to learn about autism by attending a conference, a webinar or accessing the online Autism Internet Modules (AIM).

When asked about their experience with autism, participants were asked to share if they had experience with a child who had the diagnosis as well as children they suspected as having autism. Figure 5. illustrates participants' answers to the question related to

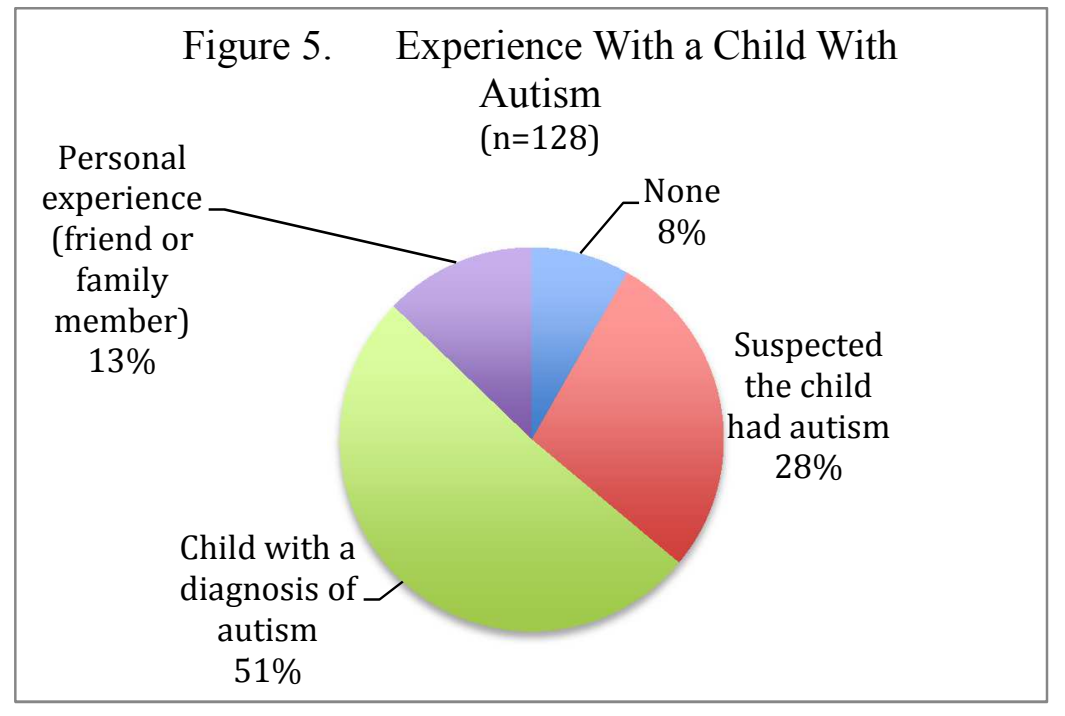

experience. Slightly

more than half $(51 \%)$ of

the participants report

working with a child

who has a formal

diagnosis of autism,

while only $8 \%$ have no

experiences. Twenty-

eight percent express that they suspected that a child they worked with might have autism and $12.7 \%$ reported having a personal experience with autism, meaning they have a family member with the diagnosis or have a friend who has the diagnosis themselves or the friend has a child diagnosed with autism. 


\section{Results of Research Questions}

\section{Research Question 1}

What are the levels of knowledge of autism, knowledge of EBP and use of EBP related to inclusion of children with ASD reported by ECE?

\section{Knowledge of Autism}

Participants were asked to use a 5-point Likert scale to rate their level of agreement with statements about autism. The ratings are as follows: 1 - strongly disagree, 2 - disagree, 3 - neutral, 4 - agree and 5 - strongly agree. For data analysis, questions were grouped into two main dimensions: general knowledge of autism and diagnostic criteria of autism, which was further divided into two sub-categories of social communication and behavioral characteristics of autism (APA, 2013).

General knowledge of autism questions were related to information about autism spectrum disorders including age of diagnosis, gender, and that autism is a neurological disorder. Table 3 illustrates the general knowledge questions along with how participants responded using the average, or mean response and standard deviation.

Table 3

Responses to General Knowledge Questions $(N=124)$

Mean

(X)

Autism is a developmental, neurological disorder.

Boys are more likely to be diagnosed with autism than girls.

Children with autism are considered strong auditory learners.

Table 3

Responses to General Knowledge Questions $(N=124)$ 


\begin{tabular}{lccc}
\hline $\begin{array}{l}\text { Children can be diagnosed with autism at 24 } \\
\text { months. }\end{array}$ & 2.90 & .891 & 35.5 \\
$\begin{array}{l}\text { Autism is a continuum that affects children } \\
\text { differently }\end{array}$ & 4.47 & .669 & 94.3 \\
\begin{tabular}{l} 
Children can be cured of autism. \\
\hline
\end{tabular} & 4.09 & .622 & 0.0 \\
\hline
\end{tabular}

The participants demonstrated that they have some understanding about general information about autism. The large standard deviations, ranging from $\mathrm{SD}=.622-1.0$ illuminates the variation in the participants' scores. A majority (94.3\%) of the participants agreed or strongly agreed with the statement that autism is a continuum and affects children differently. A majority of participants (78.2\%) also agreed that autism is a developmental, neurological disorder, while $21.7 \%$ were neutral or disagreed. Regarding gender and autism, the CDC (2016) reports boys (1 in 42) are 4.5 times more likely to be diagnosed than girls (1 in 189). Although this statistic has remained unchanged for several years (CDC, 2016), less than half the participants (48\%) agreed with statement. In other words, $52 \%$ were neutral or disagreed that boys are more likely to be diagnosed with autism than girls. When asked if children could be cured of autism, none of the participants agreed or strongly agreed, $84.8 \%$ disagreed and the remaining $15.2 \%$ were neutral with the statement; thus, a majority shows an understanding that there is not a cure for autism. While the average age of diagnosis is 4 and a half years old, experienced clinicians can diagnose children as young as 2 or younger (CDC, 2016). Participants had mixed ratings for the statement that autism "can be diagnosed at the age of 24 months" with $35.5 \%$ agreeing or strongly agreeing, $39 \%$ remaining neutral and $35.0 \%$ disagreeing with the statement. 
Individuals with autism have been described as visual learners both by persons with autism (Grandin, 1995; Endow, 2012) and in the literature related to the use of instructional practices to support young children with autism to learn (Quill, 1997; Hodgdon, 1995). Participants were asked an inverse question related to what modality is the strongest for children with autism when it comes to learning. Again, the participants had mixed ratings about the statement with the following responses: $28.5 \%$ strongly disagreed or disagreed, $50.4 \%$ neutral were neutral or disagreed and $21.1 \%$ agreeing with the statement.

The second dimension of the knowledge section relates to the criteria for diagnosis of autism including the categories of social/communication and behavioral characteristics. As such, the data has been disaggregated to look at these categories separately as illustrated in Tables 4 and 5.

\begin{tabular}{lccc}
\hline $\begin{array}{l}\text { Table } 4 \\
\text { Responses to Items for Social/Communication Characteristics }\end{array}$ (N=125) \\
\hline & Mean (X) & SD & $\begin{array}{c}\text { \% Agree or } \\
\text { Strongly Agree }\end{array}$ \\
$\begin{array}{l}\text { A child with autism may repeat a } \\
\text { phrase over and over again. }\end{array}$ & 4.06 & .796 & 85.0 \\
$\begin{array}{l}\text { Children with autism are more likely } \\
\text { to play alone than with other children. }\end{array}$ & 4.04 & .780 & 82.0 \\
$\begin{array}{l}\text { Children with autism know how to } \\
\text { act in social situations. }\end{array}$ & 4.08 & .714 & 40.6 \\
$\begin{array}{l}\text { Autism impacts a child's ability to } \\
\text { socially communicate. }\end{array}$ & 4.12 & .655 & 87.2 \\
\hline
\end{tabular}

Autism impacting a child's ability to socially communicate with others is a primary diagnostic criterion of autism (APA, 2013). Overall the participants scored an average score $(M>4, S D>.655)$ of agreed or strongly agreed with all the statements related to how autism impacts the social communication of children. Of the 
participants responding to the PECE-ASD, 87.2\% acknowledged that autism impacts a child's ability social communicate and another $40.6 \%$ agreed that a child with autism knows how to act in social situations. Another $82 \%$ agreed that children with autism are more likely to play alone; while $17.7 \%$ were neutral and $4 \%$ disagreed. Repetitive language, also called echolalia, is one of the communication markers for the autism diagnosis (APA, 2015). Consistent with this communication marker, $85 \%$ of participants agreed with the statement that children with autism might repeat a phrase over and over again. A small minority, 4.4\% disagreed with this statement and another $9.6 \%$ were neutral.

Related to the behavioral characteristics that people can observe, the participants as a group "agree" with half the statements as represented in Table 5 with questions 20 and 22 having an $\mathrm{M}>4$.18. Responses to playing with toys in usual ways and the notion that children with autism have need for routines and sameness, the majority of participates agreed or strongly agreed with these statements, $92 \%$, and $95 \%$ respectively). On the other hand, only $75 \%$ acknowledged that children with autism demonstrate repetitive body movements and another $74.2 \%$ acknowledged children with autism have very strong interests. Interpretation of this evidence should be considered with recognition to the large standardized scores ranging from $\mathrm{SD}=.587-1.09$.

\begin{tabular}{|c|c|c|c|}
\hline $\begin{array}{l}\text { Table } 5 \\
\text { Responses to Items for Behavioral Character }\end{array}$ & $(N=12$ & & \\
\hline & Mean & SD & $\begin{array}{l}\% \text { Agree or } \\
\text { Strongly Agree }\end{array}$ \\
\hline $\begin{array}{l}\text { Children with autism have unusual ways of } \\
\text { playing with toys such as lining up the same } \\
\text { toys in a row over and over or repetitively } \\
\text { spinning the wheel of a toy car. }\end{array}$ & 4.18 & .587 & 92.0 \\
\hline
\end{tabular}




\begin{tabular}{lccc}
\hline $\begin{array}{l}\text { Children with autism demonstrate repetitive } \\
\text { body movements such as hand flapping or } \\
\text { body rocking. }\end{array}$ & 3.39 & 1.09 & 75.0 \\
$\begin{array}{l}\text { Children with autism have a need for routines } \\
\text { and sameness. }\end{array}$ & 4.34 & .623 & 95.0 \\
$\begin{array}{l}\text { Children with autism have very strong interests } \\
\text { such as only talking about bugs or only playing } \\
\text { with trains. }\end{array}$ & 3.69 & .878 & 72.0 \\
\hline
\end{tabular}

\section{Knowledge of Evidence-Based Practices (EBP)}

Knowledge of the characteristics of autism and the practices that support children with autism to learn are essential for teachers to know for them to implement inclusive practices that support children with ASD to participate in daily preschool activities (Bruns \& Mogharreban, 2007). Practices for this survey were chosen from the literature review, Evidence-Based Practices for Children, Youth, and Young Adults with Autism Spectrum Disorder, completed by Wong et al. (2014). Criteria for inclusion in the survey was that the practice met the criteria for the four-year-old age population of children with autism and that at least the evidence of the practice showed positive outcomes for 6 or more of the 12 outcomes. Seven practices were identified to meet this criterion and included in the survey. These practices include Visual Supports, Reinforcement, Social Narratives, Prompting, Discrete Trial, Time Delay and Video Modeling. Inclusion, the practice of having children with autism in a classroom with same age peers who do not have a disability, was added as an $8^{\text {th }}$ category in the survey. As Inclusion is widely accepted as a beneficial practice, strategies and supports are individualized for children. Participants were asked to identify their level of knowledge about the practices using the following rating: (1) I don't know anything about this practices, (2) I have heard of this practice, but don't know anything about it, (3) I have very little knowledge of this practice, (4) I have some knowledge of this 
practice and (5) I know a lot about this practice. Figure 6. represents what the ECE reported about their knowledge related to EBP.

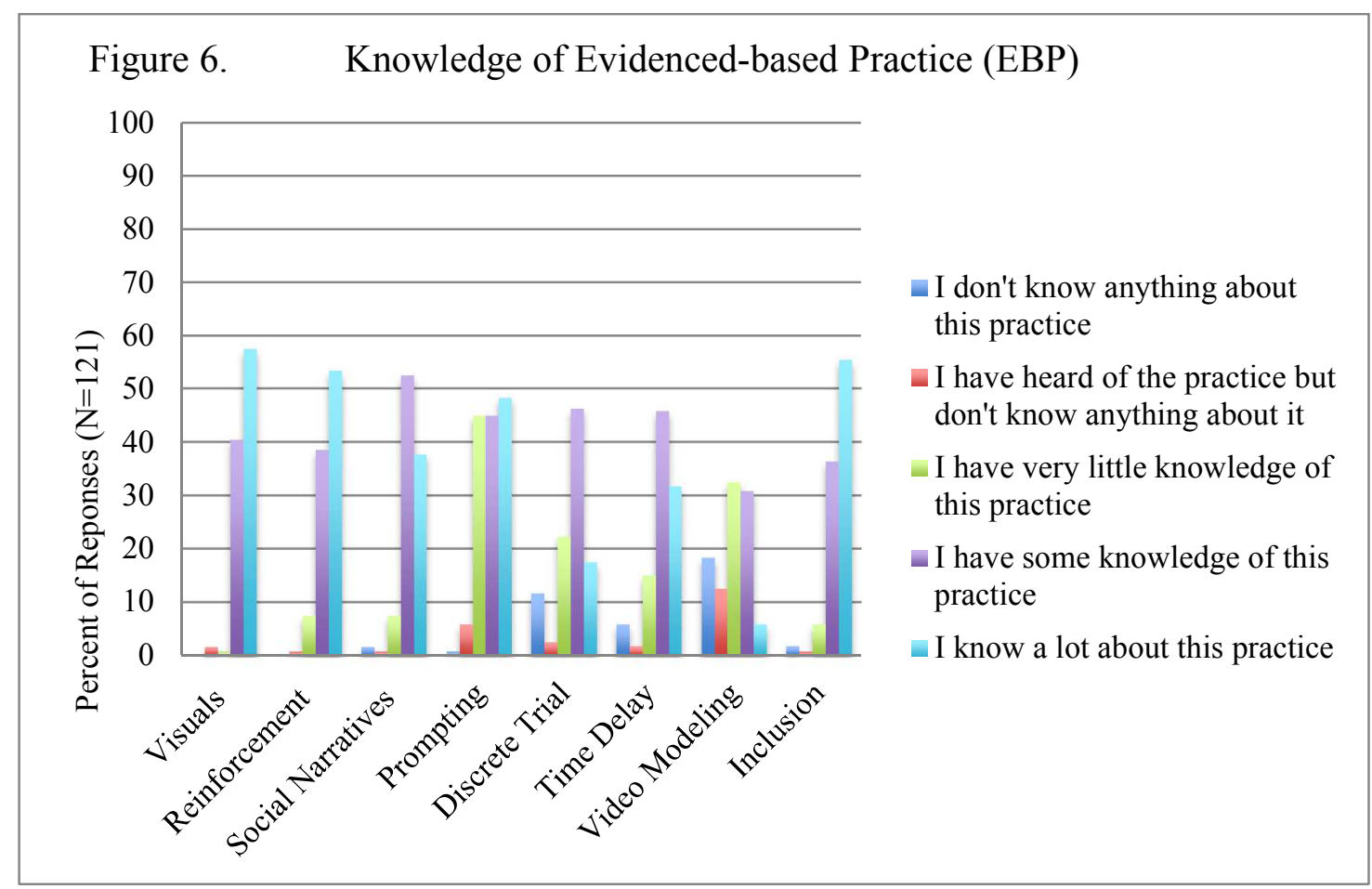

A majority of participants report having knowledge of many of the practices.

The average response for each practice in which participants reported having some or a lot of knowledge is as follows: Visuals $(\mathrm{M}=4.53, \mathrm{SD}=.606)$, Reinforcement $(\mathrm{M}=4.44, \mathrm{SD}=.669)$, Social Narratives $(\mathrm{M}=4.24, \mathrm{SD}=.761)$, Prompting $(\mathrm{M}=4.41$, $\mathrm{SD}=.642)$ and Inclusion $(\mathrm{M}=4.43, \mathrm{SD}=.783)$. Over half of the ECE reported that they have a lot of knowledge related to the practices of Inclusion (55.4\%), Reinforcement (53.3\%) and Visuals Supports (57\%). Discrete Trial Training and Time Delay practices both received means scores that fell in the middle of the range, $(\mathrm{M}=3.55, \mathrm{SD}=1.62)$ and $(M=3.96, S D=1.03)$ respectively, placing them in the response category of practitioners having a little knowledge of these practices. Video Modeling had the 
lowest average score $(\mathrm{M}=2.93, \mathrm{SD}=1.18)$, with the majority of participants $(63 \%)$ rating that they have little to no knowledge of this practice.

\section{Use of Evidence-based Practices (EBPs)}

For children to experience the positive outcomes highlighted by the NPDC (Odom et al., 2015), teachers need to use EBP. This survey was designed to ask teachers their use and/or intention of using the identified practices. Participants were asked to select on of the following statements that reflects their use or intended use of the practice: (1) never used it, don't intend to use it, (2) never used, intend to use it sometimes, (3) never used it, intend to use it frequently, (4) have used it, intend to use it sometimes, (5) have used it, intend to use it frequently. A majority of participants indicated that they had used Visual Supports (78\%), Prompting (89.9\%), Inclusion (91\%) and Reinforcement (95\%). The average scores for the use of these practices is as follows: Visual Supports $(\mathrm{M}=4.67, \mathrm{SD}=.702)$, Prompting $(\mathrm{M}=4.38, \mathrm{SD}=.863)$, Inclusion (4.34, $\mathrm{SD}=1.05)$ and Reinforcement $(\mathrm{M}=4.59, \mathrm{SD}=.749)$. Over half of the teachers reported having used Time Delay (60.8\%) and Discrete Trial training (61.6\%) to support children with autism; however, the average scores for these practices Time Delay $(\mathrm{M}=3.55, \mathrm{SD}=1.03)$ and Discrete Trail $(\mathrm{M}=3.55, \mathrm{SD}=1.162)$, indicating that many teachers have not used these practices. The one practice that stood out was Video Modeling with an average response of $\mathrm{M}=2.93$, SD 1.186. Of the 120 respondents to this question, a majority (80.9\%) reported not having used the practice. Figure 7 provides the participants answers to their use or intended use of the practices. 


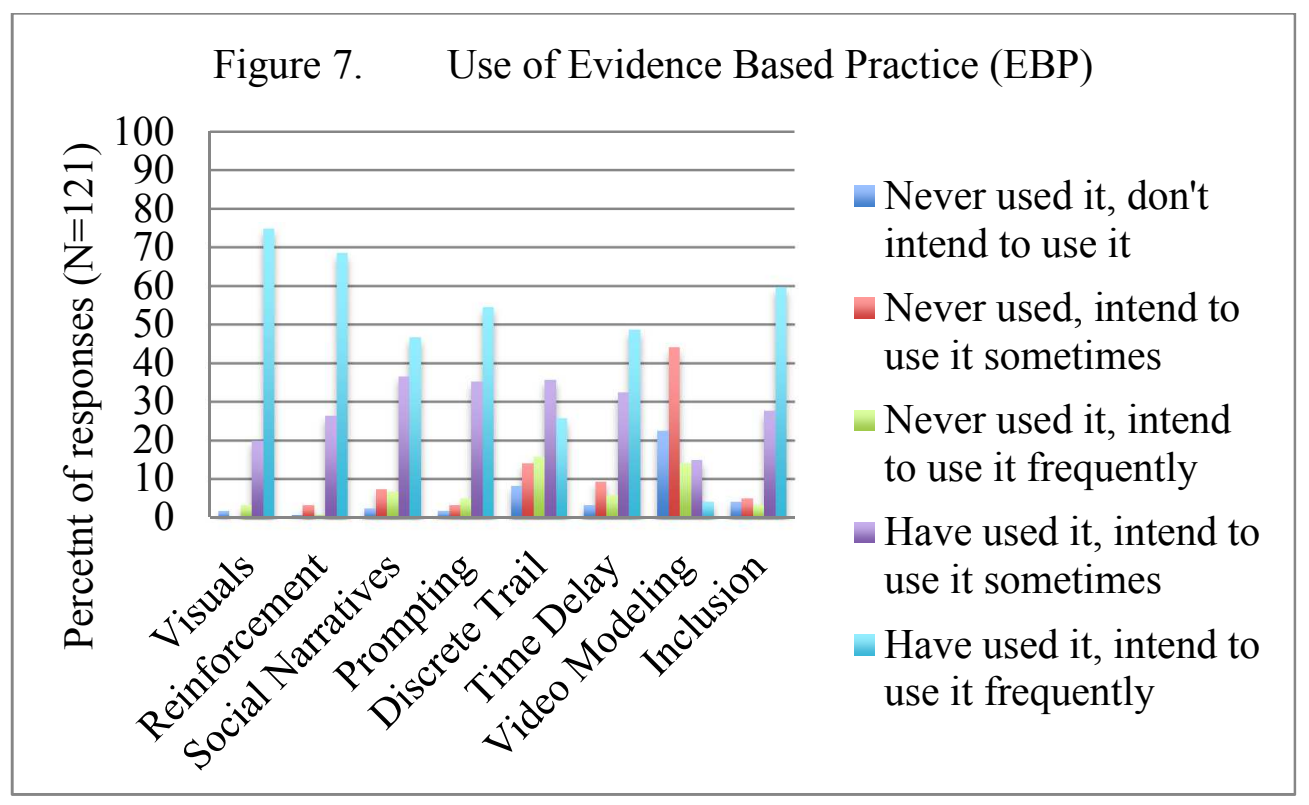

\section{Research Question 2}

To what extent is there a relationship between ECE knowledge of autism and their knowledge and use of EBP to support young children with ASD?

The results from the Pearson's Correlation Coefficient test used with the dependent variable use of specialized practice are presented in Table 6.

\begin{tabular}{lccc}
\hline $\begin{array}{l}\text { Table } 6 \\
\text { Group Correlations Related to Knowledge/Use of Specialized Practices }\end{array}$ & $\begin{array}{c}\text { General } \\
\text { knowledge of } \\
\text { autism }\end{array}$ & $\begin{array}{c}\text { Behavior } \\
\text { knowledge of } \\
\text { autism }\end{array}$ & $\begin{array}{c}\text { Knowledge/use } \\
\text { of specialized } \\
\text { practices }\end{array}$ \\
Head Start & -.102 & -.057 & -.093 \\
Community & .051 & -.096 & .041 \\
SFPK & $.199 *$ & .061 & .004 \\
Behavior knowledge of & $.285^{* *}$ & 1 & .029 \\
autism & & & $.196 *$ \\
General knowledge of & 1 & $.285^{* *}$ & \\
autism & & & \\
\hline $\mathrm{ns}=$ not significant $(\mathrm{p}>.05),{ }^{*} \mathrm{p}<.05, * * \mathrm{p}<01$ & & \\
\hline
\end{tabular}


There were no significant correlations between teachers working in a Head Start classroom and their general knowledge of autism $(r=-.102, p=.263)$, their knowledge of the behaviors associated with autism $(r=-.057, p=.535)$ and their use of specialized practices $(r=-.093, \mathrm{p}=.323)$ related to supporting children with autism in their classrooms. Likewise, there were no significant relationships between teachers working in community classroom and their general knowledge of autism $(r=.051, p=.581)$, their knowledge of the behaviors associated with autism $(r=-.096, \mathrm{p}=.294)$ and their knowledge/use of specialized practices $(r=.041, p=.668)$. For teachers working in a SFPK classroom, there was a significant positive relationship with their knowledge of the behaviors associated with autism $(r=.199, p=.028)$. However, there were no significant relationships between the SFPK and their knowledge of the general knowledge of autism $(r=.067, p=.461)$ and their knowledge/use of specialized practices $(\mathrm{r}=.071, \mathrm{p}=.454)$. A significant relationship was also found between those that have general knowledge of autism and those that identify the behaviors associated with autism $(r=.285, \mathrm{p}=.001)$. In addition, a significant relationship was found between those with general knowledge of autism and their knowledge/use of specialized practices $(r=.196, p=.035)$, suggesting that if ECE has general knowledge of autism, they are more likely to use EBP considered specialized practices including discrete trial, time delay, and video modeling.

When looking at the relationships between groups and knowledge/use of practices that are aligned to DAP practice, shown in Table 7, a statically significant relationship was found with the community group $(\mathrm{r}=.277,95 \% \mathrm{BCa}[.110, .433) \mathrm{p}=.002)$. A significant negative relationship was found with Head Start and their knowledge/use of practices aligned to DAP: Head Start $(\mathrm{r}=-.256,95 \% \mathrm{BCa}[-.428, .079], \mathrm{p}=.005)$. There was no 
relationship found between SFPK teachers and their knowledge/use of practices aligned with DAP $(r=-.029,95 \%$ BCa $[-.229, .171], p=.756$.

\begin{tabular}{lc}
\hline \begin{tabular}{l} 
Table 7 \\
Correlations Related to Knowledge/Use of Practices Aligned with DAP $(N=125)$ \\
\hline
\end{tabular} & Knowledge/use of Practices Aligned \\
Head Start & $-.256^{* *}$ \\
& $(-.428, .079)$ \\
Community & $.277^{*}$ \\
& $(.110, .433)$ \\
SFPK & -.029 \\
& $(-.229, .171)$ \\
Behavior knowledge of autism & $-.242^{* *}$ \\
& $(-.400,-.071)$ \\
General knowledge of autism & $.255^{* *}$ \\
& $(-.013, .501)$ \\
\hline$n s=$ not significant $(p>.05),{ }^{*} p<.05, * * p<01$ & \\
\hline
\end{tabular}

Another statistically significant relationship was found between those with general knowledge of autism and their use of practices aligned to DAP $(r=.255,95 \% \mathrm{BCa}$ [$.013, .501, \mathrm{p}=.005)$. A significant negative relationship was found between knowledge of the behaviors of autism and knowledge/use of practices aligned with DAP $(r=-.242,95 \%$ $\mathrm{BCa}[-.400,-.071], \mathrm{p}=.008)$. This negative relationship suggests that ECE who have more knowledge about the behaviors associated with autism, the less likely they are to use EBP, such as visual supports that are aligned to DAP.

\section{Research Question 3}

To what extent are the use of EBP of ECE influenced by their experiences, group, and knowledge of autism?

\section{Multiple regression results for specialized practices}


Results of the multiple regression first demonstrated there was no evidence of multicollinearity, with the correlations between predictors $(r<.9)$. The community group was held as the constant to which other groups were compared.

\begin{tabular}{|c|c|c|c|c|c|c|c|c|c|c|}
\hline \multicolumn{11}{|c|}{$\begin{array}{l}\text { Table } 8 \\
\text { Multiple }\end{array}$} \\
\hline \multirow[b]{4}{*}{ Model } & \multirow[b]{4}{*}{$\mathrm{R}$} & \multirow[b]{3}{*}{$\mathrm{R}$} & \multirow[b]{3}{*}{ Adjusted } & \multicolumn{2}{|l|}{ Std. } & \multicolumn{5}{|c|}{ Change Statistics } \\
\hline & & & & Error of & R & & & & & \\
\hline & & & & & Square & $\mathrm{F}$ & & & Sig. F & Durbin- \\
\hline & & Square & R Square & Estimate & Change & Change & df1 & df2 & Change & Watson \\
\hline 1 & $.201^{\mathrm{a}}$ & .040 & .023 & .19160 & .040 & 2.330 & 2 & 11 & .102 & \\
\hline 2 & $.219^{\circ}$ & .048 & .013 & .19259 & .008 & .435 & 2 & 109 & .648 & \\
\hline 3 & $.238^{\mathrm{c}}$ & .056 & .003 & .19351 & .009 & .483 & 2 & 107 & .618 & 2.110 \\
\hline
\end{tabular}

a. Predictors: (Constant), Genknowledge, Mean behaviors

b. Predictors: (Constant), Genknowledge, Mean behaviors, HeadStart, SFPK

c. Predictors: (Constant), Genknowledge, Mean_behaviors, HeadStart, SFPK, Q14.ExpASD, Q9.Educ

d. Dependent Variable: Specialized_log

The model summary, shown in Table 8 , shows that the overall fit of the models for this data is weak. Model 1, with the knowledge of autism predictors, only accounts for $4 \%$ of the variance $\left(\mathrm{r}^{2}=.04\right)$. The inclusion of the other predictor variables of groups and demographic information minimally increases the amount of variance explained, Model 2 increases the amount of variance explained to $4.8 \%\left(\mathrm{r}^{2}=.048\right)$ and Model 3 increases the amount of variance explained to $5.6 \%\left(\mathrm{r}^{2}=.056\right)$. The result is a weak model that does not fit the existing data and therefore has no explanatory power. The Durbin-Watson statistic noted in the last column provides information about the assumption of independent errors (Field, 2013). The Durbin-Watson value of 2.110 suggests that the errors in the model are independent errors. Table 9 confirms that the model is not a fit for this data with each model yielding a significance value greater than .05 .

Table 9

Multiple Regression ANOVA ${ }^{A}$ For Specialized Practices 


\begin{tabular}{llccccc}
\hline \multicolumn{1}{c}{ Model } & $\begin{array}{c}\text { Sum of } \\
\text { Squares }\end{array}$ & df & $\begin{array}{c}\text { Mean } \\
\text { Square }\end{array}$ & F & Sig. \\
1 & Regression & .171 & 2 & .084 & 2.330 & $.102^{\mathrm{b}}$ \\
& Residual & 4.075 & 111 & .037 & & \\
& Total & 4.246 & 113 & & & \\
2 & Regression & .203 & 4 & .051 & 1.371 & $.249^{\mathrm{c}}$ \\
& Residual & 4.043 & 109 & .037 & & \\
& Total & 4.246 & 113 & & & \\
3 & Regression & .240 & 6 & .040 & 1.066 & $.387^{\mathrm{d}}$ \\
& Residual & 4.007 & 107 & .037 & & \\
& Total & 4.246 & 113 & & & \\
\hline
\end{tabular}

a. Dependent Variable: Specialized_log

b. Predictors: (Constant), Genknowledge, Mean_behaviors

c. Predictors: (Constant), Genknowledge, Mean_behaviors, HeadStart, SFPK

d. Predictors: (Constant), Genknowledge, Mean_behaviors, HeadStart, SFPK, Q14.ExpASD, Q9.Educ

With these results, the models do not provide the confidence necessary to predict how the variables influence the outcome variable.

\begin{tabular}{|c|c|c|c|c|}
\hline \multicolumn{5}{|c|}{$\begin{array}{l}\text { Table } 10 \\
\text { Linear Model of Predictors of Specialized Practices, with 95\% Confidence Intervals } \\
\text { Reported in Parenthesis }\end{array}$} \\
\hline \multicolumn{5}{|c|}{$\begin{array}{ccccc} & \text { B } & \text { SE B } & \beta & p \\
\text { (Constant) } & .852 & .183 & & .000\end{array}$} \\
\hline Behaviors & $\begin{array}{c}-.004 \\
(-.021-.013)\end{array}$ & .008 & -.049 & .637 \\
\hline Genknowledge & $\begin{array}{c}.015 \\
(.000-.031)\end{array}$ & .008 & .192 & .053 \\
\hline HeadStart & $\begin{array}{c}-.021 \\
(-.100-.058)\end{array}$ & .040 & -.053 & .601 \\
\hline SFPK & $\begin{array}{c}.020 \\
(-.89-.129)\end{array}$ & .055 & .038 & .718 \\
\hline
\end{tabular}

\begin{tabular}{|c|c|c|c|c|}
\hline \multicolumn{5}{|c|}{$\begin{array}{l}\text { Table } 10 \\
\text { Linear Model of Predictors of Specialized Practices, with 95\% Confidence Intervals } \\
\text { Reported in Parenthesis }\end{array}$} \\
\hline Educ & $\begin{array}{c}.007 \\
(.011-.025)\end{array}$ & .009 & .078 & .427 \\
\hline ExpASD & $\begin{array}{c}-.014 \\
(.061-.034)\end{array}$ & .024 & -.055 & .571 \\
\hline
\end{tabular}


The information presented in Table 10 describes how the dependent variables influence the use of specialized practices. Knowledge of the behaviors associated with autism ( $b=-.004)$, working in a Head Start classroom $(b=-.021)$ and years of experience with autism $(b=-.014)$ decreases the use of specialized practices by ECE when all other variables are held constant. Having general knowledge of autism $(b=.015)$, working in a SFPK $(b=.020)$ and having more education will likely increase the use of specialized practices when all other variables are held constant. With the community group held as the constant, no significant differences between the three groups were found.

\section{Multiple Regression for Outcome Variable Practices Aligned to DAP}

The results of the multiple regressions on practices aligned to DAP (with bootstrapping).

\begin{tabular}{|c|c|c|c|c|c|c|c|c|c|c|}
\hline \multirow[b]{2}{*}{ Model } & \multirow[b]{2}{*}{$\mathrm{R}$} & \multirow[b]{2}{*}{$\begin{array}{c}\mathrm{R} \\
\text { Square }\end{array}$} & \multirow[b]{2}{*}{$\begin{array}{l}\text { Adjusted } \\
\text { R Square }\end{array}$} & \multirow{2}{*}{$\begin{array}{c}\text { Std. } \\
\text { Error of } \\
\text { the } \\
\text { Estimate }\end{array}$} & \multirow[b]{2}{*}{$\begin{array}{c}\mathrm{R} \\
\text { Square } \\
\text { Change }\end{array}$} & \multirow{2}{*}{$\begin{array}{c}\text { F } \\
\text { Change }\end{array}$} & \multicolumn{3}{|c|}{ Change Statistics } & \multirow[b]{2}{*}{$\begin{array}{l}\text { Durbin- } \\
\text { Watson }\end{array}$} \\
\hline & & & & & & & df1 & df 2 & $\begin{array}{l}\text { Sig. F } \\
\text { Change }\end{array}$ & \\
\hline 1 & $.303^{2}$ & .092 & .076 & .33257 & .092 & 5.848 & 2 & 116 & .004 & \\
\hline 2 & $.402^{b}$ & .162 & .132 & .32224 & .070 & 4.778 & 2 & 114 & .010 & \\
\hline 3 & $.429^{\circ}$ & .184 & .140 & .32085 & .022 & 1.496 & 2 & 112 & .228 & 1.809 \\
\hline $\begin{array}{l}\text { a. Pred } \\
\text { b. Pred } \\
\text { c. Pred } \\
\text { Q9. } \\
\text { d. Dep }\end{array}$ & $\begin{array}{l}\text { lictors: } \\
\text { lictors: } \\
\text { lictors: } \\
\text { ¿duc } \\
\text { endent }\end{array}$ & $\begin{array}{l}\text { (Consta } \\
\text { (Consta } \\
\text { (Consta }\end{array}$ & $\begin{array}{l}\text { nt), Genkn } \\
\text { ant), Genkn } \\
\text { nt), Genkn }\end{array}$ & $\begin{array}{l}\text { howledge, } \\
\text { nowledge, } \\
\text { howledge, }\end{array}$ & Behavior & $s$, Head & & $\begin{array}{l}\text { FPK } \\
\text { FPK }\end{array}$ & Q14.1 & ASD, \\
\hline
\end{tabular}

The model summary, in Table 11, illustrates how the predictor variables influence the use of practices aligned to DAP and shows three models. The first model, including knowledge of autism, has the strongest prediction value explaining $9.2 \%$ of the variance $\left(r^{2}=.092\right)$. Like the specialized practices model, the group of community was held as the constant for other groups to be compared. This model is significant $(\mathrm{p}=.004)$ in 
explanatory power with a p-value less than .05. Models 2 and 3 explain additional $7 \%$ and $2 \%$ and therefore the final model explained a total of $18 \%$ of the variance. Models 1 and 2 are significant as explanatory models with $\mathrm{p}$ values smaller than .05 , demonstrating that general knowledge, knowledge of behaviors and Head Start and SFPK have predictive value when community is the reference group. The Durbin-Watson value of 1.089 suggests that the errors in the model are independent errors and the assumption has been met. The ANOVA in Table 12 shows the model is a significant fit for the data with all $p$ values less than .05; thus, indicating that the model improves the prediction of how the variables influence the use of practices aligned to DAP.

\begin{tabular}{|c|c|c|c|c|c|c|}
\hline \multicolumn{2}{|c|}{ Table 12} & \multicolumn{5}{|c|}{ Multiple Regression ANOVA for the use of Practices Aligned to DAP } \\
\hline \multicolumn{2}{|c|}{ Model } & Sum of Squares & $\mathrm{df}$ & Mean & $\mathrm{F}$ & Sig. \\
\hline \multirow{3}{*}{1} & Regression & 1.294 & 2 & 647 & 5.848 & $.004^{\mathrm{b}}$ \\
\hline & Residual & 12.830 & 116 & .111 & & \\
\hline & Total & 14.124 & 118 & & & \\
\hline \multirow[t]{3}{*}{2} & Regression & 2.286 & 4 & .571 & 5.504 & $.000^{\mathrm{c}}$ \\
\hline & Residual & 11.838 & 14 & .104 & & \\
\hline & Total & 14.124 & 118 & & & \\
\hline \multirow[t]{3}{*}{3} & Regression & 2.594 & 6 & .432 & 4.200 & $.001^{\mathrm{d}}$ \\
\hline & Residual & 11.530 & 112 & .103 & & \\
\hline & Total & 14.124 & 118 & & & \\
\hline
\end{tabular}

a. Dependent Variable: align_log

b. Predictors: (Constant), Genknowledge, Behaviors

c. Predictors: (Constant), Genknowledge, Behaviors, HeadStart, SFPK

d. Predictors: (Constant), Genknowledge, Behaviors, HeadStart, SFPK, Q14.ExpASD, Q9.Educ

Table 13 
Linear Model of Predictors of Practices Aligned to DAP, with 95\% Bias Corrected and Accelerated Confidence Intervals Reported in parenthesis. Confidence Intervals and Standards Errors Based on 1000 Bootstrap Samples.

Step 3

b SE B

$\beta \quad \mathrm{p}$

(Constant)

1.178

.297

1.767

$(.589-1.767)$

Behaviors

$-.036$

.014

$-.251$

$-.009$

(-.063- -.009)

Genknowledge

.025

.013

.174

.050

$(.000-.050)$

HeadStart

$-.210$

.065

$-.301$

$-.082$

$(-.339--.082)$

$-.073$

.087

$-.079$

.101

$(-.246-.101)$

Educ

$-.024$

.014

$-.152$

.004

$(-.051-.004)$

ExpASD

.011

.039

.025

.088

p

(
$(-.066-.088)$

The model, in Table 13, shows that having knowledge of the behaviors associated with autism $(b=-.036)$ and a higher level of education $(b=-.024)$ decreases the ECE use of the practices aligned to DAP as compared to ECE in the community. On the other hand having general knowledge of autism $(b=.025)$ and more experience with autism $(b=.011)$ is predictive of an increase of the ECE use of practices aligned to DAP. 


\section{CHAPTER 5}

\section{DISCUSSION}

With more children being diagnosed with autism and having inclusive experiences (RI Kids Count, 2013; U.S.DOE, 2016a), ECE are in need of knowledge of autism and EBP in order to support children with autism learn and develop in their classrooms (Buysse \& Hollingsworth, 2009; Muccio, Kidd, White, \& Burns, 2014). Previous research has described the levels of autism knowledge of pre-service teachers, health care communities, medical communities and ECE in the international domains (Harrison et al., 2017). Research on how EBP has been used has focused on ECSE (Gable et al., 2012; Paynter et al., 2016), which has resulted in a lack of information related to what ECE know and how they implement EBP to support children with autism in the EC classroom. Measures created to capture this information have focused on disciplines other than the ECE and have used a mix of scales and True/False items (Harrison et al., 2017).

\section{Psychometric Properties of the PECE-ASD}

The PECE-ASD was developed to collect information from Rhode Island ECE on their perception of their knowledge of autism and EBP, as well as their use of EBP to support children with autism in the early childhood classroom. The 28 items were examined using a PFA. Based on the PECE-ASD pilot data and characteristics of autism, the researcher hypothesized that the items would load into the 5 main factors including knowledge of autism (with two the subgroups general knowledge of autism and characteristics of autism), knowledge of EBP and use of EBP. The PFA, using the data from the main study, supported a 4-factor model versus the 5 factor found in the pilot 
study. In all 22 items confidently loaded to the 4 factors, while 5 items were removed due to low loading strength and one due to a high factor loading with an eigenvalue over 1.

The first factor grouped 7 items whose foundations are connected to DAP. This included the following EBP: reinforcement, visual supports, social narratives and prompting. The theoretical underpinnings of these EBP are in the work of Dewey, Piaget, Vygotsky and other constructivist theorists in early childhood education. As such this first factor was aptly named Practices Aligned to DAP.

The second factor included 5 items that connected to the observable behaviors found in the diagnostic criteria of autism (APA, 2013) and the in the literature describing how these criteria apply to young children with autism (Buron \& Wolfberg, 2008, 2014; Garcia Winner, 2008; Jarrold, 2016). This factor was therefore named Behaviors of Autism. The third factor included the 6 items related to knowledge and use of the Discrete Trial and Time Delay practices. Implementation procedures for these practices are individualized with explicit and discrete instruction, which is consistent with the behavioral theories espoused by Lovaas, Skinner, Bandura, Watson, and Rayner. Video Modeling is based on a mix of theories that includes both DAP practices as well as some of the behaviorally based theories. In addition, Video Modeling includes a technology component that could limit the use by ECE making the practice a unique practice in and of itself. Due to the specialized behavior approaches used with these practices and with the video modeling technology requirements, this factor was named Specialized Practices.

The fourth and final factor represents basic or general knowledge of autism. These items pertain to information that is known about autism including that boys are more likely to be diagnosed with autism, autism is neurological disorder and that children with autism 
may repeat words or phrases and be more likely to play alone. With this context, the factor was named General Knowledge. The PECE-ASD was found to be reliable and could serve other researchers in examining these constructs with other EC educators. See Table 14 for a list of the final items on the PECE-ASD scale

Table 14

Final PECE-ASD Scale Items By Subscale

\begin{tabular}{|c|c|}
\hline Subscale & PECE-ASD Final Items \\
\hline Factor 1: Practices & 1. Knowledge of Reinforcement \\
\hline Aligned to DAP & 2. Knowledge of Visual Supports \\
\hline \multirow[t]{5}{*}{$a=.802$} & 3. Knowledge of Social Narratives \\
\hline & 4. Use of Visual Supports \\
\hline & 5. Knowledge of Prompting \\
\hline & 6. Use of Reinforcement \\
\hline & 7. Use of Prompting \\
\hline \multirow{4}{*}{$\begin{array}{l}\text { Factor 2: Behaviors } \\
\text { of Autism } \\
a=.718\end{array}$} & 8. Children with autism know how to act in social situations. \\
\hline & $\begin{array}{l}\text { 9. Children with autism have unusual ways of playing with } \\
\text { toys. }\end{array}$ \\
\hline & $\begin{array}{l}\text { 10. Autism impacts a child's ability to socially communicate. } \\
\text { 11. Children with autism have a need for routines and } \\
\text { sameness. }\end{array}$ \\
\hline & 12. Children with autism have very strong interests \\
\hline Factor 3: Specialized & 13. Knowledge of Video Modeling \\
\hline Practices & 14. Use of Video Modeling \\
\hline \multirow[t]{4}{*}{$a=.821$} & 15. Knowledge of Discrete Trial \\
\hline & 16. Use of Discrete Trial \\
\hline & 17. Knowledge of Time Delay \\
\hline & 18. Use of Time Delay \\
\hline $\begin{array}{l}\text { Factor 4: General } \\
\text { Knowledge }\end{array}$ & $\begin{array}{l}\text { 19. A child with autism may repeat a phrase over and over } \\
\text { again. }\end{array}$ \\
\hline \multirow[t]{3}{*}{$a=.577$} & $\begin{array}{l}\text { 20. Children with autism are more likely to play alone than } \\
\text { with other children. }\end{array}$ \\
\hline & $\begin{array}{l}\text { 21. Boys are more likely to be diagnosed with autism than } \\
\text { girls. }\end{array}$ \\
\hline & 22. Autism is a developmental, neurological disorder. \\
\hline
\end{tabular}

\section{ECE Knowledge of Autism}

Less than half he participants reported that participating in coursework (44\%) and/or professional development (44.8\%) related to working with children who had a 
diagnosis of autism. This is not a surprising finding due to the fact there has been little to no research conducted on pre-service education for ECE related to understanding autism. There has, however, been a limited number of studies investigating the pre-service preparation for IECSEs. Most notable Barnhill, Polloway, and Sumutka (2013) conducted a National Survey of Institutes of Higher Education (IHE) personnel to attempt to describe the pre-service coursework available to teacher candidates. Results from their surveys yielded 87 responses, from 34 states, indicating that only $41 \%$ of the IHE offered preservice education on autism. The schools reported that coursework varied from one course to a series of coursework and were situated in a both undergraduate and master degree special education programs of study or related fields of study such as occupational or speech and language therapy programs (Barnhill et al., 2013). None of the programs specifically identified providing pre-service coursework to students in EC education programs. Specific to Rhode Island, IHE have begun to address the pre-service needs of special education teacher candidates at the Master's level (Providence College, 2017; Rhode Island College, 2017; University of Rhode Island, 2017). With that said, no preservice coursework designed to prepare regular ECE to work with children with autism is available in Rhode Island. Of the Rhode Island participants who responded having had information presented to them during coursework, 48 reported having some information presented to them within a course, 7 reported participated in an entire course devoted to autism and 4 reported they had participated in a graduate course series resulting in an autism certificate. While these numbers represent less than half of the participants in the study, RI can be encouraged by the fact that autism information is making its way into some pre-service coursework. This indicates a need for a systematic and conscientious 
delivery of autism information in teacher preparation programs to prepare regular ECE for the inclusion of children with autism in their classrooms.

Less than half of the participants (44\%) responded that they had received professional development on the topic of working with young children with autism. Not surprising was that $32.2 \%$ of the participants had collaborated with a special education teacher. While the number is low, there is an expectation in Rhode Island that IECSE teachers work with ECE to support children with autism in the EC classroom. Likewise another $33 \%$ of the respondents identified having worked with a technical assistance provider (TA), coach or consultant to provide supports around working with a child with autism. What is not clear is if the TA, coach or consultant was part of the special education services provided by the local school district or if that person was from a private organization. Thirty-six percent of the participants who responded to having PD on ASD said they participated in a workshop focused on autism; smaller numbers participated in a conference (13\%), a webinar (4.5\%) or went online to the Autism Internet Modules [AIM] $(2 \%)$. Although a small sample, this study provides initial information related to the types of professional development, related to autism, in which ECE participate. Further research should be conducted to fully understand what opportunities are available for ECE to learn about autism and EBP.

Experience with autism can influence the amount of knowledge one perceives they have about autism. Ninety-one percent of respondents indicated that they had had a personal experience or an experience working with a child or individual who has autism or was suspected of having autism. These experiences could help to provide understanding about the range of answers given about the characteristics of autism. In particular, the ECE 
provided strong evidence of identifying some of the characteristics of autism such as repetitive speech, repetitive motor behaviors or that children with autism are more likely to play alone. Having some experience with a child with autism would support the ECE to identify the specific observable behavior characteristics that are not seen in typical development. Indeed the majority could answer specific questions related to behavior; however, the group had mixed responses to general knowledge questions about the disorder. Many agreed with basic questions such as autism is a neurodevelopmental disorder and autism is a continuum that affects individuals differently. Agreement with these questions was not surprising as one of the autism community mantras is that "you meet one person with autism, you meet one person with autism" (Kluth, 2003). This corroborated the work of Arif et al. (2013), who found that due to limited professional development opportunities, ECE have "media" knowledge related to autism. Media knowledge, or sound bite knowledge, refers to the environmental literature that exists in our culture and is often short bits of information that can provide individuals with a superficial amount of knowledge. Media knowledge helps to explain why the ECE in this study were able to answer some of the knowledge questions but not able to answer a broader set of questions including if autism can be cured, age of diagnosis or the learning styles associated with autism.

Interestingly when looking at knowledge across groups, SFPK teachers were the only group to demonstrate a significant positive response to identifying the behavioral characteristics of autism. With the increase in expectations and education level of SFPK teachers, it is not surprising that they were able to identify the behavioral characteristics and not the general knowledge of autism questions. Consistent with international studies 
previously discussed (Arif, Niazy, Hassan, \& Ahmed, 2013; Lindsay, Proulx, Thomson, $\&$ Scott, 2013; Liu et al., 2016), ECE continue to lack a cohesive and basic understanding of autism.

\section{ECE Knowledge and Use of EBP}

Concerning ECE knowledge and use of EBP for children with autism, the results were both surprising and inconsistent with the pilot data. From the PFA, the EBP were separated into two sets, practices aligned with DAP and specialized practices and did not hang together as the individual groups of knowledge of EBP and use of EBP as they did in the pilot study. Reflecting on this data within the context of EC education, the notion that some practices align to DAP was developed by considering how the ECE would interpret the practices. Without a definition of fidelity and how practices, such as visual supports, would be used with intensity, frequency, and consistency across the day, ECE could associate their daily use of a classroom schedule as an EBP used for children with autism. Similarly, DAP promotes the use of positive reinforcement, social conversations, and scaffolding; all that have underpinnings for the more intensive EBP, such as specialized practices, used for individual children with autism. Using this lens, the results that the ECE reported having a lot of knowledge about and used practices aligned to DAP is not surprising and thus, demonstrates their confusion about EBP for children with autism. This was particularly true for the community group who reported they were more likely to know and use EBP aligned to DAP. As with knowledge of autism, the Head Start group demonstrated significantly lower levels of knowledge and use of EBP for children with autism. The connection between how ECE interpret EBP and DAP presents an opportunity for future research. 
The results indicated that the ECE did not have knowledge of nor did they use the practices of discrete trial, time delay and video modeling (specialized practices). This result is not surprising as these practices have a foundation in behavioral theory. Behavioral theory, as seen in the context of early childhood, contradicts the play based, inquiry practices purported by DAP (Odom \& Wolery, 2003). ECE would not have education or experience with these practices unless they have actively worked with a special educator knowledgeable of the practices or they have had professional development related to these EBP; this highlights a need for continued professional development for ECE related to EBP used for children with autism.

The results positively showed that if ECE had knowledge of autism behaviors they were more likely to have knowledge and use of EBP. This result is consistent with the study conducted by Paytner et al. (2017) in which early intervention providers reported greater use of EBP linked to higher levels of knowledge of autism. This leaves the door open to exploring how having more knowledge of autism can support teachers move beyond a perfunctory behavior based understanding to a more comprehensive understanding that connects the characteristics of autism to matching EBP for individual children to support learning and development.

\section{Predictors of EBP use for Children with Autism}

Although the data collected through the PECE-ASD and the models used for analysis did not demonstrate strong predictive value, the findings serve as the first step in understanding factors that influence ECE use of EBP aligned to DAP. In regard to EBP that are more specialized, the data was inconclusive demonstrated by the weak statistical regression models. When comparing the three groups of ECE, with the community group 
as a reference group, results showed there were no significant differences among the three groups in their use of EBP.

With quality EC education a focus in the EC community, ECE education levels have been looked to as a source of increasing the quality of educational experiences for young children. However, some research has been inconclusive or has shown a negative relationship between ECE level of education contributes to increased quality of ECE practice (Early et al., 2007; Whitebrook, 2003), while others clearly link levels of education in EC education to improved outcomes for children (Barnet et al., 2015). Related to the quality of education for children with autism, this dissertation study's finding highlights the need for further investigations to understand the relationship between the education levels of ECE and how ECE make decisions related choosing and using practices to support children with autism.

The finding that ECE knowledge of the behaviors of autism was not predictive of EBP use was interesting in that the ECE reported having strong knowledge of the behavioral characteristics associated with autism. One interpretation of this finding points to a lack of understanding of the underlying factors related to why children with autism demonstrate behaviors and how the use of EBP aligned with DAP could be used in an individualized fashion to support a child with autism. For example, the participants strongly agreed with the statement that children with autism "have a strong need for routines and sameness." Children with autism often demonstrate the need for routines and sameness when they have difficulty transitioning from a preferred activity to another nonpreferred activity (APA, 2013; Buron \& Wolfberg, 2014). Understanding the need for routines and sameness which can be associated with a deficit in executive functioning 
skills, such as difficulty with working memory and impulse control (Buron \& Wolfburg, 2014), can support a teacher to make individual modifications to DAP that are used for the whole classroom of children and yet support the children with autism to make successful transitions. In this scenario, DAP recommends that teachers have a daily schedule of activities for children posted on their wall to support children's understanding of daily routines (Copple \& Bredekamp, 2009b). In an effort to support children with autism, teachers can use the EBP aligned to DAP to support them to understand the classroom routine. For example the teacher could use the EBP of visual supports to create individual daily schedule boards for children with autism to understand what the sequence of activities are during the classroom day (Buron \& Worlfberg, 2008, 2014; Quill, 1997). Although more than half of the ECE completing the PECE-ASD reported using visuals supports, new questions are raised related their level of understanding about autism and how understanding autism aids in the selection and implementation of EBP for a child with autism.

\section{Implications}

Findings suggest that ECE have a limited scope and understanding of what an autism disorder is and how autism influences a child's behavior and learning in the EC classroom. In addition, ECE purport having knowledge and using EBP that align with DAP; however, their understanding of what an EBP is for a child with autism means is unclear and may illustrate confusion about the implementation of EBP with the underpinnings of DAP associated with them. Likewise, helping ECE to understand how EBP underscored with behavioral theories can be implemented within the context of an EC classroom is an area of growth needed for ECE to effectively support children with autism 
in their classroom. Overall, this study highlights the need for ECE to learn about autism and EBP. Knowledge about autism and EBP should be embedded into both pre-service programs for EC education as well as ongoing professional development (Baker, 2012; Barnhill et al., 2013) and has implications for both policy and professional development systems.

With regard to policy implications, two policy statements have been put forth highlighting the need for ECE to have an increase in the knowledge and skills related to supporting children with disabilities in the EC classrooms (DEC/NAEYC, 2009; DHHS \& DOE, 2015). The Division of Early Childhood (DEC) and NAEYC (2009) recommended that the EC field revise program and professional competency standards to reflect how quality programs support the unique needs of children. Likewise, the 2015 DHHS and DOE EC Inclusion Policy Statement called upon states to create a common base of professional knowledge and competencies related to the inclusion of young children by engaging institutions of higher education. This means that states need to consider how knowledge of specific disability, such as autism, is embedded into their professional standards and certification requirements. Simultaneously, institutes of higher education need to revisit their EC program requires to ensure that new ECE are provided the knowledge and information they need to support children with disabilities in their classroom. As demonstrated in this study ECE teachers need to understand individual disabilities such as autism and have knowledge of EBP in order to support children with autism to learn in their classrooms. Also highlighted in this study, is the notion that ECE also need to understand the theory behind EBP to help them make intentional decisions regarding their use of EBP. Furthermore, teaching 
ECE to differentiate between broadly and narrowly defined EBP would assist them in understanding the intersections between instruction using EBP for all children and how to implement individualized EBP practices to support one child to access the curriculum.

An integrated professional development system should be used to support current ECE and ECSE currently working in the field to learn and develop the knowledge and skills needed to support children with autism in the EC classroom (DEC/NAEYC, 2009). An integrated professional development system addresses the disconnect between ECE and ECSE teachers resulting from different state agencies guiding implementation of policies, namely DHSS and DOE respectively (Odom \& Wolery, 2003). Research demonstrates that general ECE teachers need training in special education to gain positive attitudes for working with children with disabilities (Lai \& Gill, 2014; Leatherman \& Niemeyer, 2005). Research also suggests that when provided with training and education, teachers have higher self- esteem and an increased empathy for children of all abilities (Early et al., 2006; Early et al., 2007; Goble, Horm, Atanasov, Williamson, \& Choi, 2015). A 2008 study by Essa, Bennet, Burnham, Martin, Bigham and Allred demonstrated that with coursework on special education, community childcare directors and teachers were more likely to have children with disabilities in their classroom. Supporting teachers to engage in and learn how to implement inclusive practices requires a professional development system that uses multiple approaches including mentoring, coaching, collaborative problem solving and communities of practice (Buysse \& Hollingsworth, 2009; Odom, 2008). Professional development should include a variety of activities that utilize adult 
learning theory (Artman-Meeker, Fettig, Barton, Penney, Zeng, 2015) that help teachers to learn about disability and theoretical underpinnings of EBP (Florian, 2012). Opportunities, such as coaching, that include performance feedback have shown to be effective in supporting ECE to learn and use new practices that support the learning and development of children (Artman-Meeker et al., 2015; Artman-Meeker \& Hemmeter, 2013).

\section{Limitations}

As with any survey design, the limitations of this study include that the information collected is based on the perceptions and self-reporting of the respondents. This provides a limited scope of what they truly know based on the information they believe they know about autism and EBP. The end of the school year implementation of this study presents a challenge to the information collected as ECE are busy prioritizing end of the year activities and are less likely to participate in a survey, which limits the total number of respondents. In addition, as the researcher is a prominent provider of professional development in standards-based instruction, disability, and inclusion, participants may have been more likely to participate in the research study based on previous experiences with the researcher.

Although 3 out of the 4 scales on the PECE-ASD had reliability scores of more than $\mathrm{a}=.718$, the $P E C E-A S D$ has limitations in the ability to use that information for generalization across ECE outside of this study. Increasing the sample size and extending beyond the state of RI would hopefully strengthen psychometric properties of this scale. In addition, rewording items and or providing an explicit definition of what is meant by EBP would support the ECE to have a clearer understanding of the items. 


\section{Future Research}

This preliminary study provides an isolated look at a small sample of RI ECE who completed in the survey. Future research is needed to fully understand what ECE know about autism and how that information contributes to instructional decision-making. As revealed in this study, ECE responses show confusion regarding what constitutes an EBP and how they are connected to a theoretical base. Research investigating what ECE knows about EBP and how they relate to theory would be useful in understanding why or why not ECE are likely to use a practice when supporting children with autism. Furthermore, research should also explore the implementation of the U.S. DHHS and U.S. DOE National Inclusion Policy Statement by state and local agencies. Specifically, how has the policy statement been used to change professional competencies, teaching certification requirements and programmatic content in institutes of higher education focused on early childhood education?

\section{Concluding Remarks}

This study adds to the literature base of both EC and ECSE by providing insight into the perceived knowledge and practices of regular ECE related to the inclusion of preschool children with autism. Results describe a small sample in Rhode Island only. Nonetheless, they provide valuable information for the field to consider as it relates to the education and professional development for ECE working across settings. Specifically, ECE require information about what it means for a child to have autism and knowledge about what EBP are available to be used to increase the learning and development outcomes for children with autism. In regards to pre-service education, the participant responses combined with the lack of coursework available highlights a need for 
coursework on autism to be embedded into pre-service early childhood teacher programs. For professionals working in the various EC settings, ongoing professional development related to autism and EBP is needed to help them respond to the increasing numbers of children with autism in EC classrooms. The insight gained can be used to not only inform EC professional development but also the ongoing collaborative relationships between ECSE and EC educators. 


\section{APPENDICES}

\section{APPENDIX A}

\section{NAEYC Position Statement and Principles of Child Development and Learning}

(2009)

1. All the domains of development and learning are important and they are closely interrelated. Children's development and learning in one domain influence and are influenced by what takes place in other domains.

2. Many aspects of children's learning and development follow well-documented sequences, with later abilities, skills, and knowledge building on those already acquired.

3. Development and learning proceed at varying rates from child to child, as well as at uneven rates across different areas of a child's individual functioning.

4. Development and learning result from a dynamic and continuous interaction of biological maturation and experience.

5. Early experiences have profound effects, both cumulative and delayed, on a child's development and learning, and optimal periods exist for certain types of development and learning to occur.

6. Development proceeds toward greater complexity, self-regulation, and symbolic or representational capacities.

7. Children develop best when they have secure, consistent relationships with responsive adults and opportunities for positive relationships with peers.

8. Development and learning occur in and are influenced by multiple social and cultural Contexts.

9. Always mentally active in seeking to understand the world around them, children learn in a variety of ways, a wide range of teaching strategies and interactions are effective in supporting all these kinds of learning

10. Play is an important vehicle for developing self-regulation as well as for promoting language, cognition, and social competence.

11. Development and learning advance when children are challenged to achieve at a level just beyond their current mastery, and also when they have many opportunities to practice newly acquired skills

12. Children's experiences shape their motivation and approaches to learning, such as persistence, initiative, and flexibility; in turn, these dispositions and behaviors affect their learning and development. 


\section{APPENDIX B}

Perspectives of Early Childhood Educators on Autism (PECE-ASD) Scale

\section{Demographic Information}

1) What is your current role?

( ) Early Childhood Preschool Teacher

( ) Teacher Assistant

( ) Kids Connect Provider

( ) Other - Write In:

2) How many years have you been working in early childhood classrooms?
( ) 0 -1 years
( ) $2-5$ years
( ) $6-10$ years
( ) 11-15 years
( ) 16-20 years
( ) $21-25$ years
( ) 26-30 years
( ) $31+$ years

3) What is your age?
( ) $18-20$
( ) $21-30$
( ) $31-40$
( ) $41-50$
( ) $60+$
( ) Prefer to decline

4) Select your gender.
( ) Female
( ) Male
( ) Prefer to decline
( ) Prefer to self describe - Write In:

5) How do you describe your race/ethnicity?
( ) Asian
( ) Black
( ) Hispanic
( ) Native American
() White
( ) Other - Write In:
( ) Prefer to decline 
6) Please choose the location that best describes your school/program.
( ) Urban
( ) Suburban
( ) Rural

7) Please choose the type of classroom that you work in.

( ) Community-based preschool classroom

( ) Head Start preschool classroom

( ) State Funded Pre-K classroom

( ) Private Preschool classroom

( ) District General Education preschool classroom, not identified as a State Funded Pre-k classroom or special education classroom

( ) Other - Write In:

8) Which level of education best describe your highest level of schooling?

() Some high school

( ) High school diploma or equivalency certificate

( ) Child Development Associate (CDA) Credential

( ) Some college courses, degree not obtained yet

( ) Associate of Early Childhood Education

( ) Associate degree in an area other than early childhood education

( ) Bachelor's degree of Early Childhood Education

( ) Bachelor's degree in a field other than early childhood education

( ) Master's degree in Early Childhood Education

( ) Master's degree in a field other than early childhood education

( ) Combined Bachelor's/Master's of Early Childhood Education and Special Education

( ) Other - Write In:

9) Have you had undergraduate or graduate coursework that included specific information related to autism?
() Yes
() No
( ) Unsure

10) If yes, the information on autism was...
( ) Briefly presented in one class
( ) Presented in one class devoted to the topic of autism spectrum disorders
( ) Presented in multiple class sessions
( ) Presented in an entire course on autism spectrum disorders
( ) Presented in several courses resulting in a certificate or certification of autism studies
( ) Other - Write In: 
11) Have you participated in professional development on autism? (Professional development refers to the continuing education opportunities that you have in your post school career. These opportunities can be provided by the organization that you work for or workshops/events/meetings that you have attended on your own.)
() Yes
() No
( ) Unsure

12) If yes, please describe the types of professional development you have participated in. Please check all that apply.
[] Workshop
[ ] Conference
[ ] Webinar
[ ] Autism Internet Modules
[ ] Worked with a consultant or clinician (this is a time limited opportunity in which a person with expertise in autism gave you recommendations on how to work with a child with autism)
[ ] Coaching (an opportunity in which you have an ongoing relationship with someone who has expertise that works in your classroom and helps to problem solve strategies tow work with a child with autism)
[ ] Worked with a special education teacher around the needs of a child with autism
[ ] Other - Write In

13) Have you had experiences with children who have autism? Please check all that apply.

() I have not had any experiences with a child who has autism.

( ) I have experience working with a child who I suspected as having autism.

( ) I have had experience working with a child who has the diagnosis of autism.

( ) I have had personal experience, such as a family member or friend, who has a child with autism.

Thank you for sharing this information press next to continue. 


\section{Knowledge}

In the following section, please rate yourself on your knowledge of children with autism. The word autism will be used here and throughout the remainder of this questionnaire to refer to all children who have an autism spectrum disorder diagnosis.

Please rate your level of agreement with the following statements.

\begin{tabular}{|c|c|c|c|c|c|}
\hline & $\begin{array}{l}\text { Strongly } \\
\text { Disagree }\end{array}$ & Disagree & Neutral & Agree & $\begin{array}{l}\text { Strongly } \\
\text { Agree }\end{array}$ \\
\hline $\begin{array}{l}\text { 14. Autism is a developmental, } \\
\text { neurological disorder. }\end{array}$ & ( ) & () & () & ( ) & () \\
\hline $\begin{array}{l}\text { 15. Boys are more likely to be } \\
\text { diagnosed with autism than girls. }\end{array}$ & ( ) & ( ) & ( ) & () & () \\
\hline $\begin{array}{l}\text { 16. A child with autism may repeat a } \\
\text { phrase over and over again. }\end{array}$ & ( ) & () & () & () & () \\
\hline $\begin{array}{l}\text { 17. Children with autism are more } \\
\text { likely to play alone than with other } \\
\text { children. }\end{array}$ & ( ) & () & () & ( ) & ( ) \\
\hline $\begin{array}{l}\text { 18. Children with autism know how to } \\
\text { act in social situations. }\end{array}$ & ( ) & () & () & () & () \\
\hline $\begin{array}{l}\text { 19. Children with autism have unusual } \\
\text { ways of playing with toys such as } \\
\text { lining up the same toys in a row } \\
\text { over and over or repetitively } \\
\text { spinning the wheel of a toy car. }\end{array}$ & () & () & ( ) & () & () \\
\hline $\begin{array}{l}\text { 20.Children with autism demonstrate } \\
\text { repetitive body movements such as } \\
\text { hand flapping or body rocking. }\end{array}$ & ( ) & () & ( ) & ( ) & ( ) \\
\hline $\begin{array}{l}\text { 21. Children with autism have a need } \\
\text { for routines and sameness. }\end{array}$ & () & ( ) & ( ) & () & ( ) \\
\hline $\begin{array}{l}\text { 22. Children with autism are } \\
\text { considered strong auditory } \\
\text { learners. }\end{array}$ & () & () & () & () & ( ) \\
\hline $\begin{array}{l}\text { 23. Children with autism have very } \\
\text { strong interests such as only talking } \\
\text { about bugs or only playing with } \\
\text { trains. }\end{array}$ & () & () & () & ( ) & () \\
\hline $\begin{array}{l}\text { 24. Autism impacts a child's ability to } \\
\text { socially communicate. }\end{array}$ & () & () & () & () & ( ) \\
\hline $\begin{array}{l}\text { 25. Children can be diagnosed with } \\
\text { autism at } 24 \text { months. }\end{array}$ & () & ( ) & ( ) & ( ) & ( ) \\
\hline
\end{tabular}




\begin{tabular}{|l|l|l|l|l|l|}
\hline & \multicolumn{1}{|c|}{$\begin{array}{c}\text { Strongly } \\
\text { Disagree }\end{array}$} & Disagree & Neutral & Agree & \multicolumn{1}{|c|}{$\begin{array}{c}\text { Strongly } \\
\text { Agree }\end{array}$} \\
\hline $\begin{array}{c}\text { 26. Autism is a continuum that affects } \\
\text { children differently }\end{array}$ & $($ ) & $($ ) & $($ ) & ( ) & ( ) \\
\hline 27. Children can be cured of autism. & $($ ) & $($ ) & $($ ) & ( ) & ( ) \\
\hline
\end{tabular}

Please click next to continue.

Practices

Now you will be asked questions about practices that are known to be used with children who have autism.

Please rate your knowledge about the practices used with children who have autism.

\begin{tabular}{|c|c|c|c|c|c|}
\hline & $\begin{array}{l}\text { I don't } \\
\text { know } \\
\text { anything } \\
\text { about } \\
\text { this } \\
\text { practice. }\end{array}$ & $\begin{array}{l}\text { I have } \\
\text { heard of } \\
\text { this } \\
\text { practice } \\
\text { but don't } \\
\text { know } \\
\text { anything } \\
\text { about it. }\end{array}$ & $\begin{array}{c}\text { I have } \\
\text { very little } \\
\text { knowled } \\
\text { ge about } \\
\text { this } \\
\text { practice. }\end{array}$ & $\begin{array}{l}\text { I have } \\
\text { some } \\
\text { knowled } \\
\text { ge about } \\
\text { this } \\
\text { practice. }\end{array}$ & $\begin{array}{l}\text { I know a } \\
\text { lot about } \\
\text { this } \\
\text { practice. }\end{array}$ \\
\hline $\begin{array}{l}\text { 28. Visual supports: visuals used } \\
\text { in the classroom to provide } \\
\text { children with information } \\
\text { about appropriate behavior, } \\
\text { expectations, social } \\
\text { information and daily } \\
\text { routines. Examples include } \\
\text { stop signs, daily schedule, } \\
\text { maps and visuals that show a } \\
\text { routine such as hand washing. }\end{array}$ & ( ) & () & () & ( ) & () \\
\hline $\begin{array}{l}\text { 29. Social Narratives: support } \\
\text { children to understand a social } \\
\text { situation by providing social } \\
\text { information and expectations } \\
\text { of how to behave during a } \\
\text { specific interaction, using a } \\
\text { visual story. }\end{array}$ & () & ( ) & ( ) & ( ) & () \\
\hline $\begin{array}{l}\text { 30. Reinforcement: a systematic } \\
\text { process in which children are } \\
\text { provided positive } \\
\text { consequences following a } \\
\text { desired behavior. }\end{array}$ & ( ) & ( ) & () & ( ) & () \\
\hline
\end{tabular}




\begin{tabular}{|c|c|c|c|c|c|}
\hline & $\begin{array}{l}\text { I don't } \\
\text { know } \\
\text { anything } \\
\text { about } \\
\text { this } \\
\text { practice. }\end{array}$ & $\begin{array}{l}\text { I have } \\
\text { heard of } \\
\text { this } \\
\text { practice } \\
\text { but don't } \\
\text { know } \\
\text { anything } \\
\text { about it. }\end{array}$ & $\begin{array}{l}\text { I have } \\
\text { very little } \\
\text { knowled } \\
\text { ge about } \\
\text { this } \\
\text { practice. }\end{array}$ & $\begin{array}{l}\text { I have } \\
\text { some } \\
\text { knowled } \\
\text { ge about } \\
\text { this } \\
\text { practice. }\end{array}$ & $\begin{array}{l}\text { I know } \\
\text { a lot } \\
\text { about } \\
\text { this } \\
\text { practice. }\end{array}$ \\
\hline $\begin{array}{l}\text { 31. Prompting: procedures } \\
\text { include providing a child with } \\
\text { visual, verbal or gestural help } \\
\text { to complete a skill. Prompting } \\
\text { is provided before or at the } \\
\text { same time a child attempts a } \\
\text { skill. }\end{array}$ & ( ) & ( ) & () & ( ) & ( ) \\
\hline $\begin{array}{l}\text { 32. Discrete Trial: a type of adult } \\
\text { directed systematic instruction } \\
\text { using repetitive teaching, } \\
\text { prompting, and reinforcement } \\
\text { that breaks learning down into } \\
\text { smaller steps. }\end{array}$ & () & ( ) & ( ) & ( ) & ( ) \\
\hline $\begin{array}{l}\text { 33. Time Delay: giving wait time } \\
\text { between instruction and } \\
\text { providing assistance for a } \\
\text { child to complete a task. }\end{array}$ & ( ) & ( ) & () & ( ) & ( ) \\
\hline $\begin{array}{l}\text { 34. Video Modeling: a visual } \\
\text { movie demonstrating a } \\
\text { desired behavior or skill to a } \\
\text { child. }\end{array}$ & () & ( ) & ( ) & () & ( ) \\
\hline $\begin{array}{l}\text { 35. Inclusion: the practice of } \\
\text { supporting a child with autism } \\
\text { to learn in an early childhood } \\
\text { classroom with his/her peers. }\end{array}$ & ( ) & ( ) & () & ( ) & ( ) \\
\hline
\end{tabular}


Please express your use or intention of using the following practices that are known to support children with autism. When rating, please base your intentions on the idea that you may someday have a child with autism in your classroom.

\begin{tabular}{|c|c|c|c|c|c|}
\hline & $\begin{array}{l}\text { Never } \\
\text { used it, } \\
\text { don't } \\
\text { intend to } \\
\text { use it. }\end{array}$ & $\begin{array}{l}\text { Never used } \\
\text { it, intend to } \\
\text { use it } \\
\text { sometimes. }\end{array}$ & $\begin{array}{l}\text { Never used } \\
\text { it, intend to } \\
\text { use it } \\
\text { frequently. }\end{array}$ & $\begin{array}{l}\text { Have used it, } \\
\text { intend to use } \\
\text { it sometimes. }\end{array}$ & $\begin{array}{l}\text { Have used } \\
\text { it, intend to } \\
\text { use it } \\
\text { frequently. }\end{array}$ \\
\hline $\begin{array}{l}\text { 36. Visual supports: } \\
\text { visuals used in the } \\
\text { classroom to } \\
\text { provide children } \\
\text { with information } \\
\text { about appropriate } \\
\text { behavior, } \\
\text { expectations, } \\
\text { social information } \\
\text { and daily routines. } \\
\text { Examples include } \\
\text { stop signs, daily } \\
\text { schedule, maps } \\
\text { and visuals that } \\
\text { show a routine } \\
\text { such as hand } \\
\text { washing. }\end{array}$ & () & ( ) & ( ) & ( ) & ( ) \\
\hline $\begin{array}{l}\text { 37. Social Narratives: } \\
\text { support children to } \\
\text { understand a social } \\
\text { situation by } \\
\text { providing social } \\
\text { information and } \\
\text { expectations of } \\
\text { how to behave } \\
\text { during a specific } \\
\text { interaction, using a } \\
\text { visual story. }\end{array}$ & ( ) & ( ) & ( ) & ( ) & () \\
\hline $\begin{array}{l}\text { 38. Reinforcement: a } \\
\text { systematic process } \\
\text { in which children } \\
\text { are provided } \\
\text { positive } \\
\text { consequences } \\
\text { following a desired } \\
\text { behavior. }\end{array}$ & ( ) & ( ) & ( ) & ( ) & () \\
\hline
\end{tabular}




\begin{tabular}{|c|c|c|c|c|c|}
\hline & $\begin{array}{l}\text { Never } \\
\text { used it, } \\
\text { don't } \\
\text { intend } \\
\text { to use it }\end{array}$ & $\begin{array}{l}\text { Never used } \\
\text { it, intend to } \\
\text { use it } \\
\text { sometimes. }\end{array}$ & $\begin{array}{l}\text { Never used } \\
\text { it, intend to } \\
\text { use it } \\
\text { frequently. }\end{array}$ & $\begin{array}{l}\text { Have used it, } \\
\text { intend to use } \\
\text { it sometimes. }\end{array}$ & $\begin{array}{l}\text { Have used it, } \\
\text { intend to use it } \\
\text { frequently. }\end{array}$ \\
\hline $\begin{array}{l}\text { 39. Prompting: } \\
\text { procedures include } \\
\text { providing a child } \\
\text { with visual, verbal } \\
\text { or gestural help to } \\
\text { complete a skill. } \\
\text { Prompting is } \\
\text { provided before or } \\
\text { at the same time a } \\
\text { child attempts a } \\
\text { skill. }\end{array}$ & ( ) & ( ) & ( ) & () & () \\
\hline $\begin{array}{l}\text { 40. Discrete Trial: a } \\
\text { type of adult } \\
\text { directed systematic } \\
\text { instruction using } \\
\text { repetitive teaching, } \\
\text { prompting, and } \\
\text { reinforcement that } \\
\text { breaks learning } \\
\text { down into smaller } \\
\text { steps. }\end{array}$ & ( ) & ( ) & ( ) & ( ) & ( ) \\
\hline $\begin{array}{l}\text { 41. Time Delay: giving } \\
\text { wait time between } \\
\text { instruction and } \\
\text { providing assistance } \\
\text { for a child to } \\
\text { complete a task. }\end{array}$ & ( ) & ( ) & ( ) & ( ) & ( ) \\
\hline $\begin{array}{l}\text { 42. Video Modeling: a } \\
\text { visual movie } \\
\text { demonstrating a } \\
\text { desired behavior or } \\
\text { skill to a child. }\end{array}$ & ( ) & ( ) & ( ) & ( ) & ( ) \\
\hline $\begin{array}{l}\text { 43. Inclusion: the } \\
\text { practice of } \\
\text { supporting a child } \\
\text { with autism to learn } \\
\text { in an early } \\
\text { childhood } \\
\text { classroom with } \\
\text { his/her peers. }\end{array}$ & ( ) & ( ) & ( ) & ( ) & () \\
\hline
\end{tabular}




\section{APPENDIX C}

\section{PECE-ASD Reviewer Form}

Thank you for supporting me in my research efforts to understand regular early childhood educator's perspectives related to the inclusion of young children in their classrooms. I appreciate your time, expertise and knowledge that you are sharing with me.

The purpose of this review is to establish content validity and ease of participate use for my scale. The goal of the scale is to collect information from regular early childhood educators about their knowledge of autism, their beliefs about the inclusion of children with autism and their practices related to supporting children with autism. In addition, demographic information will also be collected.

Please note there are two terms that are important to consider during this review. The term autism will be used to address the entire autism spectrum. Additionally the term "regular" education is used to describe early childhood teachers. This language is consistent with IDEA language as it relates to the 619 provision for supporting preschool children in the least restrictive environment.

Please use the following questions to guide your review and feel free to provide any comments or additional information that you think will improve this scale. Section 1: Demographic information

\begin{tabular}{|c|c|c|c|c|}
\hline Review Question & Yes & No & Unsure & $\begin{array}{l}\text { If no or unsure, please list } \\
\text { the question } \# \text { and the } \\
\text { comment or suggestion for } \\
\text { change }\end{array}$ \\
\hline \multicolumn{5}{|l|}{$\begin{array}{l}\text { Are the questions related to demographic } \\
\text { information sensitive when addressing } \\
\text { diversity of all groups? (Questions 1-7) }\end{array}$} \\
\hline \multicolumn{5}{|l|}{$\begin{array}{l}\text { Are all groups represented that should be } \\
\text { represented? (Questions 1-7) }\end{array}$} \\
\hline \multicolumn{5}{|l|}{$\begin{array}{l}\text { Are the questions related to education } \\
\text { level clearly stated? } \\
\text { (Question 8-10) }\end{array}$} \\
\hline \multicolumn{5}{|l|}{$\begin{array}{l}\text { Are the questions related to professional } \\
\text { development clearly stated? } \\
\text { Questions }(11 \& 12)\end{array}$} \\
\hline \multicolumn{5}{|l|}{$\begin{array}{l}\text { Are the questions related to experience } \\
\text { with children with autism clearly stated? } \\
\text { (Questions 13-16) }\end{array}$} \\
\hline $\begin{array}{l}\text { Please provide any additional comments } \\
\text { information? }\end{array}$ & & & ne collect & of demographic \\
\hline
\end{tabular}


Section 2: Knowledge of Autism Spectrum Disorders

\begin{tabular}{|l|l|l|l|l|}
\hline Review Question & Yes & No & Unsure & $\begin{array}{l}\text { If no or unsure, please list } \\
\text { the question \# and the } \\
\text { comment or suggestion for } \\
\text { change }\end{array}$ \\
\hline $\begin{array}{l}\text { Do questions 1-18 capture a general } \\
\text { understanding of the diagnosis \& } \\
\text { characteristics of autism? }\end{array}$ & & & & \\
\hline $\begin{array}{l}\text { Do questions 19-23 capture the ECE } \\
\text { teachers understanding of how a } \\
\text { diagnosis of autism impacts a child's } \\
\text { educational program? }\end{array}$ & & & & \\
\hline $\begin{array}{l}\text { Are the questions related to knowledge of } \\
\text { autism clearly stated? }\end{array}$ & & & \\
\hline $\begin{array}{l}\text { Please provide any additional comments that will improve the collection of the ECE teacher's } \\
\text { knowledge of autism? }\end{array}$ & & \\
\hline
\end{tabular}

\section{Section 3: Practices}

\begin{tabular}{|l|l|l|l|l|}
\hline Review Question & Yes & No & Unsure & $\begin{array}{l}\text { If no or unsure, please list } \\
\text { the question \# and the } \\
\text { comment or suggestion for } \\
\text { change }\end{array}$ \\
\hline $\begin{array}{l}\text { Do questions 1-9 the capture } \\
\text { ECE teacher's use of EBP? }\end{array}$ & & & & \\
\hline $\begin{array}{l}\text { Do questions 1-9 the capture } \\
\text { ECE teacher's familiarity of } \\
\text { EBPs? }\end{array}$ & & & & \\
\hline
\end{tabular}

Please provide any additional comments that will improve the collection of information related to the ECE teacher's use of EBP?

Thanks so much you are almost done - just a few more general questions!

\begin{tabular}{|l|l|l|l|l|}
\hline Review Question & Yes & No & Unsure & $\begin{array}{l}\text { If no or unsure, please list } \\
\text { the question \# and the } \\
\text { comment or suggestion for } \\
\text { change }\end{array}$ \\
\hline $\begin{array}{l}\text { In general, do you think the questions are } \\
\text { written so that an ECE teacher of all } \\
\text { levels will be able to answer the } \\
\text { questions? }\end{array}$ & & & & \\
\hline Is the survey an appropriate length? & & & & \\
\hline $\begin{array}{l}\text { Are their items that should be included } \\
\text { that were not? }\end{array}$ & & & \\
\hline Any additional comments? & & & \\
\hline
\end{tabular}




\title{
APPENDIX D
}

\section{IRB Approved Consent Document}

\author{
Rhode Island College
}

Early Childhood Educators Perceptions of Including Children with Autism

You are being asked to be in a research study about including children with autism into a regular preschool classroom. You are being asked because you are an early childhood educator. Please read this form and ask any questions that you have before choosing whether to be in the study.

Amy Grattan, a doctoral candidate, at Rhode Island College/University of Rhode Island, is doing this study. Dr. Paul LaCava, an associate professor at Rhode Island College, is the major professor for this candidate.

\section{Why this Study is Being Done (Purpose)}

We are doing this study to learn about how regular early childhood educators feel about including children with autism in their preschool classrooms. In addition this study will look at the relationships between EC educators knowledge and attitudes and how this may or may not influence their use of evidence based practices with children with autism.

\section{What You Will Have to Do (Procedures)}

If you choose to be in the study, we will ask you to complete an online questionnaire. First we will ask you basic questions about yourself, like your years of experience and your highest level of school. Then you will be asked to answer questions related to how you feel about including children with autism in the classroom and what you know about the diagnosis of autism. This questionnaire could take 20-30 minutes.

\section{Drawing for a $\$ 50.00$ gift card}

As a way to thank you for your time, you will have the option to be put into a drawing to receive a gift card. Upon completion of the questionnaire you will be asked if you would like to be entered into a drawing for a \$50.00 Amazon gift card. If yes, you will be provided a link to a new web page where you will be asked to provide your name and email address. Using the link to go to a new web page will ensure that your personal information is disconnected from your survey answers. Only participants who complete the survey will have the opportunity to enter the drawing.

\section{$\underline{\text { Risks or Discomforts }}$}

If at any time you want to stop the survey you may do so. Additionally, you can skip any questions you don't want to answer. Participation in this study poses no more risks than what you would encounter in your typically daily activities. 


\section{Benefits of Being in the Study}

Being in this study will not benefit you directly.

\section{Deciding Whether to Be in the Study}

Being in the study is your choice to make. Nobody can force you to be in the study. You can choose not to be in the study, and nobody will hold it against you. You can change your mind and quit the study at any time, and you do not have to give a reason. If you decide to quit later, nobody will hold it against you.

\section{How Your Information will be protected}

Because this is a research study, results will be summarized across all participants and shared in reports that we publish and presentations that we give. We will be using a secure web based survey tool to ensure that your information is private. Your name will not be asked for in the survey itself. If you choose to enter the drawing for a gift card, you will follow a link that will disconnect your name from your survey results. Your name will not be used in any reports. The information will stored on the Rhode Island College web server and seen only by myself and other researchers who work with me. If there are problems with the study, the records may be viewed by the Rhode Island College review board responsible for protecting the rights and safety of people who participate in research. The information will be kept for a minimum of three years after the study is over, after which it will be destroyed.

\section{Who to Contact}

If you have any questions later, you can contact Amy Grattan at 401-456-4739 or agrattan@ric.edu or Dr. Paul LaCava at 401-456-9703 or placava@ric.edu.

If you think you were treated badly in this study, have complaints, or would like to talk to someone other than the researcher about your rights or safety as a research participant, please contact Cindy Padula at IRB@ric.edu, by phone at 401-456-9720.

By pressing the button and continuing on to the survey, you are choosing to participate in study Early Childhood Educators Perceptions of Including Children with Autism.

I agree that I would like to participate in the study Early Childhood Educators Perceptions of Including Children with Autism.

If you do not want to participate in the survey, please close the browser. Thank you for your time. 


\section{APPENDIX E \\ Initial Email to Administrators and Organizations}

To whom this May Concern,

My name is Amy Grattan and I am a doctoral candidate in the Joint Educational Leadership Doctoral Program with Rhode Island College and the University of Rhode Island. I am currently seeking regular preschool early childhood classroom educators (ECE), both teachers and staff members, to take part in a survey for my dissertation project on early childhood educator's perceptions of including children with autism spectrum disorders (ASD) in their classrooms.

The purpose of my survey is collect information from early childhood classroom staff to understand their perceptions of including children with ASD in their classrooms. The outcome of this survey is gather information that will inform future professional development designed to support regular education educators who have or may have children with ASD in their classrooms.

Research suggests that regular ECE have an important role as the leaders of an inclusive classroom. With a recent focus on the inclusion of children with ASDs in the regular education classroom, it is important that professional development opportunities are designed to support ECEs to have knowledge and skills that support them with their inclusive practices.

I am asking you to please forward the attached research announcement to EC educators and teaching assistants in preschool classrooms. All who teach in a preschool classroom are welcome to participate. Please know that you under no obligation to forward this. Your decision will not influence any relationships that we have may have. Please feel free to contact my advisor, Paul LaCava, or me if you have any questions or concerns.

Thank you,

Amy Grattan. M.Ed.

Education Leadership Doctoral Candidate

$\mathrm{RIC} / \mathrm{URI}$

(401) 456-4739

agrattan@ric.edu

Paul LaCava, Ph.D.

Associate Professor of Special Education, Rhode Island College

placava@ric.edu 


\section{APPENDIX F}

\section{Follow up Email}

Dear Colleague,

This is a follow up email regarding the research announcement sent to you last week. The purpose of my survey is collect information from early childhood classroom staff to understand their perceptions of including children with ASD in their classrooms. The outcome of this survey is gather information that will inform future professional development designed to support regular education educators who have or may have children with ASD in their classrooms.

I am asking you to please forward the attached research announcement to EC educators and teaching assistants in preschool classrooms. If you have already

forwarded the email, I would ask that you please send the announcement again as a way to remind early childhood educators and assistants to consider participation in this survey.

Thank you

Amy Grattan. M.Ed.

Education Leadership Doctoral Candidate

RIC/URI

(401) 456-4739

agrattan@ric.edu

Paul LaCava, Ph.D.

Associate Professor of Special Education, Rhode Island College

placava@ric.edu 


\section{APPENDIX G}

Summary of Variables aligned Research Questions

\begin{tabular}{|c|c|}
\hline Research Question & Observed Variables \\
\hline RQ1: What are the levels of knowledge & Levels of knowledge of autism \\
\hline of autism, knowledge of EBP and use of & $\begin{array}{l}\text { Knowledge of autism } \\
\qquad \quad \text { General knowledge of autism }\end{array}$ \\
\hline EBP related to inclusion of children with & - Knowledge of the behaviors of autism \\
\hline ASD reported by ECE? & $\begin{array}{c}\text { Knowledge and use of EBP } \\
\text { - } \quad \text { Practice aligned to DAP } \\
\text { - } \quad \text { Specialized Practices }\end{array}$ \\
\hline Research Question & Observed Variables \\
\hline
\end{tabular}

RQ2: To what extent is there a

Experience with autism

relationship between ECE knowledge of

ECE group

Knowledge of autism

- General knowledge of autism

autism and their knowledge and use of

EBP to support young children with

- Knowledge of the behaviors of autism

Knowledge and use of EBP

ASD?

- Practice aligned to DAP

- Specialized Practices

\begin{tabular}{ccc}
\hline \multirow{2}{*}{ Research Question } & Independent & Dependent \\
& Variable(s) & Variables \\
\hline
\end{tabular}

RQ 3: To what extent are the use of EBP

Experience with autism Knowledge

ECE group $\quad$ EBP

of ECE influenced by their experiences,

group and knowledge of autism?

Knowledge of autism

- General knowledge of autism

- Knowledge of the behaviors of autism
- Practice aligned to DAP

- Specialized Practices 


\section{BIBLIOGRAPHY}

Akalın, S., Demir, Ş., Sucuoğlu, B., Bakkaloğlu, H., \& İşcen, F. (2014). The needs of inclusive preschool teachers about inclusive practices. Eurasian Journal of Educational Research, 54, 39-60.

American Psychiatric Association. (2013). Diagnostic and statistical manual of mental disorders, fifth edition. Arlington Virgina: American Psychiatric Association Publishing.

Artman-Meeker K., Fettig A., Barton E. E., Penney A., \& Zeng S. (2015). Applying an evidence-based coaching framework to the early childhood professional development literature. Topics in Early Childhood Special Education, 35, 183196

Artman-Meeker K., Hemmeter M. L. (2013). Supporting teachers' use of recommended practices through e-mail performance feedback. Topics in Early Childhood Special Education, 33, 112-123.

Artman-Meeker K., Hemmeter M. L., \& Snyder P. (2014). Effects of distance coaching on teachers' use of pyramid model practices: A pilot study. Infants \& Young Children, 27, 325-344.

Austin, L. J. E., Kipnis, F., Sakai, L., Whitebook, M., \& Ryan, S. (2013). The state of early childhood higher education in Rhode Island: The Rhode Island early childhood higher education inventory. Retrieved from Berkely, CA: Author.

Bakers, C. (2012). Preparing teachers for students with autism. New horizons for learning, 10(2).

Baker, J. (2013). Autism at 70 - redrawing the boundaries. New England Journal of 
Medicine, 369 (12), 1089-1090.

Bandura, A. (1971). Social learning theory. New York, NY: General Learning Press.

Banks, J., Cochran-Smith, M., Moll, L., Richert, A., Zeichner, K., LePage, P., . . . Mcdonald, M. (2005). Teaching diverse learners. In L. Darling-Hammond \& J. Bransford (Eds.), Preparing teachers for a changing world. San Francisco, Ca: Jossey-Bass.

Barned, N., Knapp, N., \& Neuharth-Pritchett, S. (2011). Knowledge attitudes of early childhood preservice teachers regarding the inclusions of children with autism spectrum disorder. Journal of Early Childhood Teacher Education, 32, 302321.

Barnett, S. (2003a). Better teachers, better preschools: Student achievement linked to teacher qualifications. New Brunswick, NJ: NIEER.

Barnett, S. (2003b). Low wages=low quality solving the real preschool teacher crisis. New Brunswick, NJ: NIEER.

Barnett, S. (2011). Minimum requirements for preschool teacher educational qualification. In E. Zigler, W. Gilliam, \& S. Barnett (Eds.), The pre-k debates, current controversies \& issues (pp. 48-54). Baltimore: Brookes.

Barnett, W. S., Friedman-Krauss, A. H., Weisenfeld, G. G., Horowitz, M., Kasmin, R., \& Squires, J. H. (2017). The State of Preschool 2016: State Preschool Yearbook. New Brunswick, NJ: National Institute for Early Education Research. 
Barnhill, G. P., Polloway, E. A., \& Sumutka, B. M. (2010). A survey of personnel preparation practices in autism spectrum disorders. Focus on Autism and Other Developmental Disabilities, 26(2), 75-86.

Barnhill, G. P., Sumutka, B., Polloway, E. A., \& Lee, E. (2013). Personnel preparation practices in ASD. Focus on Autism and Other Developmental Disabilities, $29(1), 39-49$.

Beavers, A., Lounsbury, J., Richards, J., Huck, S., Skolits, G., \& Esquivel, S. (2013). Practical considerations for using exploratory factor analysis in educational research. Practical Assessment, Research \& Evaluation, 18(6), 1-13.

Bowman, B. (2011). Bachelor's degrees are necessary but not surricient, preparing teachers to teach young childen. In E. Zigler, W. Gilliam, \& S. Barnett (Eds.), The pre-k debates, current controversies \& issues (pp. 54-57). Baltimore: Brookes Publishing Co.

Bradely, D., Herzenberg, S., \& Price, M. (2005). Losing Ground in Early Childhood Education: Declining Workforce Qualifications in an Expanding Industry, 1979-2004.

Bredekamp, S., \& Copple, C. (1997). Developmentally appropriate practice in early childhood education (Revised ed.). Washington DC: National Association for the Education of Young Children.

Brightstars. (2013). Child care center and preschool quality framework RIAECY.

Retreived on April 8, 2017 at

http://www.brightstars.org/uploads/EXCEED Brightstars Preschool Final2.p

$\underline{\text { df }}$ 
Bruns, D. A., \& Mogharreban, C. C. (2007). The gap between beliefs and practices: Early childhood practitioners' perceptions about inclusion. Journal of Research in Childhood Education, 21(3), 229-241.

Buron, K., \& Wolfberg, P. (Eds.). (2008). Learners on the autism spectrum: preparing highly qualified educators. Shawnee Mission, Kansas: Autism Asperger Publishing Co.

Buron, K., \& Wolfberg, P. (Eds.). (2014). Learners on the autism spectrum: preparing highly qualified educators and related practitioners (Second ed.). Shawnee Mission, Kansas: Autism Asperger Publishing Co.

Buysse, V., \& Hollingsworth, H. L. (2009). Program quality and early childhood inclusion: Recommendations for professional development. Topics in Early Childhood Special Education, 29(2), 119-128.

Buysse, V., \& Wesley, P. (2006). Evidenced-based practice: How did it emerge and what does it really mean for the early childhood field. In V. Buysse \& P. Wesley (Eds.), Evidence-based practice in the early childhood field. Washington, D.C.: ZERO TO THREE.

Buysse, V., Wesley, P. W., Keyes, L., \& Bailey, B. A. (1996). Assessing the comfort zone of childcare teachers in serving young children with MSD. Journal of Early Intervention, 20(3), 189-204.

Campbell, D., Reichle, N. \& Bourgondien, M. (1996). The autism survey: An evaluation of reliability and validity. Journal of Autism and Developmental Disorders. 26(6), 621-634. 
Campbell, J. \& Barger, B. (2011). Middle school student's knowledge of autism. Journal of Autism and Developmental Disorders, 41(6), 732-740.

Cassidy, J. (2011). Teachers attitudes toward the inclusion of students with autism and emotional behavioral disorder. Electronic Journal of Inclusive Education, 2(7).

Chang, F., Early, D., \& Winton, P. (2005). Early childhood teacher preparation in special education at 2- and 4-year institutions of higher education. Journal of Early Intervention, (27), 110-124.

Center on the Developing Child. (2007). The Science of Early Childhood Development (InBrief). Retrieved on April 8, 2017 at www.developingchild.harvard.edu.

Centers for Disease Control and Prevention [CDC]. (2016). CDC estimates 1 in 68 school-aged children have autism; no change from previous estimate. Retrieved on May 6, 2017 from https://www.cdc.gov/media/releases/2016/p0331-children-autism.html

Chen, G. (2017). Understanding self-contained classrooms in public schools. Retrieved on June 6, 2017 at https://www.publicschoolreview.com/blog/understanding-self-containedclassrooms-in-public-schools

Cohen, H., Amerine-Dickens, M., Smith, T. (2006). Early intensive behavioral Treatment: Replication of the UCLA model in a community setting. Journal of Developmental \& Behavioral Pediatrics, 27 (2), 145-155.

Committee on Integrating the Science of Early Childhood Development. (2000). From Neurons to Neighborhoods: The Science of Early Childhood Development. Jack P. Shonkoff and Deborah A. Phillips, eds. Board on Children, Youth, and 
milies, Commission on Behavioral and Social Sciences and Education. Washington, D.C.: National Academy Press.

Cook, B. G., Buysse, V., Klingner, J., Landrum, T. J., McWilliam, R. A., Tankersley, M., \& Test, D. W. (2014). CEC's standards for classifying the evidence base of practices in special education. Remedial and Special Education, 36(4), 220234.

Copple, C. \& Bredekamp, S. (2009a). Developmentally appropriate practice in early childhood programs serving children from birth through age 8 (3rd ed.). Washington, DC: National Association for the Education of Young Children.

Copple, C., \& Bredekamp, S. (2009b). Basics of developmentally appropriate practice an introduction for teachers of children 3 to 6 . Washington, DC: National Association for the Education of Young Children.

Costello, A., \& Osborne, W. (2005). Best practices in exploratory factor analysis: Four recommendations for getting the most from your analysis. Practical Assessment, Research \& Evaluation, 10(7), 1-9.

Council for Exceptional Children [CEC]. (2000). Early childhood special educator. Making a difference in the lives of students with disabilities. Arlington, Virginia: The National Clearinghouse for Professions in Special Education. Creswell, J. (2014). Research design qualitative, quantitative and mixed methods approaches (Fourth Edition ed.). Los Angeles, CA: Sage.

Danforth, S., \& Rhodes, W. (1997). Deconstructing disability. Remedial and Special Education, 18(6), 257-366. 
DeValenzuela, J. S., Connery, M. C., \& Musanti, S. (2000). The theoretical foundations of professional development in special education. Remedial and Special Education, 21(2), 111-120.

DeVellis, R. (2003). Scale development (Vol. 26). Thousand Oaks, CA: Sage.

Dillman, D., Smyth, J., \& Chrstian, L. (2009). Internet, mail, and mixed-mode surveys, The tailored design method (Third Edition ed.). Hoboken, NJ: John Wiley \& Sons, Inc.

Dinnebeil, L., \& McInerney, W. (2011). A guide to itinerant early childhood special education services. Baltimore, Maryland: Brookes Publishing Co.

Dinnebeil, L., McInerney, W., \& Hale, L. (2006). Understanding the roles and responsibilities of Itinerant ECSE teachers through Delphi Research. Topics in Early Childhood Special Education, 26(3), 153-166.

Division For Early Childhood [DEC].(2007). Promoting positive outcomes for children with disabilities: Recommendations for curriculum, assessment, and program evaluation. Missoula, MT: Author.

Division for Early Childhood/National Association for the Education of Young Chidlren [DEC/NAEYC]. (2009). Early childhood inclusion: A joint position statement of the Division for Early Childhood (DEC) and the National Association for the Education of Young Children (NAEYC). Chapel Hill: The University of North Carolina.

Dunst, C., \& Bruder, M. (2013). Preservice professional preparation and teachers' self-efficacy appraisal of natural environment and inclusion practices. Teacher Education and Special Education, 37(2), 121-132. 
Dunst, C. J., \& Trivette, C. M. (2012). Moderators of the effectiveness of adult learning method practices. Journal of Social Sciences, 8(2), 143.

Early, D., Bryant, D. M., Pianta, R., Clifford, R., Burchinal, M., Ritchie, S., . . . Barbarin, O. (2006). Are teachers' education, major, and credentials related to classroom quality and children's academic gains in pre-kindergarten? Early Childhood Research Quarterly, 21(2), 174-195.

Early, D., Maxwell,K., Burchinal, M., Alva, S. Bender, R., Bryant, D., Cai, K., ... Zill, N. (2007). Teachers' education, classroom quality, and young children's academic skills: Results from seven studies of preschool programs. Child Development, 78(2), pp. 558-580.

Endow, J. (2012). Learning the hidden curriculum: The oddyssey of one autisic adult. Shawnee Mission, KS: AAPC Publishing.

Essa, E., Bennett, P., Burnham, M., Martin, S., Bingham, A., \& Allred, K. (2008). Do variables associated with quality child care programs predict the inclusion of children with disabilities? Topics in Early Childhood Special Education, 28(3), 171-180.

Fabrigar, L., Wegener, D., MacCallum, R., \& Strahan, E. (1999). Evaluating the use of exploratory factor analysis in psychological research. Psychological Methods, 4(3), 279-299.

Faul, F., Erdfelder, E., Lang, A., \& Buchner, A. (2007). G*power 3: a flexible statistical power analysis program for the social, behavioral, and biomedical sciences. Behavior Research Methods, 39(2), 175-191. 
Field, A. (2013). Discovering statistics using IBM SPSS statistics (Fourth ed.). Los Angeles, CA: SAGE.

Finch, K, Watson, R., MacGregor, C. \& Precise, N. (2013). Teacher needs for educating children with autism spectrum disorders in the general education classroom. The Journal of Special Education Apprenticeship, 2(2).

Florian, L. (2012). Preparing teachers to work in inclusive classrooms: Key lessons for the professional development of teacher educators from Scotland's Inclusive Practice Project. Journal of Teacher Education, 63(4), 275-285.

Fraenkel, J., Wallen, N., \& Hyun, H. (2012). How to design and evaluate research in education (Eighth ed.). New York, New York: McGraw-Hill.

Gable, R. A., Tonelson, S. W., Sheth, M., Wilson, C., \& Park, K. (2012). Importance, usage, and preparedness to implement evidence-based practices for students with emotional disabilities: A comparison of knowledge and skills of special education and general education teachers. Education and Treatment of Children, 35(4), 499-520.

Garcia Winner, M. (2008). Social thinking: Cognition to enhance communication and learning. In K. Dunn Buron \& P. Wolfberg (Eds.), Learners on the autism spectrum, preparing high qualified educators (pp. 209-234). Shawnee Mission, Kansas: Autism Asperger Publishing Co.

Gartrell, D. (2012). Education for a civil society: How guidance teaches young children democratic life skills. United States of America: National Association of the Education of Young Children.

Goble, C., Horm, D., Atanasov, A., Williamson, A., \& Choi, J. Y. (2015). Knowledge 
and beliefs of early childhood education students at different levels of professional preparation. Journal of Early Childhood Teacher Education, $36(3), 211-231$.

Gongola, L., \& Sweeney, J. (2012). Discrete trial teaching: Getting started. Intervention in School \& Clinic, 47(3), 183-190.

Grandin, T. (2009). How does visual thinking work in the mind of a person with autism? A personal account. Philolosophical Transactions of the Royal Society B: Biological Sciences. 364, 1437-1442.

Green, K., Terry, N., \& Gallagher, P. (2014). Progress in language and literacy skills among children with disabilities in inclusive early reading first classrooms. Topics in Early Childhood Special Education, 33, 249-259.

Gronland, G. (2006). Make early standards come alive: Connecting your practice and curriculum to state guidelines. St. Paul, MN: Redleaf.

Harrison, A., Slane, M., Hoang, L., \& Campbell, J. (2017). An international review of autism knowledge assessment measures. Autism, 21(3), 262-275.

Head Start. (2017). Head Start policy and regulations, 1302.13. Recruitment of children. Retrieved on May 4, 2017 at https://eclkc.ohs.acf.hhs.gov/policy/45cfr-chap-xiii/1302-13-recruitment-children

Hodgdon, L.Q. (1995). Solving social-behavioral problems through the use of visually supported communication. In K. A. Quill (Ed.), Teaching children with autism: Strategies to enhance communication and socialization (pp. 265-286). New York: Delmar. 
Hogarty, K. Y., Hines, C. V., Kromrey, J. D., Ferron, J. M., \& Mumford, K. R. (2005). The quality of factor solutions in exploratory factor analysis: The influence of sample size, communality, and overdetermination. Educational and Psychological Measurement, 65(2), 202-226.

Holahan, A., \& Costenbader, V. (2000). A comparison of developmental gains for preschool children with disabilities in inclusive and self-contained classrooms. Topics in Early Childhood Special Education, 20(4), 224-235.

Husen, T. (2001). Fifty modern thinkers on education from Piaget to the present. In J. Palmer (Ed.), (pp. 58-63). New York, NY: Routeldge.

Hutcheson, G., \& Sofroniou, N. (1999). The multivariate social scientist: Introductory statistics using generalized linear models. Thousand Oaks, CA: Sage.

Individuals with Disabilities Education Improvement Act of 2004 [IDEIA]. Public Law No: 109-446, § 20 U.S.C. (2004).

Jarrold, C. (2016). A review of research into pretend play in autism. Autism, 7(4), 379390.

Jennett, H. K., Harris, S. L., \& Mesibov, G. B. (2003). Commitment to philosophy, teacher efficacy, and burnout among teachers of children with autism. Journal of Autism and Developmental Disorders, 33(6), 583-593.

Johnson, P., Porter, K. J., \& McPherson, I. (2012). Autism knowledge among preservice teachers specialized in children birth through age five: Implication for health education. American Journal of Health Education, 43(5), 279-287.

Kanner, L. (1943). Autisitic disturbances of affective contact. The Journal of the Nervous Child, 2, pp. 217-250. 
Karagiannis, A., Stainback, S., \& Stainback, W. (1996). Historical overview of inclusion. In S. Stainback \& W. Stainback (Eds.), Inclusion: A guide for educators (pp. 17-28). Balitmore: Paul H. Brookes.

Kennedy, A. (2012). What have theories go to do with it? National Quality Standard Professional Leaning Program e-newletter. Retrieved on April 4, 2017 at https://www.earlychildhoodaustralia.org.au/nqsplp/wpcontent/uploads/2012/05/NQS_PLP_E-Newsletter_No31.pdf

Kluth, P. (2013). "You're going to love this kid". Teaching students with autism in the inclusive classroom, second edition. Baltimore, MD: Brookes.

Knight, G. (1982). Issues \& alternatives in educational philosophy. Berrien Springs, Michigan: Andrews University Press.

Kozulin, A. (1994). The cognitive revolution in learning: Piaget and Vygotsky. In J. Mangier \& C. Collins (Eds.), Creating powerful thinking in teachers and students (pp. 269-287). Fort Worth, TX: Harcourt Brace College Publishing.

Kretlow, A. G., \& Bartholomew, C. C. (2010). Using coaching to improve the fidelity of evidence-based practices: A review of studies. Teacher Education and Special Education: The Journal of the Teacher Education Division of the Council for Exceptional Children, 33(4), 279-299.

Krishnan, V. (2010). Early childhood devleopment: A conceptual model. Paper presented at the Early Childhood Council Annual Conference 20110, "Valuing Care", Christchurch, New Zealand.

Kuhl, P. K. (2011). Early language learning and literacy: Neuroscience implications for education. Mind, Brain, and Education, 5(3), 128-142. 
Lai, Y. C., \& Gill, J. (2014). Multiple perspectives on integrated education for children with disabilities in the context of early childhood centres in hong kong. Educational Review, 66(3), 345-361.

Leatherman, J. M., \& Niemeyer, J. A. (2005). Teachers' attitudes toward inclusion: Factors influencing classroom practice. Journal of Early Childhood Teacher Education, 26(1), 23-36

Leblanc, L., Richardson, W., \& Burns, K. A. (2009). Autism spectrum disorder and the inclusive classroom: Effective training to enhance knowledge of ASD and evidence-based practices. Teacher Education and Special Education, 32(2), 166-179.

Lee, H.-J. (2005). Developing a professional development program model based on teachers' needs. The Professional Educator, XXVII(2), 39-49.

Lian, W., Ying, S. H., Tean, S. C., Lin, D. C., Lian, Y. C., \& Yun, H. L. (2008). Preschool teachers' knowledge, attitudes and practices on childhood developmental and behavioural disorders in Singapore. Journal of Paediatrics and Child Health, 44(4), 187-194.

Lindsay, S., Proulx, M., Thomson, N., \& Scott, H. (2013). Educators' challenges of including children with autism spectrum disorder in mainstream classrooms. International Journal of Disability, Development and Education, 60(4), 347362.

Liu, Y., Li, J., Zheng, Q., Zaroff, C., Hall, B., Li, X., \& Hao, Y. (2016). Knowledge, attitudes, and perceptions of autism spectrum disorder in a stratified sampling of preschool teachers in China. BMC Psychiatry, 16(142), 2-12. 
Mallory, B. L., \& New, R. S. (1994). Social constructivist theory and principles of inclusion: Challenges for early childhood. Journal of Special Education, 28(3), 322.

McDonald, J. H. (2014). Handbook of Biological Statistics (3rd ed.). Baltimore, Maryland: Sparky House Publishing.

McLeod, S. A. (2016). Bandura - social learning theory. Retrieved on April 28, 2017 from http://www.simplypsychology.org/bandura.html

Mesibov, G., \& Shea, V. (2008). Structured teaching and environmental supports. In K. Dunn Buron \& P. Wolfberg (Eds.), Learners on the autism spectrum, preparing highly qualified educators (pp. 115-138). Shawnee Mission, Kansas: Autism Asperger Publishing Co.

Miniwatts Marking Group. (2016). Internet world stats, usage and population statistics, United States. Retrieved on June 17, 2017 at http://www.internetworldstats.com/unitedstates.htm - RI

Moll, L. C. (2014). L.S. Vygotsky and education. New York: Routledge.

Mooney, C. G. (2013). Theories of Childhood: An Introduction to Dewey, Montessori, Erikson, Piaget \& Vygotsky (Second ed.). St Paul MN: Red Leaf Press.

Muccio, L. S., Kidd, J. K., White, C. S., \& Burns, M. S. (2014). Head Start instructional professionals' inclusion perceptions and practices. Topics in Early Childhood Special Education, 34(1), 40-48.

Nakamura, B. J., Higa-McMillan, C. K., Okamura, K. H., \& Shimabukuro, S. (2011). Knowledge of and attitudes towards evidence-based practices in community 
child mental health practitioners. Administration and Policy in Mental Health and Mental Health Services Research, 38(4), 287-300.

Nahmias, A., Kase, C., \& Mandell, D. (2014). Comparing cognitive outcomes among children with autism spectrum disorders receiving community-based early intervention in one of three placements. Autism, 18(3), 311-320.

National Association for the Education of Young Children [NAECY]. (2009). Developmentally appropriate practice in early childhood programs serving children from birth through age 8. Retrieved on April 4, 2017 at https://www.naeyc.org/files/naeyc/file/positions/PSDAP.pdf

National Association for the Education of Young Children [NAECY] \& National Association of Early Childhood Specialists in State Departments of Education (NAECS/SDE). (2002). Early learning standards creating the conditions for success. Washington, DC: Author.

National Autism Center. (2009). National standards report: National standards project - Addressing the need for evidence-based practice guidelines for autism spectrum disorders. Randolph, MA: National Autism Center.

National Autism Center. (2015). Findings and conclusions: National standards project, phase 2. Randolph, MA: Author

National Research Council. (2001). Educating children with autism. Committee on Educational Interventions for Children with Autism. Catherine Lord and James P. McGee, Eds. Division of Behavioral and Social Sciences and Education. Washington, DC: National Academy Press. 
Odom, S. (2000). Preschool inclusion: What we know and where we go from here. TECSE, 20(1), 20-27.

Odom, S. (2008). The tie that binds: Evidence-based practice, implementation science, and outcomes for children. Topics in Early Childhood Special Education, 29(1), 53-61.

Odom, S., Buysse, V., \& Soukakou, E. (2011). Inclusion for young children with disabilities: A quarter century of research perspectives. Journal of Early Intervention, 33(4), 344-356.

Odom, S. L., Collet-Klingenberg, L., Rogers, S. J., \& Hatton, D. D. (2010). Evidencebased practices in interventions for children and youth with autism spectrum disorders. Preventing School Failure: Alternative Education for Children and Youth, 54(4), 275- 282.

Odom, S., \& Wolery, M. (2003). A unified theory of practice in early intervention/early childhood special education: Evidence based practices. The Journal of Special Education, 37(3), 164-173.

Office of Special Education and Rehabilitative Services (OSERS). (2010). Thirty-five years of progress in educating children with disabilities through IDEA. Washington, DC: Author.

Paynter, J. M., Ferguson, S., Fordyce, K., Joosten, A., Paku, S., Stephens, M., . . Keen, D. (2017). Utilisation of evidence-based practices by ASD early intervention service providers. Autism, 21(2). 
Paytner, J., \& Keen, D. (2015). Knowledge and use of intervention practices by community-based early intervention service providers. Journal of Autism and Development Disorders, 45(6), 1614-1623.

Prizant, B. (2011). The use and misuse of evidence-based practice. Implications for person with ASD. Autism Spectrum Quarterly, 43, 43-49.

Providence College. (2017). 2009-2011 Graduate catalog special education.

Retrieved on June 10, 2017 at

http://catalog.providence.edu/preview program.php?catoid=2\&poid=98\&retur $\underline{\text { nto }=67}$

Purper, C. J., VanderPyl, T., \& Juarez, S. W. (2015). Resources to increase practitioners' knowledge and use of evidence-based practices. Young Exceptional Children, 19(4).

Quill, K. (1997). Instructional considerations for young children with autism: The rationale for visually cued instruction. Journal of Autism and Developmental Disorders, 27(6), 697-714.

Raab, M., Trivet, C., \& Dunst, C. (2013). Adult learning procedure for promoting caregiver use of everyday child language learning practices. Everyday Child Language Learning Reports Vol. 3. Asheville, NC: Orelena Hawks Puckett Institute.

Rafferty, Y., Piscitelli, V., \& Boettcher, C. (2003). The impact of inclusion on language development and social competence among preschoolers with disabilities. Exceptional Children, 69(4), 467-479. 
Rhode Island College. (2017). Special Education M.Ed.—with concentration in early childhood-birth through grade 2. Retrieved on June 10, 2017 at http://ric.smartcatalogiq.com/en/2016-2017/Catalog/Feinstein-School-ofEducation-and-Human-Development/Special-Education/Special-Education$\underline{\text { Programs-M-Ed/Special-Education-M-Ed-with-Concentration-in-Early- }}$ Childhood-Birth-Through-Grade-2

Rhode Island Department of Children, Youth and Families [DCYF]. (2013). Child care program regulations for licensure. Retrieved on May 29, 2017 at http://www.dcyf.ri.gov/docs/center regs.pdf

Rhode Island Department of Education. (2016). Early childhood programs. Retrieved on January 4, 2017 at http://www.ride.ri.gov/InstructionAssessment/EarlyChildhoodEducation/Progr $\underline{\text { ams.aspx\#13020-pre-k-programs }}$

Rhode Island Department of Human Services, RI Department of Elementary and Secondary Education, \& Families. (ND). Quality for every child: Developing a continuum of quality standards for Rhode Island's early care and education programs [Press release]. Retrieved on June 17, 2017 at https://exceed.ri.gov/Docs/RI_PSA_TechPaper.pdf.

Rhode Island KIDS COUNT. (2015). 2015 Rhode Island kids count factbook.

Providence, RI: Rhode Island KIDS COUNT.

Rhode Island KIDS COUNT. (2016). 2016 Rhode Island kids count factbook. Providence, RI: Rhode Island KIDS COUNT.

RI Department of Labor and Training. (2010). Rhode Island race \& ethnic origin 
demographics by county 200-2010. Retrieved on January 4, 2017 at http://www.dlt.ri.gov/lmi/census/demo/ethnic.htm

Rhode Island Department of Labor and Training. (2014). Labor market information. occupational employment by gender. Retrieved on January 4, 2017 at http://www.dlt.ri.gov/lmi/pdf/gender.pdf

RI.gov. (2016). Fun facts and trivia. Retrieved on June 29, 2017 at https://www.ri.gov/cts/trivia.php

Salve Regina University. (2017). Applied behavior analysis. Retrieved on June 17 at http://www.salve.edu/graduate-studies-and-continuing-education/appliedbehavior-analysis

Schilder, D. (2016). Early childhood teacher education policies: Research review and state trends (Policy Report). New Brunswick, NJ: Center on Enhancing Early Learning Outcomes.

Segall, M., \& Campbell, J. (2012). Factors relating to education professionals' classroom practices for the inclusion of students with autism spectrum disorders. Research in Autism, 6(3), 1156-1167.

Simpson, R. L., Mundschenk, N. A., \& Heflin, L. J. (2011). Issues, policies, and recommendations for improving the education of learners with autism spectrum disorders. Journal of Disability Policy Studies, 18, 133-147.

Smith, T., \& Eikeseth, S. (2011). O. Ivar Lovaas: Pioneer of applied behaivoral analysis and intervention for children with autism. Journal Autism Development Disorders, 41, 375-378. 
Snow, K. (2013). Who is the early childhood workforce. Retrieved on May 19, 2017 at http://www.naeyc.org/blogs/gclarke/2013/11/who-early-care-and-educationworkforce-0

Stahmer, A. C., Collings, N. M., \& Palinkas, L. A. (2005). Early intervention practices for children with autism: Descriptions from community providers. Focus on autism and other developmental disabilities, 20(2), 66-79.

Stone, W. (1987). Cross-disciplinary perspectives on autism. Journal of Pediatric Psychology, 12, 615-630.

Stone, W., \& Rosenbaum, J. (1988). A comparison of teacher and parent views of autism. Journal of Autism and Developmental Disorders, 18(3), 403-414.

Stormont, M., Reinke, W., \& Herman, K. (2011). Teachers' knowledge of evidencebased interventions and available school resources for children with emotional and behavioral problems. Journal of Behavioral Education, 20(2), 138-147.

Strain, P. S. (2015). Lessons learned over three decades of inclusion for young children with autism: The LEAP preschool model. Paper presented at the 2015 Early Childhood Inclusion Institute, Chapel Hill, NC.

Strain, P. S., \& Bovey, E. H. (2011). Randomized, controlled trial of the LEAP model of early intervention for young children with autism spectrum disorders. Topics in Early Childhood Special Education, 31(3), 133-154.

Strain, P. S., \& McConnell, S. R. (1992). Behaviorism in early intervention. Topics in Early Childhood Special Education, 12(1), 121-141.

Strunk, J. A. (2009). School nurses' knowledge of autism spectrum disorders. The Journal of School Nursing, 25(6), 445-452. 
Trent, S., Artiles, A., \& Englert, C. (1998). From deficit thinking to social constructivism: A review of theory, research and practice in special education. Review of Research in Education, 23, 277-307.

United States Census Bureau. (2017). Quick facts selected: Rhode Island. Retrieved on August 12, 2017 from United State Census Bureau online access: https://www.census.gov/quickcts/table/PST045216/44,00

United States Bureau of Labor Statistics (2016a). May 2015 state occupational employment and wage estimates Rhode Island. http://www.bls.gov/oes/current/oes_ri.htm\#25-0000 (Division of Occupational Employment Statistics)

United States Department of Education. (2016b). IDEA Section 618 data products: Static tables: Teachers employed (FTE) to work with children, ages 3 through 5, who are receiving special education under IDEA, Part B, by qualification status and state, 2014-2015. Retrieved on January 4, 2017 at http://www2.ed.gov/programs/osepidea/618-data/static-tables/index.html United States Department of Education. (2016c) IDEA Section 618 data products: Static tables: Number of children ages 3 through 5 served under IDEA, Part B, by disability and state: 2014-15, Retrieved on January 4, 2017 at http://www2.ed.gov/programs/osepidea/618-data/static-tables/index.html United States Department of Education [DOE], U.S. Office of Special Education and Rehabilitative Services [OSERS] \& U.S. Office of Special Education Programs [OSEP]. (2015). 37th annual report to congress on the implementation of the 
Individuals with Disabilities Education Act, 2015, Retrieved from http://www.ed.gov/about/reports/annual/osep

United States Department of Education, United States Office of Special Education and Rehabilitative Services \& United States Office of Special Education Programs. (2014). 36th Annual Report to Congress on the Implementation of the Individuals with Disabilities Education Act, 2014, Retrieved on January 4, 2016 at http://www.ed.gov/about/reports/annual/osep

United States Department of Health and Human Services \& United States Department of Education. (2015). Policy statement on inclusion of children with disabilities in early childhood programs. Washington, DC: U.S. Department of Health and Human Services.

University of Rhode Island. (2017). Welcome to the University of Rhode Island 20162017 online catalog. Retrieved on June 17, 2017 from http://web.uri.edu/catalog/

Vakil, S., Welton, E., O’Connor, B., \& Kline, L. S. (2008). Inclusion means everyone! The role of the early childhood educator when including young children with autism in the classroom. Early Childhood Education Journal, 36(4), 321-326.

Vygotsky, L. S. (1978). Mind in society: The development of higher psychological processes. Cambridge, MA: Harvard University Press.

Watson, J., \& Rayner, R. (1920). Conditioned emotional reactions. Journal of Experimental Psychology, 3(1), 1-14. 
Wetherby, A., \& Prutting, C. (1984). Profiles of communicative and cognitive-social abilities in autistic children. Journal of Speech, Language, and Hearing Research, 27, 364-377.

Whitebook, M. (2003). Early education quality: Higher teacher qualifications for better learning environments - A review of the literature. Berkeley, CA: Center for the Study of Child Care Employment, University of California, Berkeley.

Whitebook, M., McLean, C., and Austin, L.J.E. (2016). Early childhood workforce index - 2016. Berkeley, CA: Center for the Study of Child Care Employment, University of California, Berkeley.

Wilczynski, S., Green, G., Ricciardi, J., Boyd, B., Hume, A., Ladd, M., \& Rue, H. (2009). National standards report: The national standards project: Addressing the need for evidence-based practice guidelines for autism spectrum disorders. Randolph, MA: The National Autism Center.

Wilczynski, S. (2017). Evidence-based practice and autism spectrum disorders: The national standards project. Retrieved on May 27, 2017 at http://www.slsd.org/webpages/bmcnabb/index.cfm?subpage=1682610

Williams, B., Onsman, A., \& Brown, T. (2010). Exploratory factor analysis: A fivestep guide for novices. Journal of Emergency Primary Health Care (JEPHC), $8(3)$.

Wolfberg, P., Bottema-Beutel, K,, \& DeWitt, M. (2009). Including children with autism in social and imaginary play with typical peers. Integrated play groups. American Journal of Play, 5(1), 1-26. 
Wong, C., Odom, S. L., Hume, K. A., Cox, A. W., Fettig, A., Kucharczyk, S., . . . Schultz, T. R. (2015). Evidence-based practices for children, youth, and young adults with autism spectrum disorder: A comprehensive review. Journal of Autism and Developmental Disorders, 45(7), 1951-1966.

Yoshikawa, H., Weiland, C., Brooks-Gunn, J., Burchinal, M., Espinosa, L., Gormley, W., Zaslow, M. J. (2013). Investing in our future: The evidence base for preschool education. Policy brief, society for research in child development and the foundation for child development. Washington, DC: Foundation for Child Development. 